Portland State University

PDXScholar

TREC Final Reports

Transportation Research and Education Center

(TREC)

$10-2011$

\title{
Bridge Damage Models for Seismic Risk Assessment of Oregon Highway Network
}

Peter Dusicka

Portland State University

Jeffery Roberts

Portland State University

Follow this and additional works at: https://pdxscholar.library.pdx.edu/trec_reports

Part of the Civil and Environmental Engineering Commons, and the Transportation Commons Let us know how access to this document benefits you.

\section{Recommended Citation}

Dusicka, Peter and Jeffery Roberts. Bridge Damage Models for Seismic Risk Assessment of Oregon Highway Network. OTREC-RR-11-08. Portland, OR: Transportation Research and Education Center (TREC), 2011. https://doi.org/10.15760/trec.19

This Report is brought to you for free and open access. It has been accepted for inclusion in TREC Final Reports by an authorized administrator of PDXScholar. Please contact us if we can make this document more accessible: pdxscholar@pdx.edu. 


\section{SOTREC}

FINAL REPORT

\section{Bridge Damage Models for Seismic Risk Assessment of Oregon Highway Network}

OTREC-RR-11-08

October 2011 



\title{
BRIDGE DAMAGE MODELS FOR SEISMIC RISK ASSESSMENT OF OREGON HIGHWAY NETWORK
}

\author{
Final Report \\ OTREC-RR-11-08 \\ by \\ Jeff Roberts \\ Peter Dusicka \\ Portland State University
}

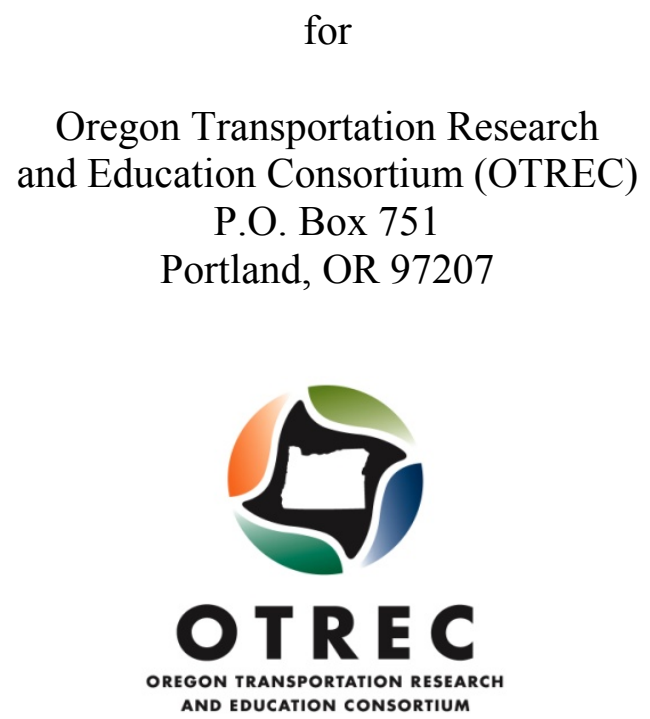

October 2011 



\begin{tabular}{|c|c|c|}
\hline \multicolumn{3}{|c|}{ Technical Report Documentation Page } \\
\hline $\begin{array}{l}\text { 1. Report No. } \\
\text { OTREC RR-11-08 }\end{array}$ & 2. Government Accession No. & 3. Recipient's Catalog No. \\
\hline \multirow{2}{*}{\multicolumn{2}{|c|}{$\begin{array}{l}\text { 4. Title and Subtitle } \\
\text { Bridge Damage Models For Seismic Risk Assessment of Oregon Highway Network }\end{array}$}} & $\begin{array}{l}\text { 5. Report Date } \\
\text { October } 2011\end{array}$ \\
\hline & & 6. Performing Organization Code \\
\hline \multicolumn{2}{|c|}{$\begin{array}{l}\text { 7. Author(s) } \\
\text { Peter Dusicka and Jeffery Roberts }\end{array}$} & 8. Performing Organization Report No. \\
\hline \multirow{2}{*}{\multicolumn{2}{|c|}{$\begin{array}{l}\text { 9. Performing Organization Name and Address } \\
\text { Portland State University } \\
\text { Department of Civil and Environmental Engineering } \\
\text { PO Box } 751 \\
\text { Portland, Oregon, } 97207\end{array}$}} & 10. Work Unit No. (TRAIS) \\
\hline & & 11. Contract or Grant No. \\
\hline \multirow{3}{*}{\multicolumn{2}{|c|}{$\begin{array}{l}\text { 12. Sponsoring Agency Name and Address } \\
\text { Oregon Transportation Research } \\
\text { and Education Consortium (OTREC) } \\
\text { P.O. Box 751 } \\
\text { Portland, Oregon } 97207\end{array}$}} & 13. Type of Report and Period Covered \\
\hline & & Final Report \\
\hline & & 14. Sponsoring Agency Code \\
\hline
\end{tabular}

\section{Abstract}

The highway transportation network of the United States relies on the health and integrity of major infrastructure elements such as bridges. Frequently traveled parts of Oregon are within the seismically active Pacific Northwest and many of the bridges were designed and built to lateral demands that were assumed to be less than the current expectation, a deficiency caused by our growing awareness of seismic hazard and our enhanced understanding of the non-linear response of bridges. This vulnerability to damage from earthquakes can result in not only immediate damage, but also in potentially lingering economic impact caused by the disruption to traffic and freight mobility.

Using analytical methods, fragility curves were constructed assuming lognormal capacity and demand distributions. Probability of failure was determined for the four damage state conditions of slight, moderate, extensive, and complete levels of damage. These statistical values were compared to the median and dispersion values proposed by other researchers, in addition to those calculated using guidelines from the HAZUS Technical Manual. Older multiple-span Oregon bridges were found to be significantly more fragile than the HAZUS models.

As a result of this modeling and analysis effort, the relative fragility of the modeled typical 3-span and 5-span bridges was determined and quantified. Possible causes of the relatively high fragilities were also considered.

\section{Key Words}

Seismic, fragility, bridge, structural performance, column, ductility
18. Distribution Statement

No restrictions. Copies available from OTREC: www.otrec.us

\begin{tabular}{|l|l|l|l|}
\hline $\begin{array}{l}\text { 19. Security Classification (of this report) } \\
\text { Unclassified }\end{array}$ & $\begin{array}{l}\text { 20. Security Classification (of this page) } \\
\text { Unclassified }\end{array}$ & $\begin{array}{c}21 . \text { No. of Pages } \\
106\end{array}$ & 22. Price \\
\hline
\end{tabular}




\section{ACKNOWLEDGEMENTS}

This project was funded by the Oregon Transportation Research and Education Consortium (OTREC). All dissemination should include the OTREC logo and reference as a sponsoring agency.

\section{DISCLAIMER}

The contents of this report reflect the views of the authors, who are solely responsible for the facts and the accuracy of the material and information presented herein. This document is disseminated under the sponsorship of the U.S. Department of Transportation University Transportation Centers Program and the Oregon Department of Transportation in the interest of information exchange. The U.S. Government and the Oregon Department of Transportation assume no liability for the contents or use thereof. The contents do not necessarily reflect the official views of the U.S. Government or the Oregon Department of Transportation. This report does not constitute a standard, specification, or regulation. 


\section{TABLE OF CONTENTS}

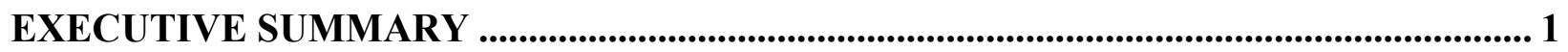

1.0 OVERVIEW OF BRIDGE FRAGILITY WORK ................................................ 3

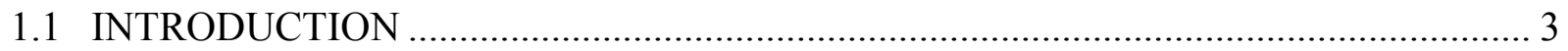

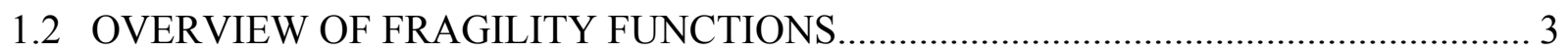

1.2.1 EMPERICAL FRAGILITY CURVES …………............................................... 4

1.2.2 EXPERT-BASED FRAGILITY FUNCTIONS ..................................................... 4

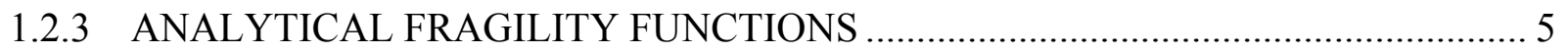

2.0 GROUND-MOTION SUMMARY ................................................................................. 7

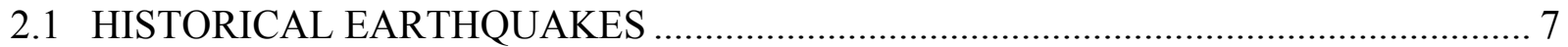

2.2 PROPOSED GROUND MOTIONS IN THE PACIFIC NORTHWEST ............................ 8

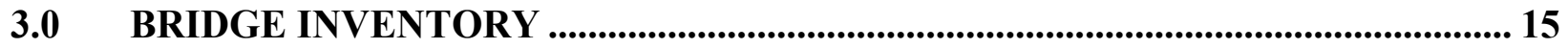

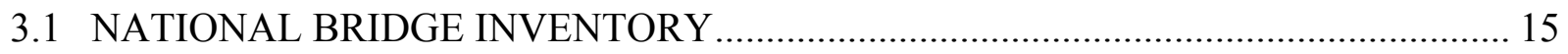

3.2 DETERMINATION OF TYPICAL THREE-SPAN BRIDGE …………………............ 15

3.3 DETERMINATION OF TYPICAL FIVE-SPAN BRIDGE ......................................... 17

4.0 THREE-DIMENSIONAL MODELS OF TYPICAL BRIDGES ................................. 19

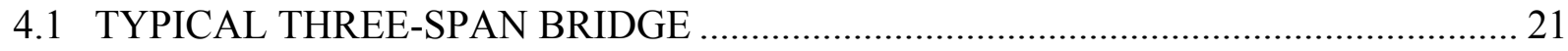

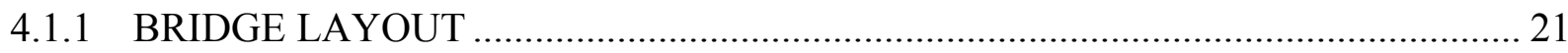

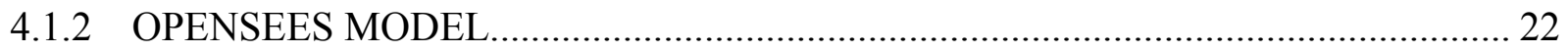

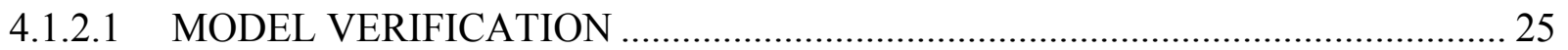

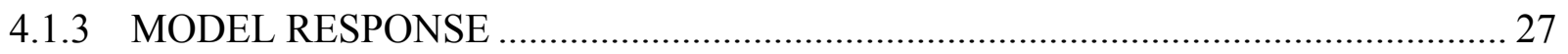

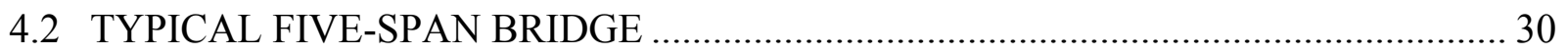

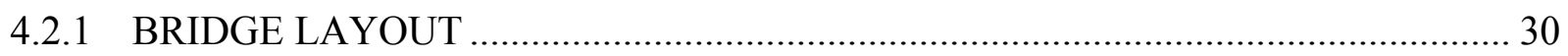

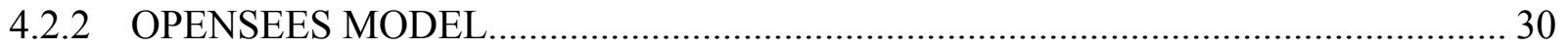

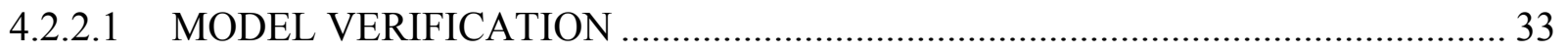

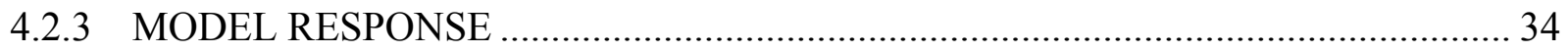

5.0 PROBABALISTIC SEISMIC DEMAND ANALYSIS ….............................................. 39

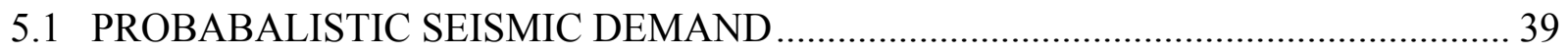

5.2 PSDM FOR TYPICAL THREE-SPAN BRIDGE ...................................................... 42

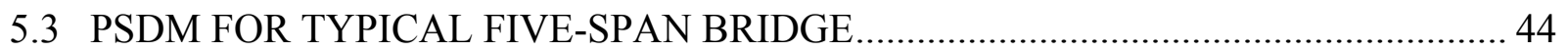

6.0 SEISMIC FRAGILITY ANALYSIS OF BRIDGES ................................................4 4

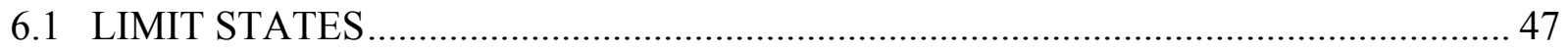

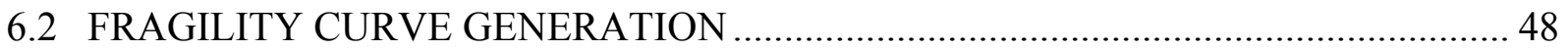

6.3 THREE-SPAN BRIDGE FRAGILITY CURVES ……............................................ 49

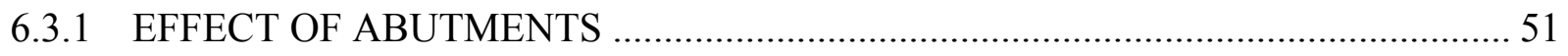

6.3.2 EFFECT OF GROUND-MOTION SUITE CHANGE ........................................... 52

6.3.3 EFFECT OF DECREASING THE NUMBER OF RUNS ………............................. 53

6.3.4 EFFECT OF GROUND-MOTION ORIENTATION ……………………………..... 54

6.3.5 EFFECT OF CONCRETE CONFINEMENT RETROFIT …………………............. 55

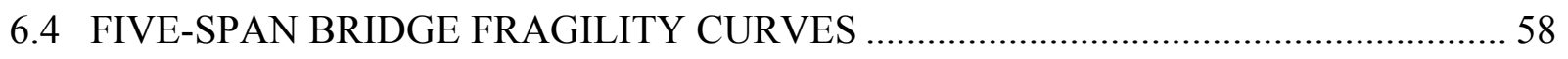

7.0 DISCUSSION AND CONCLUSIONS ........................................................................... 61

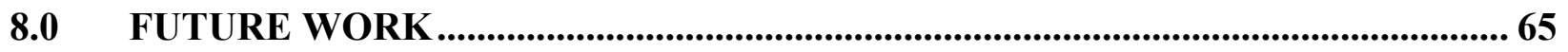




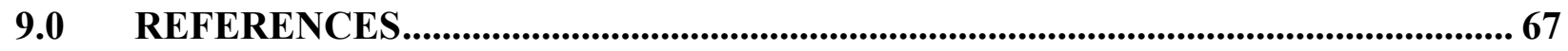

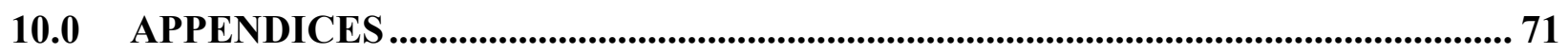

10.1 OPENSEES SCRIPT FOR THREE-SPAN GEOMETRY …........................................ 71

10.2 OPENSEES SCRIPT FOR THREE-SPAN GRAVITY LOADS ................................ 84

10.3 OPENSEES SCRIPT FOR THREE-SPAN EXTERNAL LOADS ............................... 88 


\section{LIST OF TABLES}

Table 2.1: Selected U.S. Earthquakes of General Historic Interest (USGS, 2009) ........................ 7

Table 2.2: Seattle Ground Motions with POE of $10 \%$ in 50 Years (SAC, 1997) ........................... 8

Table 2.3: Seattle Ground Motions with POE of 2\% in 50 Years (SAC, 1997) .............................. 8

Table 3.1: NBI Database Search Criteria............................................................................... 15

Table 3.2: NBI Item 43A - Kind of Material/Design Used on Oregon Bridges on Chosen

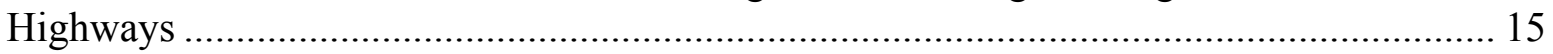

Table 3.3: NBI Item 43B - Type of Design/Construction Used on Oregon Bridges on Chosen

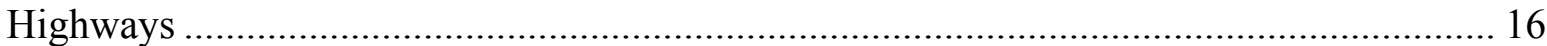

Table 3.4: Statistics of Three-Span NBI Code 202 Oregon Bridges on Chosen Highways ......... 16

Table 3.5: Bridge Used In Three-Span Study (Oregon Bridge 07865A East)............................... 16

Table 3.6: Kind of Material/Design Used on Five-Span Oregon Bridges on Chosen Highways. 17

Table 3.7: Type of Design/Construction on Five-Span Oregon Bridges on Chosen Highways... 17

Table 3.8: Majority of Bridge Types on Oregon Bridges on Chosen Highways.......................... 17

Table 3.9: Statistics of Five-Span NBI Code 202 Oregon Bridges on Chosen Highways ............ 18

Table 3.10: Bridge Used In Five-Span Study (Oregon Bridge 07628)......................................... 18

Table 4.1: Element Types Used With Three-Span Model.......................................................... 22

Table 4.2: ElasticPPGap Material Values for Three-Span Abutment-Soil Model ........................ 22

Table 4.3: Element Values for Three-Span Deck ………........................................................... 22

Table 4.4: Concrete04 Values for Confined Concrete Used With Three-Span Bridge ................. 23

Table 4.5: Concrete01 Values for Cover Concrete Used With Three-Span Bridge ...................... 24

Table 4.6: Hysteretic Steel Values Used with Five-Span Bridge ................................................. 24

Table 4.7: OpenSees Boundary Conditions for Three-Span Bridge............................................ 25

Table 4.8: Estimated Stiffness Values for Three-Span Bridge .................................................... 26

Table 4.9: Calculated Periods of Vibration for Various Three-Span Bridge Models.................... 27

Table 4.10: Maximum Displacements Using POE-of-10\%-in-50-Years Group ........................... 29

Table 4.11: Maximum Displacements Using POE-of-2\%-in-50-Years Group ............................. 29

Table 4.12: Element Types Used With Five-Span Model ........................................................... 31

Table 4.13: ElasticPPGap Material Values for Five-Span Abutments ........................................... 31

Table 4.14: elasticBeamcolumn Element Values for Five-Span Deck .......................................... 31

Table 4.15: Concrete01 Values for Confined Concrete Used With Five-Span Bridge ................. 32

Table 4.16: Concrete01 Values for Cover Concrete Used With Five-Span Bridge ....................... 32

Table 4.17: Hysteretic Steel Values Used With Five-Span Bridge ................................................ 33

Table 4.18: Estimated Stiffness Values for Five-Span Bridge ………....................................... 34

Table 4.19: Calculated Periods of Vibration for Various Five-Span Bridge Models ..................... 34

Table 4.20: Maximum Displacements Using POE-of-10\%-in-50-Years Group ............................. 36

Table 4.21: Maximum Displacements Using POE-of-2\%-in-50-Years Group .............................. 36

Table 5.1: Displacement Ductilities Using POE-of-10\%-in-50-Years Group................................. 43

Table 5.2: Displacement Ductilities Using POE-of-2\%-in-50-Years Group............................... 43

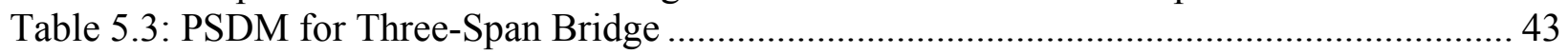

Table 5.4: Displacement Ductilities Using POE-of-10\%-in-50-Years Group.............................. 44

Table 5.5: Displacement Ductilities Using POE-of-2\%-in-50-Years Group................................... 44

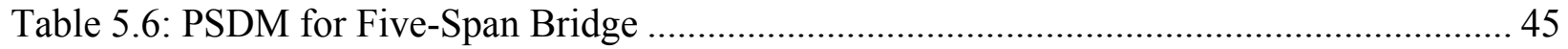




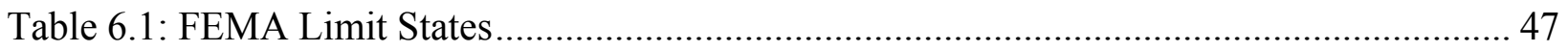

Table 6.2: Model Bridge Capacity Values............................................................................. 48

Table 6.3: Fragility Curves Values for Typical Three-Span Bridge.......................................... 49

Table 6.4: Fragility Curves Values for Typical Three-Span Bridge and Reference Values......... 50

Table 6.5: Fragility Curve Values With and Without Abutments ............................................ 51

Table 6.6: Fragility Curve Values with All Abutments and Longitudinal Abutments Only....... 52

Table 6.7: Fragility Medians Using POE-10\%-in-50-Years Ground-Motion Suite .................... 52

Table 6.8: Fragility Medians Using Reduced Data Set........................................................... 53

Table 6.9: Fragility Medians after Ground Motion Rotation $\left(\theta=45^{\circ}\right)$ Using POE-10\%-in-50-

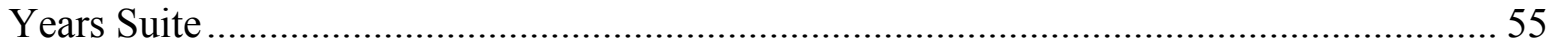

Table 6.10: Fragility Medians after Steel Retrofit Using POE-10-in-50 Suite.......................... 57

Table 6.11: Fragility Curves Values for Typical Five-Span Bridge ......................................... 58 


\section{LIST OF FIGURES}

Figure 1.1: Analytical Fragility Curve Generation Using Nonlinear Time-History Analysis........ 6

Figure 2.1: Histogram of PGA Values of POE-2\%-in-50-Years Suite ....................................... 9

Figure 2.2: Histogram of PGA Values of POE-10\%-in-50-Years Suite ........................................ 9

Figure 2.3: Histogram of PGA Values of All SAC Ground-Motion Time Histories Used ........... 10

Figure 2.4: Displacement Spectrum (5\% damping) - POE-2\%-in-50-Years Suite ....................... 11

Figure 2.5: Displacement Spectrum (5\% damping) - POE-10\%-in-50-Years Suite..................... 11

Figure 2.6: Pseudo-Acceleration Spectrum (5\% damping) - POE-2\%-in-50-Years Suite ........... 12

Figure 2.7: Pseudo-Acceleration Spectrum (5\% damping) - POE-10\%-in-50-Years Suite ........ 13

Figure 3.1: Elevation View of Oregon Bridge 07865A (Taylor Street East, Lane County)......... 17

Figure 3.2: Elevation View of Oregon Bridge 07628 (Sutherlin Creek, Douglas County)........... 18

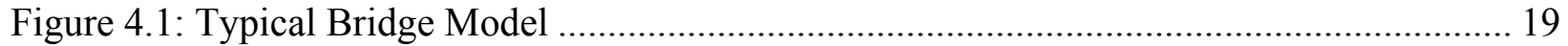

Figure 4.2: Ground-Motion Sample from POE-of-10\% Group ................................................ 20

Figure 4.3: Ground-Motion Sample from POE-of-2\% Group …………...................................... 20

Figure 4.4: Concrete Member Reinforcement for Three-Span Bridge ........................................ 21

Figure 4.5: OpenSees Material Types Used In Reinforced Concrete Models (from OpenSees

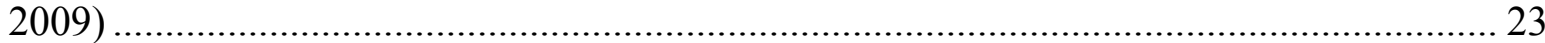

Figure 4.6: OpenSees Model for Three-Span Bridge ………................................................ 24

Figure 4.7: Comparison of Experimental and Modeled Hysteretic Behavior of Test Column .... 26

Figure 4.8: Mode Shapes of Typical Three-Span Bridge with no Soil-Abutment Stiffness

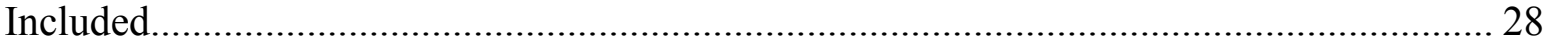

Figure 4.9: Concrete Member Reinforcement for Typical Five-Span Bridge ............................... 30

Figure 4.10: OpenSees Model for Typical Five-Span Bridge …………………………............ 33

Figure 4.11: Mode Shapes of Typical Five-Span Bridge with no Soil-Abutment Stiffness

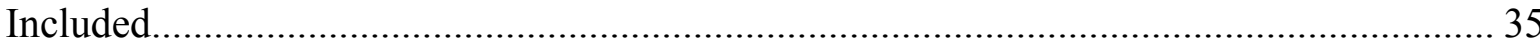

Figure 5.1: PSDM Illustration in Lognormal Space (Padgett, 2007) ......................................... 41

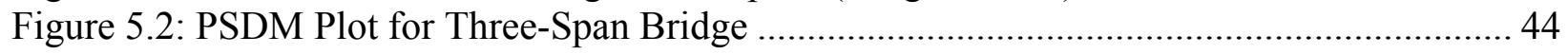

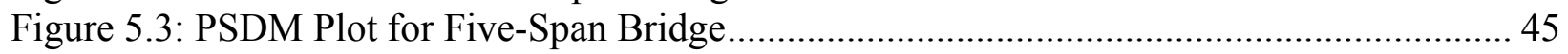

Figure 6.1: Fragility Curves for Three-Span Bridge.................................................................. 49

Figure 6.2: Complete and Extensive Damage Fragility Curve for Three-Span Bridge without

Abutments .............................................................................................................. 51

Figure 6.3: Complete and Extensive Damage Fragility Curve for Three-Span Bridge Suite

Change ………....................................................................................................... 53

Figure 6.4: Complete and Extensive Damage Fragility Curves for Three-Span Bridge without

Abutments ................................................................................................................ 54

Figure 6.5: Complete and Extensive Damage Fragility Curves for Three-Span Using Rotated Ground-Motion Suite ..................................................................................................... 55

Figure 6.6: Slight and Moderate Damage Fragility Curves for Three-Span Using Retrofitted

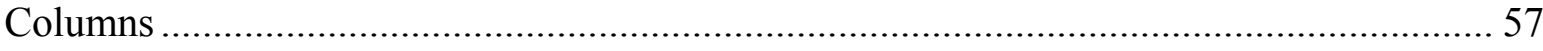

Figure 6.7: Extensive and Complete Damage Fragility Curves for Three-Span Using Retrofitted

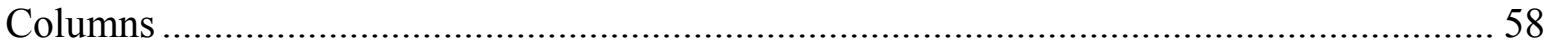

Figure 6.8: Fragility Curves for Five-Span Bridge ……….................................................... 59 


\section{EXECUTIVE SUMMARY}

The U.S. highway transportation network relies on the health and integrity of major infrastructure elements such as bridges. Frequently traveled parts of Oregon are within the seismically active Pacific Northwest, and many of the bridges were designed and built to lateral demands that were assumed to be less than the current expectation, a deficiency caused by our growing awareness of seismic hazard and our enhanced understanding of the non-linear response of bridges. This vulnerability to damage from earthquakes can result in not only immediate damage, but also in potentially lingering economic impacts caused by the disruption to traffic and freight mobility.

One of the key components in determining the impact of an earthquake on the transportation network is the bridge damage state model represented by fragility curves. A bridge fragility curve provides the probability that a bridge is damaged beyond a specified damage state under various levels of ground movement. Several methods of producing fragility curves were considered, specifically curves based upon actual failure data, expert opinion, and analytical models derived from the physics of the actual bridge system.

In order to fully define a bridge fragility curve, demands imposed upon the structure must be known or assumed. These demands are typically provided by using suites of ground-motion time histories, and may come from actual time histories from strong ground-motion records from the area of interest or synthetically produced. Two sets of ground motions were developed for the Seattle area by the SAC Joint Venture. The first having a probability of exceedance of $2 \%$ in 50 years, and the second having a probability of exceedance of $5 \%$ in 50 years. These sets are a combination of actual and synthetic time histories.

The other requirement to developing a structure's fragility curves is the ability to model the capacity of that structure. To do this, an inventory of a subset of Oregon bridges was made, from which a typical three-span and five-span bridge was identified using average attributes. Then, an OpenSees (Open System for Earthquake Engineering Simulation) model was made for both of these average bridges. Various assumptions were made during the modeling process, but most notable were the assumptions that the bridge deck would behave elastically and the columns would behave inelastically. Because of the expected inelastic behavior the columns were modeled using the OpenSees beamWithHinges element. This specialized element considers plasticity to be concentrated over specified hinge lengths at the element ends. Each ground motion was then applied to the two OpenSees models, from which the displacement response was determined for each column and from each ground motion the maximum PGA was determined. Since both capacity and demand distributions were assumed to be lognormal, for each ground motion a data pair was made relating the logarithm of the maximum PGA and the logarithm of the maximum column displacement seen by each structure in the OpenSees model. When these data pairs spanning all ground-motion records were combined into one data set for each average bridge, a best-fit line was determined by performing a regression analysis, resulting in the capacity model used in the fragility curves. 
The probability of demand exceeding the capacity of the structure was then determined by using standard worksheet software, resulting in fragility curves for both typical structures under consideration.

Using analytical methods, fragility curves were constructed using the calculated median value and dispersion (standard deviation) values of the lognormal capacity distributions for the four damage-state conditions of slight, moderate, extensive, and complete levels of damage. These statistical values were compared to the median and dispersion values proposed by other researchers, in addition to those calculated using guidelines from the HAZUS Technical Manual.

As a result of this modeling and analysis effort, the relative fragility of the modeled typical threespan and five-span bridges was determined and quantified. Possible causes of the relatively high fragilities were also considered. 


\subsection{OVERVIEW OF BRIDGE FRAGILITY WORK}

\subsection{INTRODUCTION}

Portland State University has developed a computer model of ODOT-identified freight routes of the western Oregon and Columbia River highway network using new Geographic Information System (GIS) software called REDARS2 (Risks from Earthquake Damage to Roadway Systems). The methodology and software was the result of 12 years of development with the primary financial sponsorship of the Federal Highway Administration and significant contributions from Caltrans. The Oregon study area was chosen to represent areas of relatively high seismic risk and strategic importance. The Oregon model was created by combining the structural, transportation, geotechnical and seismic attributes of the bridges, roadways and soils of the study area. This information was available on various databases, which were collected, interpreted and modified to the format recognized by the program. Using the REDARS2 model, bridge vulnerability and the associated impact to Oregon's economy can be assessed in different ways. Deterministic or probabilistic seismic risk analysis (SRA) can be performed on the Oregon network providing multilevel economic and structural damage assessments, as well as transportation functions such as post-earthquake travel time and detour-route assessments. As part of this scope, PSU has successfully performed both types of SRA to provide an initial assessment of bridge and highway network vulnerability to regional seismic activity.

Although three previous REDARS2 models have been constructed (in the New Madrid, Bay Area and Los Angeles seismic zones), the Oregon highway network model developed by PSU constitutes the first use of the program by anyone outside of the team that originally developed the software. The Oregon model encompasses a much larger area and assesses more bridges than ever attempted using this technology. Finally, the Oregon model is the first REDARS2 model to assess vertical settlement from liquefaction as part of the transportation network assessment.

In order to fully exploit the capabilities of REDARS2, proper fragility curves applicable to Oregon bridges needed to be developed. The following section provides a brief overview of bridge fragility work. Subsequent chapters describe the methods that were used in this study to develop fragility curves (also called fragility functions) for typical Oregon three-span and fivespan continuous, reinforced-concrete bridges.

\subsection{OVERVIEW OF FRAGILITY FUNCTIONS}

One of the key issues in determining an earthquake's impact on the transportation network is to estimate damage to components of lifeline systems. Modeling the performance of structures as a function of a chosen ground-motion intensity measure can do this. Peak Ground Acceleration (PGA) or Spectral Acceleration $\left(\mathrm{S}_{\mathrm{a}}\right)$ values are commonly used for intensity measures. The performance can be modeled using two methods. If discrete probabilities are associated with the intensity measure, then a damage probability matrix (Filliben et al., 2002) can be assembled. If a continuous relationship is used fragility curves can be formulated, which describes how likely a 
structure will meet or exceed a specified level of damage (limit state) given a specific ground motion intensity. Symbolically this is written as:

$$
\text { Fragility }=\text { Probability }[\mathrm{LS} \mid \mathrm{IM}=i m]
$$

where LS is the limit state or level of damage experienced by the structure, IM is the ground motion intensity measure (i.e., PGA or $\mathrm{S}_{\mathrm{a}}$ ), and $\mathrm{im}$ is a specific value of the intensity measure. Once a fragility function is generated, the user can predict the level of damage a system (or components, if fragility functions are available at the component level) may experience for a given intensity of earthquake.

Various methods can be used to construct structural fragility curves, with three being described here: empirical, expert-based and analytical methods.

\subsubsection{EMPERICAL FRAGILITY CURVES}

Empirical fragility curves are developed using statistical methods on post-earthquake inspection data. After the Northridge, CA (Jan. 17, 1994) and Loma Prieta, CA (Oct. 17, 1989) earthquakes, more effort was invested in the development of empirical fragility curves (Basoz et al., 1998, and Shinozuka et al., 2003). This was primarily due to more complete ground-motion data being available in addition to better bridge-damage data. Data from the Kobe, Japan (Jan. 17,1995 ) earthquake has also been used to develop empirical fragility curves (Shinozuka et al., 2003).

The general methodology used to develop empirical fragility curves can be generalized as follows. First, bridges of interest are assigned to distinct classes according to common structural characteristics. Post-earthquake assessments are then performed on each of these bridges in order to determine bridge-specific damage states. Correlation studies are then used to determine relationships between ground-motion intensity measures and damage states. This also can be extended to include repair-cost considerations.

This method lends itself to look at bridges in a relatively broad sense. For example, the data may be categorized by something general such as $\mathrm{R} / \mathrm{C}$ column or multi-span $\mathrm{R} / \mathrm{C}$ bridge type. Because of the subjective nature of the input inspection data and the coarseness of the data, the uncertainties associated with this approach can be high.

\subsubsection{EXPERT-BASED FRAGILITY FUNCTIONS}

Through the SRA process, the probability of earthquake damage is synthesized from information from different fields like seismology, geology, engineering and economics (Wen et al., 2003). Any other information used during SRA is qualitative and can't easily be described using statistical means. Expert-based development of functions can be challenging since subjectivity introduces high levels of uncertainty.

A procedure to implement (Porter et al., 2007) expert-based functions can be outlined as follows. Note that only experts with professional experience in the design or post-earthquake observation of the component of interest should be used. Using a provided form, advice from the experts 
should be solicited about their judgment regarding a specific engineering demand parameter (EDP) at which a particular damage state may occur. Using this data, simple relations are used to estimate a median value of the EDP and dispersion (standard deviation). If the dispersion is uncharacteristically low, indicating possible overconfidence by the experts, then provisions are made to use a minimum value of 0.4 for the dispersion.

\subsubsection{ANALYTICAL FRAGILITY FUNCTIONS}

Analytical fragility curves are primarily used when sufficient actual bridge damage and groundmotion data aren't available to predict the performance of bridge structures. Much research has been devoted to this subject using various methodologies (Nielson, 2006; Saxena et al., 2000; Mander, 1999; Hwang et al., 2001). Bridge-damage states are related to the capacity of the structure, and ground shaking is linked to the demand of the structure. The magnitude of ground shaking is usually quantified by using a ground-motion intensity factor of Peak Ground Acceleration (PGA) or Spectral Acceleration $\left(\mathrm{S}_{\mathrm{a}}\right)$. The probability of failure of a bridge or component can be described as the probability that the seismic demand (D) will exceed the capacity (C) of the bridge or component. This is usually written as:

$$
p_{f}=p\left[\frac{C}{D} \leq 1\right\rceil
$$

When this probability is modeled as a lognormal distribution, the fragility curve can be represented by a lognormal cumulative distribution function as follows:

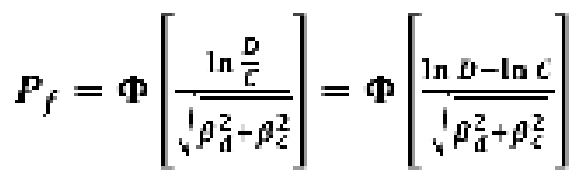

where $\mathrm{D}$ is the median value of the seismic demand in terms of an intensity parameter, $\mathrm{C}$ is the median value of the capacity defined for a particular damage state, and the $\beta$ terms are the logarithmic standard deviations for the demand and capacity distributions. Equation 1-1 can be written in various forms as will be shown in Chapter 5.

Several methods have been researched and used to model the structural demand and capacity. Three common methods used are elastic spectral response, nonlinear static analysis, and nonlinear time-history analysis.

Using the elastic spectral response method to generate fragility curves is one of the simplest available; however, forces and displacements are determined using linear elastic analysis. The applicability of this method decreases with increasing nonlinear behavior that is typically expected from bridge columns exposed to extreme ground motion.

The nonlinear static analysis method is an improvement to the elastic spectral analysis method, and is also called the capacity spectrum method (CSM) or a pushover analysis. With this method, forces are applied to a structural model that can include nonlinear properties such as the yielding of steel members. Although this method attempts to take into account nonlinear behavior and doesn't have the computation overhead of the nonlinear time history (NLTH) 
method, the CSM should be considered as a coarser approximation when compared to the NLTH method.

The nonlinear time history method is a more reliable method for modeling capacity and demand. However, this approach can be very computationally expensive. The NLTH method was used in this study, and the implementation used will be discussed in more detail in Chapter 5. A basic graphic showing the NLTH method used in this study is included as Figure 1.1.

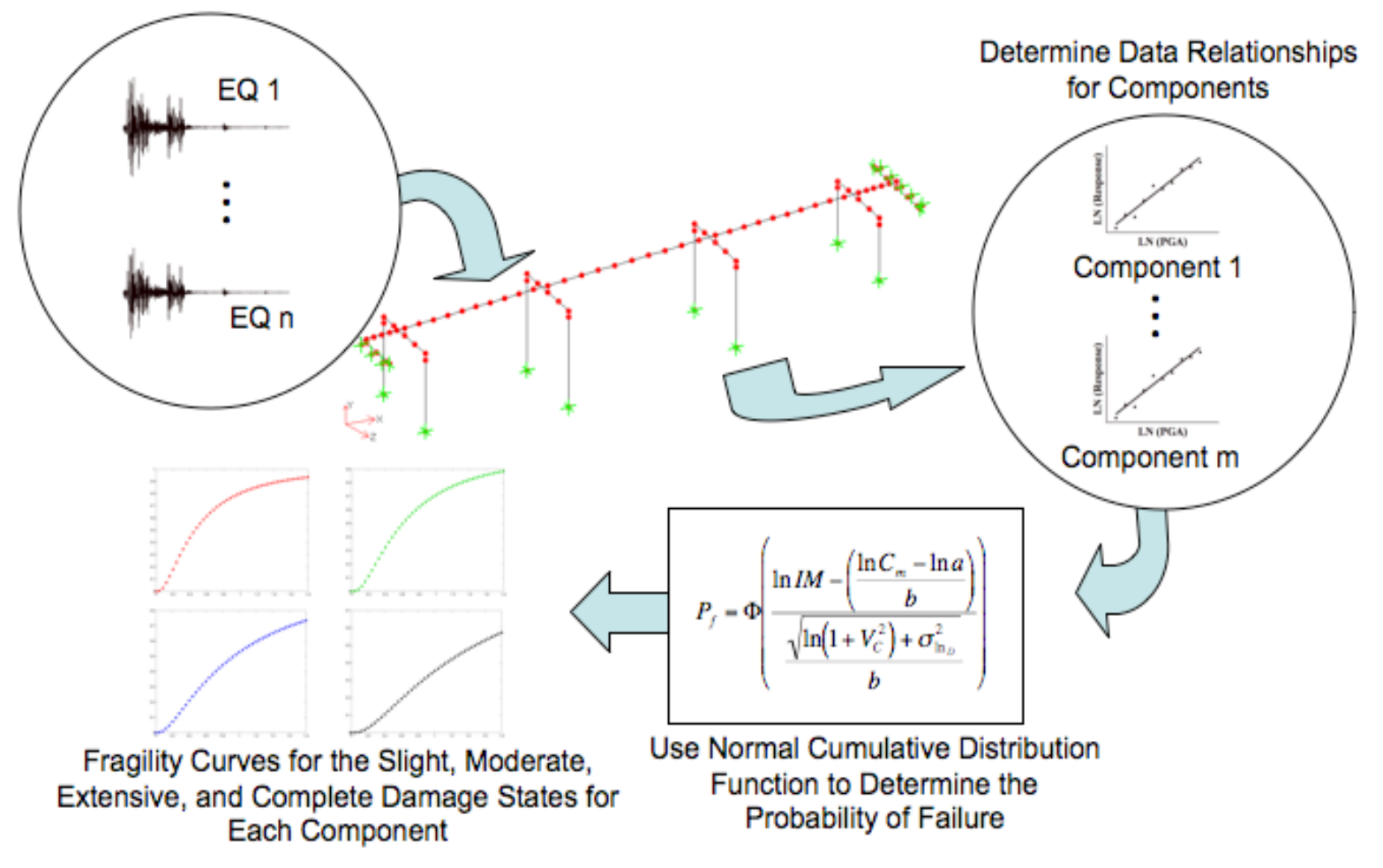

Figure 1.1: Analytical Fragility Curve Generation Using Nonlinear Time-History Analysis 


\subsection{GROUND-MOTION SUMMARY}

\subsection{HISTORICAL EARTHQUAKES}

Geologists have indicated that the question is not if a catastrophic earthquake will occur in Oregon, but when one will occur. Evidence indicates that off the Oregon coast, Cascadia subduction zone earthquakes of magnitude 8.0 or greater have occurred once every 300 to 600 years, most recently in late January of 1700 A.D (Oregon Coastal Management Program, 2007). Shallow crustal earthquakes also routinely occur throughout the western part of the state. One specific year, 1993, saw two notable earthquakes at Scotts Mills (5.6 magnitude) (Ludwin et al., 1996) and Klamath Falls (6.0 magnitude). These earthquakes provided a reminder of Oregon seismicity, with the resulting damage from these events being around $\$ 30$ million despite the relatively low magnitude.

Referring to the magnitudes published by the United States Geological Survey, as seen in Table 2.1, one of the largest earthquakes in the United States was from the Cascadia subduction zone.

Table 2.1: Selected U.S. Earthquakes of General Historic Interest (USGS, 2009)

\begin{tabular}{c|l|l|c}
\hline No. & Date & Location & Magnitude \\
\hline 1 & March 28, 1964 & Prince William Sound, Alaska & 9.2 \\
\hline 2 & January 26, 1700 & Cascadia Subduction Zone & 9.0 \\
\hline 3 & February 4, 1965 & Rat Islands, Alaska & 8.7 \\
\hline 4 & March 9, 1957 & Andreanof Islands, Alaska & 8.6 \\
\hline 5 & November 10, 1938 & Shumagin Islands, Alaska & 8.2 \\
\hline 6 & April 1, 1946 & Unimak Island, Alaska & 8.1 \\
\hline 7 & December 16, 1811 & New Madrid Region & 8.1 \\
\hline 8 & September 10,1899 & Yakutat Bay, Alaska & 8.0 \\
\hline 9 & February 7, 1812 & New Madrid Region & 8.0 \\
\hline 10 & November 3, 2002 & Denali Fault, Alaska & 7.9 \\
\hline 11 & June 10, 1996 & Andreanof Islands, Alaska & 7.9 \\
\hline 12 & May 7, 1986 & Andreanof Islands, Alaska & 7.9 \\
\hline 13 & September 4, 1899 & Cape Yakataga, Alaska & 7.9 \\
\hline 14 & April 3, 1868 & Ka'u District, Hawaii & 7.9 \\
\hline
\end{tabular}

Evidence has been cited (Heaton et al., 1987) that suggests that the Cascadia subduction zone has characteristics found in other subduction zones that have experienced large shallow earthquakes. Examples are subduction zones in southern Chile, southwestern Japan and Columbia. Although these similarities may lead to the conclusion that there is a potential for large subduction earthquakes in the Cascadia subduction zone, a better state would be if there were direct evidence suggesting that the subduction zone is actually storing elastic energy along with evidence of prehistoric earthquakes. Possible evidence includes the lack of raised Holocene terraces in Oregon and Washington and extensive Holocene turbidites. An assumption could also be made that Cascadia zone earthquakes would resemble earthquakes of zones most similar (i.e., southern Chile, SW Japan and Colombia), and if so, then earthquakes ranging from magnitudes $\left(\mathrm{M}_{\mathrm{w}}\right) 8.1$ to 9.5 should be expected, resulting in relatively strong shaking and large 
and potentially destructive local tsunamis. Also, comparisons (Atwater et al., 1995) can be made between the Cascadia subduction zone and other subduction zones and from geodetic and heatflow evidence to show that the Cascadia subduction zone is accumulating energy that could be released in future earthquakes.

\subsection{PROPOSED GROUND MOTIONS IN THE PACIFIC NORTHWEST}

To assess the vulnerability of the civil infrastructure to the associated seismic hazard of the state of Oregon, specific ground-motion time histories representative of the area were needed. Time histories, both naturally occurring and synthetic, produced from a previous study were used.

SAC (SAC, 1997) is a joint venture of the Structural Engineers Association of California (SEAOC), the Applied Technology Council (ATC), and California Universities for Research in Earthquake Engineering (CUREe). The SAC Joint Venture was formed in mid-1994 with the specific goal of investigating the damage to welded steel moment-frame buildings in the 1994 Northridge earthquake, and developing repair techniques and new design approaches to minimize damage to steel moment-frame buildings in future earthquakes. The purpose of Task 5.4.1 of the SAC project was to provide response spectra and time histories for use in case studies and trial applications in the SAC Phase 2 Steel Project. The ground motions from Task 5.4.1 developed for the Seattle area were prepared in two sets, resulting in a ground-motion suite. The first set has a probability of exceedance (POE) of 10\% in 50 years, shown in Table 2.2. The second set of motions has a probability of exceedance of $2 \%$ in 50 years, shown in Table 2.3. In these tables, two orthogonal horizontal directions are shown for each time history.

Table 2.2: Seattle Ground Motions with POE of $10 \%$ in 50 Years (SAC, 1997)

\begin{tabular}{|c|c|c|c|c|}
\hline Location & Magnitude & $\begin{array}{c}\text { Duration } \\
\text { (secs) }\end{array}$ & $\begin{array}{c}\text { PGA } \\
\text { Horizontal dir1 } \\
\text { (g) } \\
\end{array}$ & $\begin{array}{c}\text { PGA } \\
\text { Horizontal dir2 } \\
\text { (g) } \\
\end{array}$ \\
\hline Long Beach, Vernon CMD Bldg. & 6.5 & 39.08 & 0.174 & 0.135 \\
\hline Morgan Hill, 1984, Gilroy & 6.2 & 59.98 & 0.386 & 0.662 \\
\hline West. Washington, Olympia, 1949 & 6.5 & 79.98 & 0.383 & 0.352 \\
\hline West. Washington, Seattle Army B., 1949 & 6.5 & 66.68 & 0.295 & 0.388 \\
\hline North Palm Springs, 1986 & 6 & 59.98 & 0.587 & 0.599 \\
\hline Puget Sound, Wa., Olympia, 1949 & 7.1 & 81.82 & 0.752 & 0.596 \\
\hline Puget Sound, Wa., Federal OFC B., 1949 & 7.1 & 74.08 & 0.369 & 0.303 \\
\hline Eastern Wa., Tacoma County, 1949 & 7.1 & 59.98 & 0.290 & 0.574 \\
\hline Llolleo, Chile 1985 & 8 & 99.975 & 0.697 & 0.670 \\
\hline Vinadel Mar, Chile, 1985 & 8 & 99.975 & 0.541 & 0.384 \\
\hline
\end{tabular}

Table 2.3: Seattle Ground Motions with POE of $2 \%$ in 50 Years (SAC, 1997)

\begin{tabular}{l|c|c|c|c}
\hline Location & Magnitude & $\begin{array}{c}\text { Duration } \\
\text { (secs) }\end{array}$ & $\begin{array}{c}\text { PGA } \\
\text { Horizontal dir1 } \\
(\mathbf{g})\end{array}$ & $\begin{array}{c}\text { PGA } \\
\text { Horizontal dir2 } \\
(\mathbf{g})\end{array}$ \\
\hline 1992 Mendocino & 7.1 & 59.98 & 0.755 & 0.485 \\
\hline 1992 Erzincan & 6.7 & 20.775 & 0.605 & 0.539 \\
\hline 1949 Olympia & 6.5 & 79.98 & 0.895 & 0.821 \\
\hline 1965 Seattle & 7.1 & 81.82 & 1.755 & 1.390 \\
\hline 1985 Valpariso & 8 & 99.975 & 1.636 & 1.573 \\
\hline Deep Interplate (simulation) & 8 & 99.975 & 1.270 & 0.901 \\
\hline
\end{tabular}




\begin{tabular}{l|c|c|c|c}
\hline Location & Magnitude & $\begin{array}{c}\text { Duration } \\
\text { (secs) }\end{array}$ & $\begin{array}{c}\text { PGA } \\
\text { Horizontal dir1 } \\
(\mathbf{g})\end{array}$ & $\begin{array}{c}\text { PGA } \\
\text { Horizontal dir2 } \\
\text { (g) }\end{array}$ \\
\hline 1978 Miyagi-oki & 7.4 & 79.98 & 0.606 & 0.783 \\
\hline Shallow Interplate (simulation) & 7.9 & 79.98 & 0.563 & 0.534 \\
\hline Shallow Interplate (simulation) & 7.9 & 79.98 & 0.578 & 0.749 \\
\hline
\end{tabular}

The distribution of PGA values for the individual suites are shown in Figure 2.1 and Figure 2.2. The values range from a minimum of $0.485 \mathrm{~g}$ to a maximum of $1.755 \mathrm{~g}$ when using the POE-2\%in-50-years suite and range from a minimum of $0.135 \mathrm{~g}$ to a maximum of $0.752 \mathrm{~g}$ when using the POE-10\%-in-50-years suite.

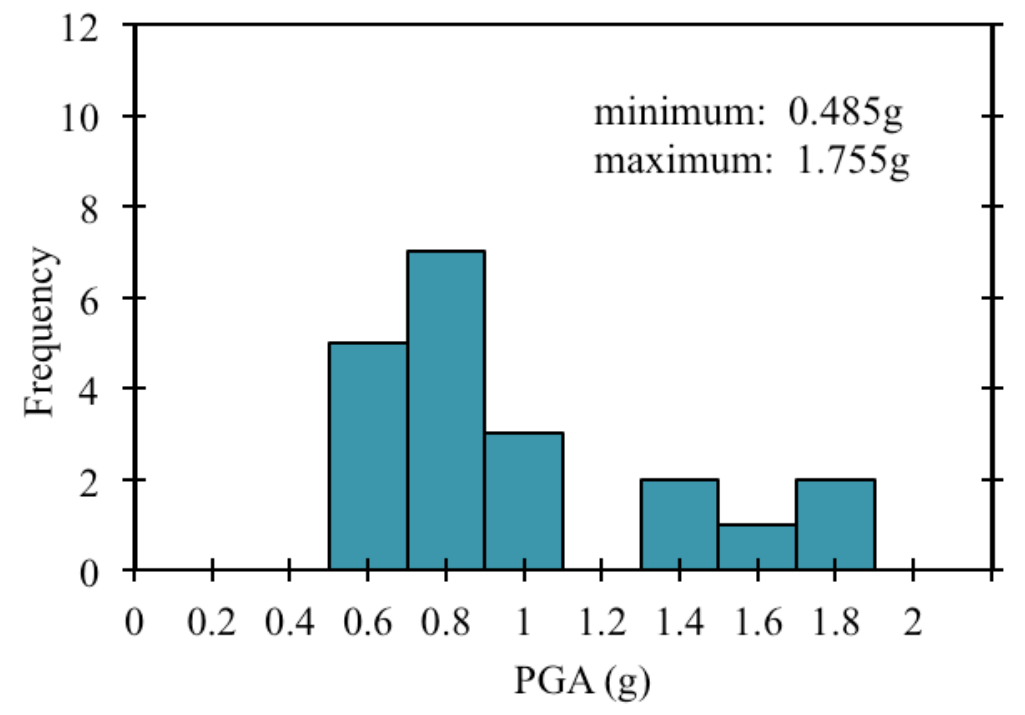

Figure 2.1: Histogram of PGA Values of POE-2\%-in-50-Years Suite

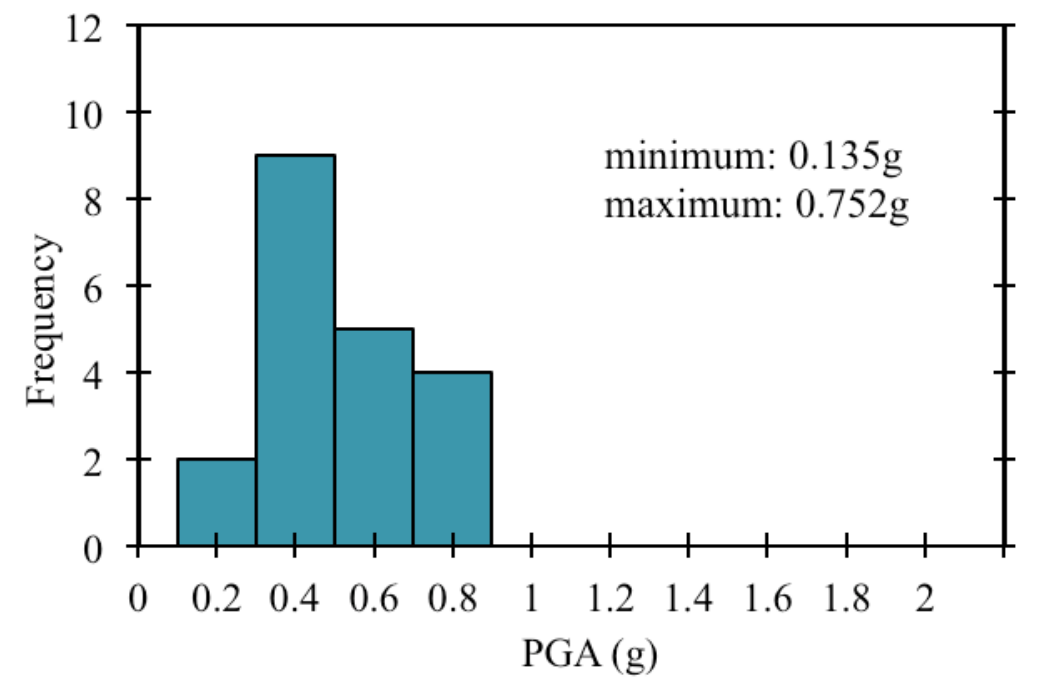

Figure 2.2: Histogram of PGA Values of POE-10\%-in-50-Years Suite 
As can be seen, the PGA distribution for the 2\%-in-50-years suite has some ground motions at the higher end of the distribution in the $1.4 \mathrm{~g}$ to $1.8 \mathrm{~g}$ range, whereas this high level of acceleration is not seen in the other suite. The distribution of PGA values for both suites combined is shown in Figure 2.3. The suite is skewed to the left, giving emphasis to accelerations less than 1g; however, the PGA values have a considerable range from $0.135 \mathrm{~g}$ to $1.755 \mathrm{~g}$.

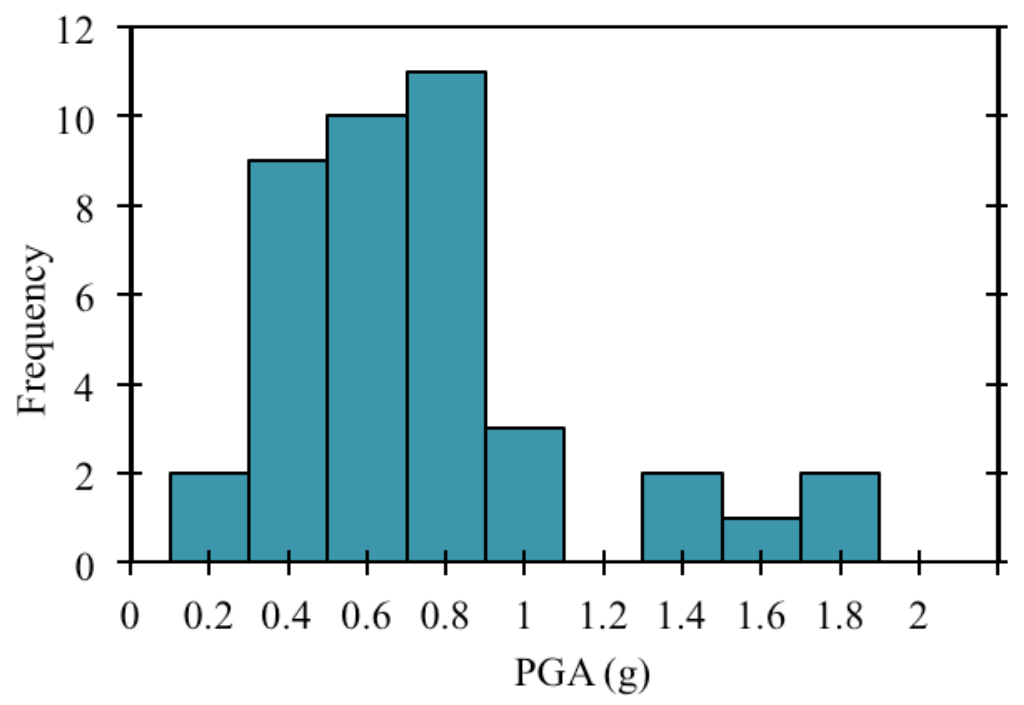

Figure 2.3: Histogram of PGA Values of All SAC Ground-Motion Time Histories Used

This combined suite is in contrast to the earthquake records used by other researchers (Nielson, 2005 and Hwang et al., 2001). For example, the two groups of ground motions used by Nielson have geometric mean PGA values ranging from $0.06 \mathrm{~g}$ to $0.66 \mathrm{~g}$ and $0.022 \mathrm{~g}$ to $0.764 \mathrm{~g}$, with both groups skewed to the left emphasizing the lower accelerations.

In order to predict reasonable responses to the SAC ground-motion suites, the acceleration time histories were integrated resulting in the distance traveled of a simple single degree of freedom (SDOF) system. Using analysis techniques (Chopra, 2007) that rely on a recurrence formulation derived from exact solutions of the equation of motion, the displacement spectrums of the two suites of ground motions were determined and are shown in Figure 2.4 and Figure 2.5.

Two specific periods, with the corresponding ranges of displacement, are noted on the two displacement spectrums. These chosen periods correspond to specific mode shapes of vibration for specific models. The mode shapes, and the model variations considered in this study, are discussed in detail in Chapter 4. 


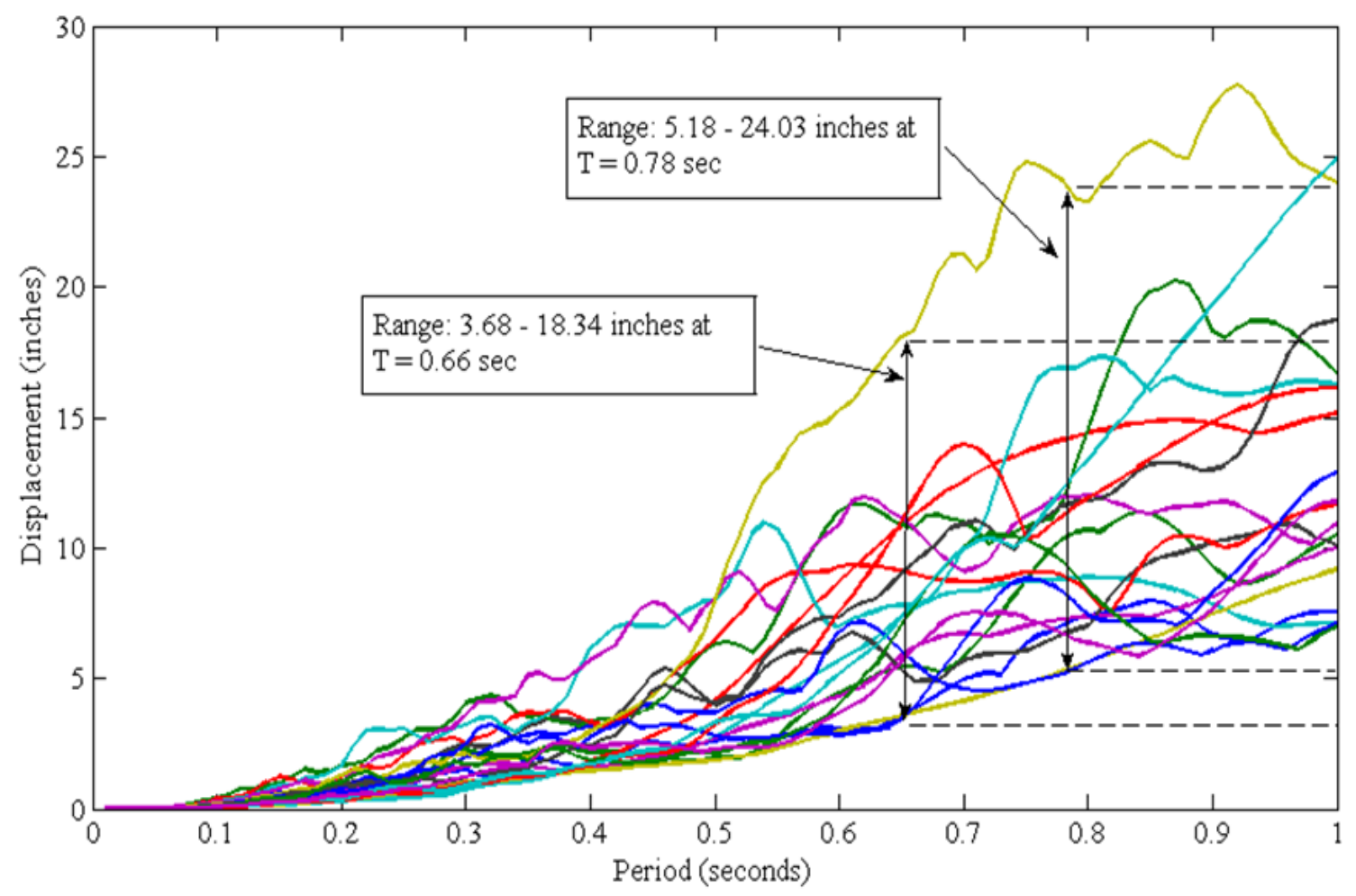

Figure 2.4: Displacement Spectrum (5\% damping) - POE-2\%-in-50-Years Suite

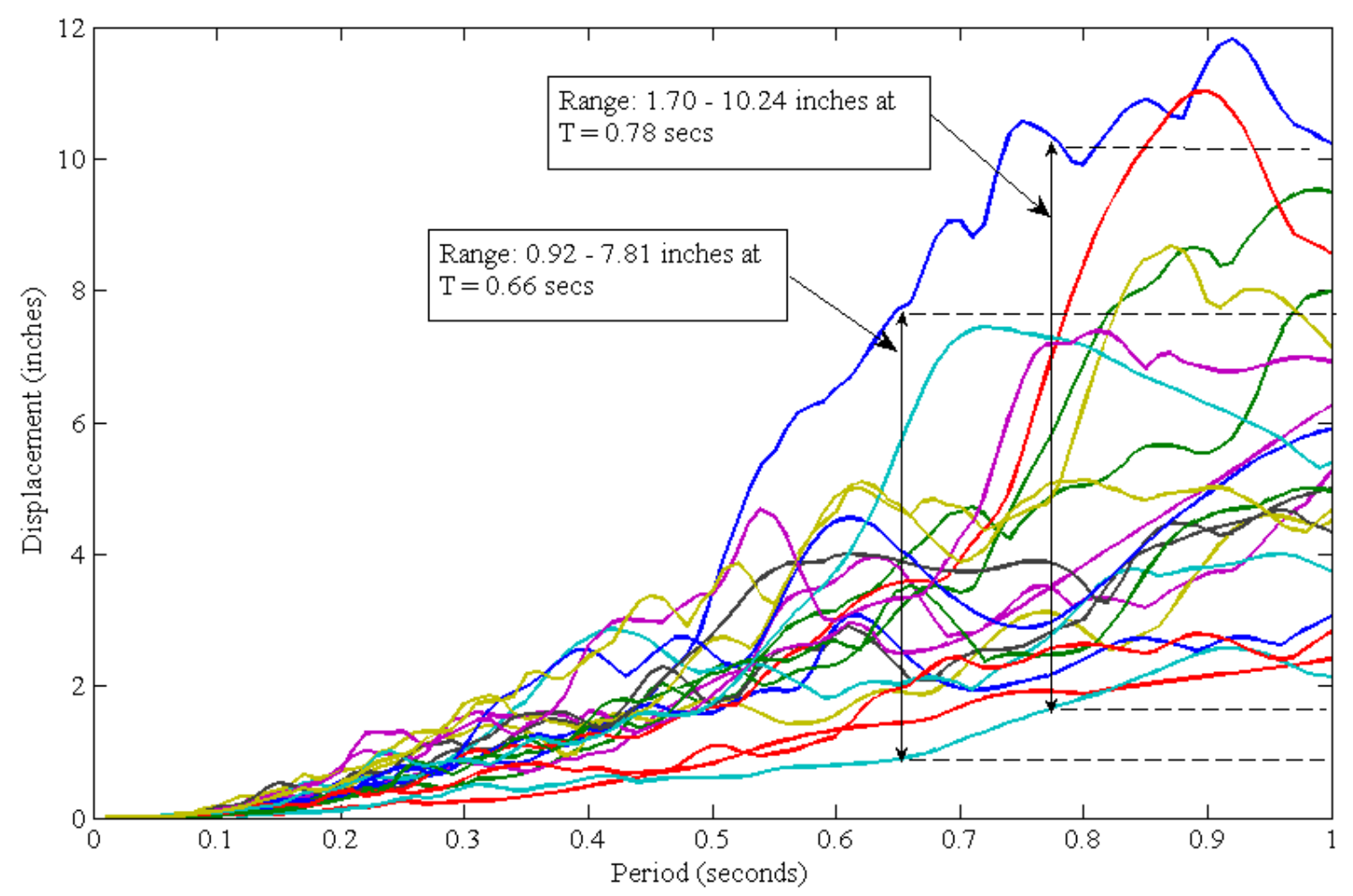

Figure 2.5: Displacement Spectrum (5\% damping) - POE-10\%-in-50-Years Suite 
Referring to the $2 \%$ exceedance displacement spectrum (Figure 2.3), for a SDOF structure with a fundamental period of $\mathrm{T}=0.66 \mathrm{secs}$, the maximum expected displacement should be around 18 inches. Referring to the $10 \%$ exceedance displacement spectrum (Figure 2.2), for a SDOF structure with a fundamental period of $\mathrm{T}=0.66 \mathrm{secs}$, the maximum expected displacement should be around eight inches. The maximum displacement from the $2 \%$ exceedance portion of the ground-motion suite is significantly larger than that expected from the $10 \%$ exceedance portion, which should be expected since the maximum PGA values are significantly larger with the maximum PGA value of almost $1.8 \mathrm{~g}$. These expected displacement values will be compared to the displacements found using the OpenSees (Open System for Earthquake Engineering Simulation 2010) models in Chapter 4. Both of the ground-motion suites described in this section were used in the modeling process unless otherwise noted.

The pseudo-acceleration spectrums for the SDOF structure using the two suites were determined using:

$$
\Delta=\left(\frac{2 \pi}{T}\right)^{2} D\left(\frac{1 g}{3 \pm 61 \frac{1 \pi}{\sec ^{2}}}\right)
$$

where $\mathrm{A}$ is the pseudo-acceleration of the system, $\mathrm{T}$ is the period of vibration and $\mathrm{D}$ is the displacement from Figure 2.4 and Figure 2.5. The pseudo-acceleration spectrums for the two suites are shown in Figure 2.6 and Figure 2.7.

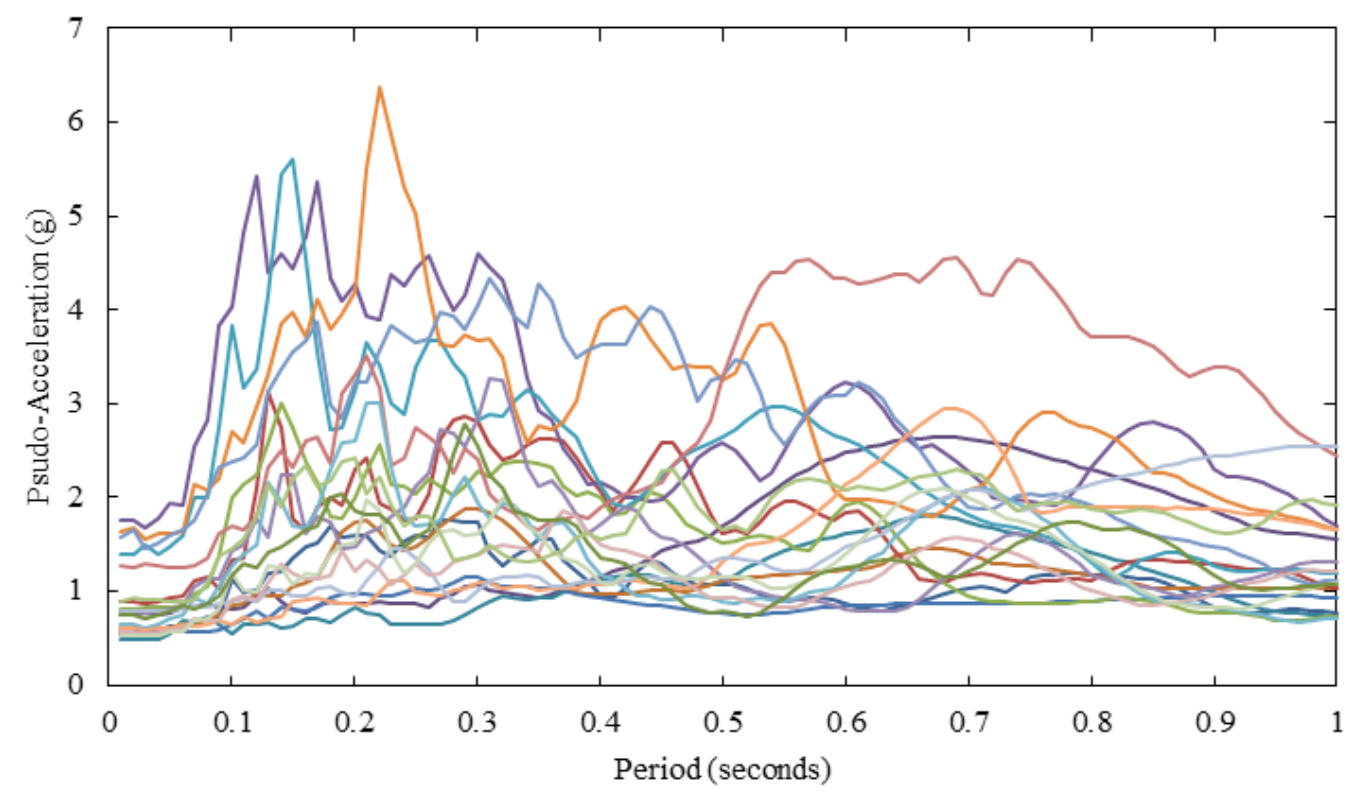

Figure 2.6: Pseudo-Acceleration Spectrum (5\% damping) - POE-2\%-in-50-Years Suite 


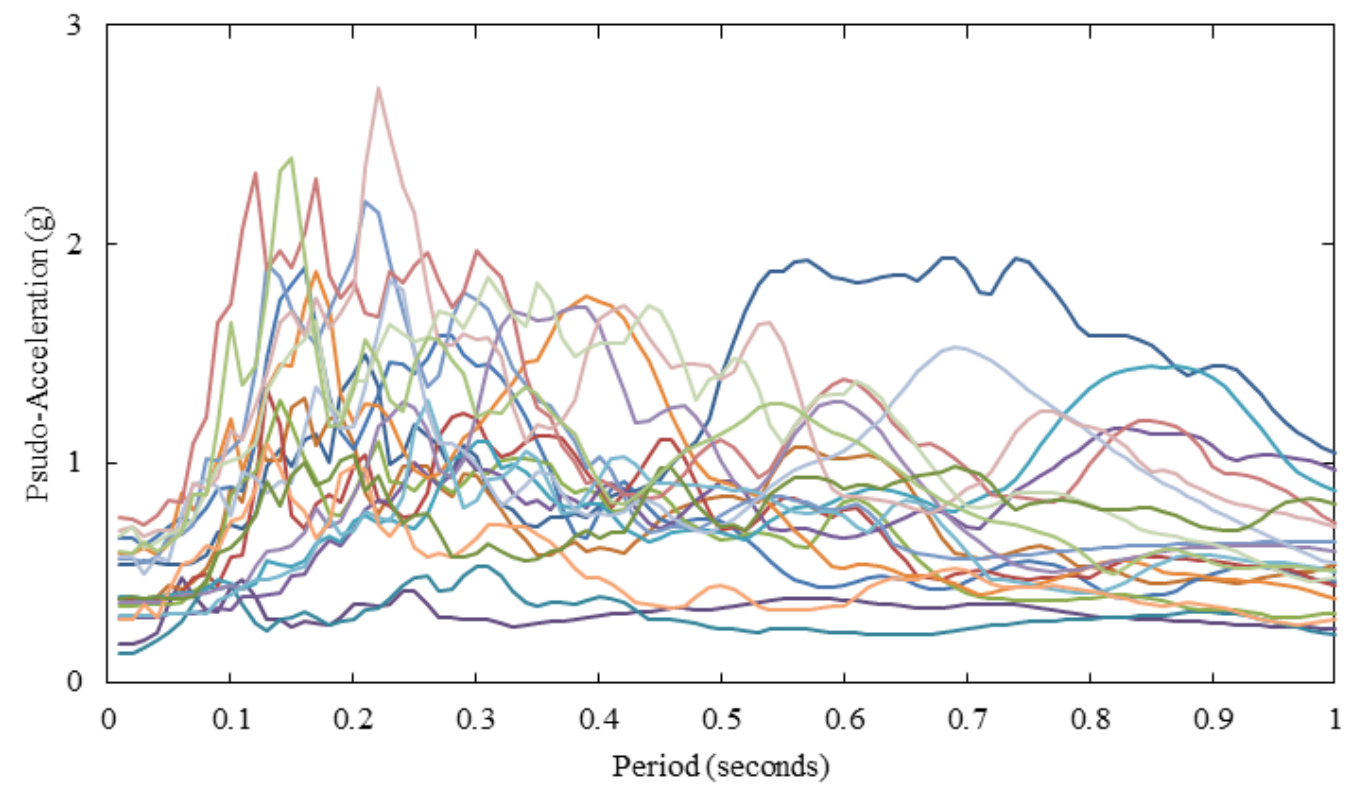

Figure 2.7: Pseudo-Acceleration Spectrum (5\% damping) - POE-10\%-in-50-Years Suite

When using the POE-2\%-in-50-years suite with a SDOF system, Figure 2.6 shows the higher pseudo-accelerations occur when the period of the system is between around 0.1 and 0.3 seconds with a maximum value of $6.4 \mathrm{~g}$ at 0.22 seconds. In this range the maximum equivalent static force on the SDOF would be expected to occur, resulting in the maximum moment at the base support.

When using the POE-10\%-in-50-years suite with a SDOF system, Figure 2.7 shows the higher pseudo-accelerations again occur when the period of the system is between around 0.1 and 0.3 seconds with a maximum value of $2.7 \mathrm{~g}$ at 0.22 seconds. In this range the maximum equivalent static force on the SDOF would be expected to occur, resulting in the maximum moment at the base support. 


\subsection{BRIDGE INVENTORY}

\subsection{NATIONAL BRIDGE INVENTORY}

In 1967, there was a sudden collapse of the Silver Bridge, a pin-connected link suspension bridge over the Ohio River at Point Pleasant, WV, with the loss of 46 lives. As a result, the Federal Highway Act of 1968 initiated a national bridge inspection program that recognized the need for periodic and consistent bridge inspections. A direct result was the initiation of the National Bridge Inspection Standards (NBIS) in 1971. These standards currently require that every bridge on public roads be inspected at least every two years (FHWA, 2004).

To facilitate the inspection process, a coding guide (FHWA, 1995) was prepared for use by inspection authorities in recording and coding the information that make up the National Bridge Inventory (NBI) database. This study made use of the coding guide and the NBI in order to obtain dimensional information about Oregon bridges, such as longest span length and structure width. When using the NBI, care should be taken to use the proper units as specified by the coding guide.

\subsection{DETERMINATION OF TYPICAL THREE-SPAN BRIDGE}

NBI database data were manipulated so that only three-span structures that meet the criteria given in Table 3.1 were considered.

Table 3.1: NBI Database Search Criteria

\begin{tabular}{l|l}
\hline NBI Item & Value \\
\hline 5 C & Designated Level of Service $=1$ (Mainline) \\
\hline 7 & $\begin{array}{l}\text { Facility Carried By Structure }=\text { I-5, I-84, I-205, } \\
\text { OR-99W, US-26, and US-30 }\end{array}$ \\
\hline 27 & Year Built $\leq 1969$ \\
\hline
\end{tabular}

The resulting list of bridges was then sorted according to NBI Items No. 43A and 43B. Item No. 43A provides the kind of material/design used for the structure, and item No. 43B provides the type of construction used on the structure.

The quantity and percentage of Oregon bridges carrying I-5 for several materials and construction methods used are shown in Table 3.2 and Table 3.3.

Table 3.2: NBI Item 43A - Kind of Material/Design Used on Oregon Bridges on Chosen Highways

\begin{tabular}{l|l|c|c}
\hline NBI Code & Description & Quantity & Percentage \\
\hline 1 & Concrete & 8 & 3.0 \\
\hline 2 & Concrete Continuous & 193 & 73.1 \\
\hline 3 & Steel & 4 & 1.5 \\
\hline 4 & Steel Continuous & 19 & 7.2 \\
\hline
\end{tabular}




\begin{tabular}{l|l|c|c}
\hline NBI Code & Description & Quantity & Percentage \\
\hline 5 & Pre-Stressed Concrete & 37 & 14.0 \\
\hline 6 & Pre-Stressed Concrete Continuous & 1 & 0.4 \\
\hline 7 & Timber & 2 & 0.8 \\
\hline
\end{tabular}

Table 3.3: NBI Item 43B - Type of Design/Construction Used on Oregon Bridges on Chosen Highways

\begin{tabular}{l|l|c|c}
\hline NBI Code & Description & Quantity & Percentage \\
\hline 01 & Slab & 42 & 22.5 \\
\hline 02 & Stringer/Multi-beam or Girder & 124 & 66.3 \\
\hline 03 & Girder and Floorbeam System & 2 & 1.1 \\
\hline 05 & Box Beam or Girders - Multiple & 19 & 10.2 \\
\hline
\end{tabular}

The continuous concrete bridge, with over $73 \%$, was found to be the most common bridge type along the defined Oregon highways. The most common construction type was then found to be multi-beam or girder, with over $66 \%$ of the bridges using this construction type.

To determine the dimensions of the three-span model bridge, the average and standard deviation values for bridge width and longest span were calculated from Oregon three-span bridges along the defined Oregon highways. Table 3.4 shows that the average three-span bridge has an average deck width of almost 58 feet, and the longest span has an average length of slightly over 58 feet.

Table 3.4: Statistics of Three-Span NBI Code 202 Oregon Bridges on Chosen Highways

\begin{tabular}{l|c|c}
\hline Dimension & $\begin{array}{c}\text { Average } \\
\text { (ft) }\end{array}$ & $\begin{array}{c}\text { Std Deviation } \\
\text { (ft) }\end{array}$ \\
\hline Width & 57.3 & 23.7 \\
\hline Longest Span (S2) & 50.7 & 15.0 \\
\hline Overall Length & 126.8 & 42.6 \\
\hline
\end{tabular}

The three-span bridge $07865 \mathrm{~A}$, having dimensions close to these average values, was chosen from the NBI database to be a typical three-span bridge. Table 3.5 gives the dimensions for the typical three-span bridge that was modeled, and an elevation view is shown in Figure 3.1.

Table 3.5: Bridge Used In Three-Span Study (Oregon Bridge 07865A East)

\begin{tabular}{l|c}
\hline Dimension & $\begin{array}{c}\text { Value } \\
\text { (ft) }\end{array}$ \\
\hline Width & 33.3 \\
\hline Main Span (S2) Length & 48.0 \\
\hline Secondary Span (S1/S3) Length & 36.0 \\
\hline Total Structure Length & 120.0 \\
\hline
\end{tabular}

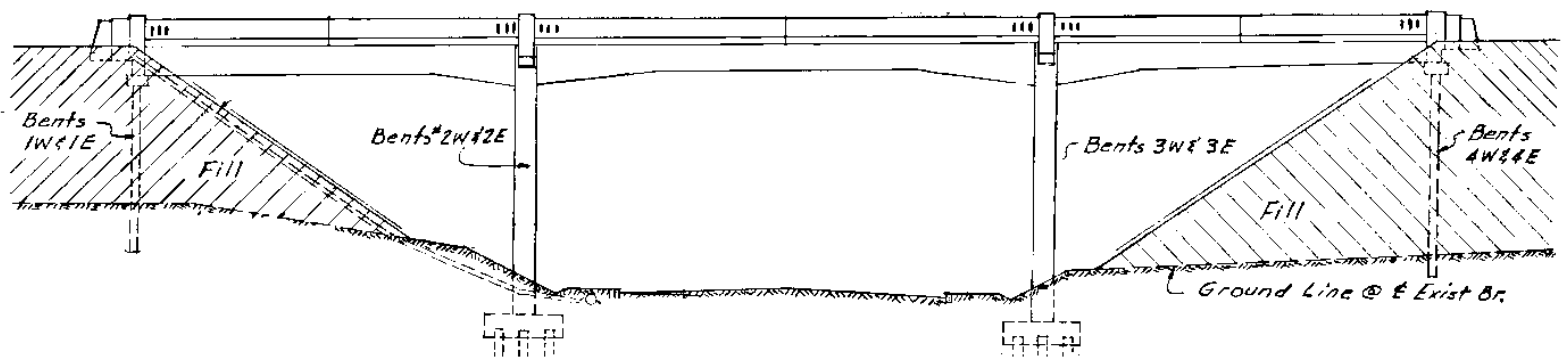


Figure 3.1: Elevation View of Oregon Bridge 07865A (Taylor Street East, Lane County)

\subsection{DETERMINATION OF TYPICAL FIVE-SPAN BRIDGE}

A similar methodology was used to determine which five-span bridges would be included in the study. The same set of highways was considered when gathering data from the NBI database: I5, I-84, I-205, OR-99W, US-26, and US-30 highways. Table 3.6 through Table 3.10 provide data for five-span bridges from these highways.

Table 3.6: Kind of Material/Design Used on Five-Span Oregon Bridges on Chosen Highways

\begin{tabular}{l|l|c|c}
\hline $\begin{array}{l}\text { Segment 43A } \\
\text { NBI Code }\end{array}$ & Description & Quantity & Percentage \\
\hline 2 & Concrete Continuous & 46 & 59.7 \\
\hline 3 & Steel & 6 & 7.8 \\
\hline 4 & Steel Continuous & 5 & 6.5 \\
\hline 5 & Pre-Stressed Concrete & 11 & 14.3 \\
\hline 6 & Pre-Stressed Concrete Continuous & 4 & 5.2 \\
\hline 7 & Timber & 5 & 6.5 \\
\hline
\end{tabular}

Table 3.7: Type of Design/Construction on Five-Span Oregon Bridges on Chosen Highways

\begin{tabular}{l|l|c|c}
\hline $\begin{array}{l}\text { Segment 43B } \\
\text { NBI Code }\end{array}$ & Description & Quantity & Percentage \\
\hline 01 & Slab & 1 & 1.3 \\
\hline 02 & Stringer/Multi-beam or Girder & 65 & 84.4 \\
\hline 05 & Box Beam or Girders - Multiple & 5 & 6.5 \\
\hline 06 & Box Beam or Girders - Single or Spread & 1 & 1.3 \\
\hline 07 & Frame & 2 & 2.6 \\
\hline 09 & Truss - Deck & 2 & 2.6 \\
\hline 11 & Arch - Deck & 1 & 1.3 \\
\hline
\end{tabular}

The continuous concrete bridge, with almost $60 \%$, was found to be the most common five-span bridge type along the chosen highways in Oregon. The most common construction type is multibeam or girder, with over $84 \%$ of the bridges using this construction type.

When considering only continuous concrete designed bridges, most of the bridges of this design are girder type, as shown in Table 3.8 .

Table 3.8: Majority of Bridge Types on Oregon Bridges on Chosen Highways

\begin{tabular}{l|l|c|c}
\hline $\begin{array}{l}\text { Segment 43 } \\
(\mathbf{4 3 A + 4 3 B )} \\
\text { NBI Code }\end{array}$ & Description & Quantity & Percentage \\
\hline 202 & $\begin{array}{l}\text { Concrete Continuous - String/Multi-beam } \\
\text { or Girder }\end{array}$ & 42 & 54.5 \\
\hline 502 & $\begin{array}{l}\text { Prestressed Concrete - Stringer/Multi- } \\
\text { beam or Girder }\end{array}$ & 11 & 14.3 \\
\hline
\end{tabular}




\begin{tabular}{l|l|l|l}
\hline 702 & Timber - Stringer/Multi-beam or Girder & 5 & 6.5 \\
\hline
\end{tabular}

To determine the dimensions of the five-span model bridge, the average and standard deviation values for bridge width and longest span were used from Oregon five-span bridges along the chosen highways. Table 3.9 shows that the average five-span bridge has an average deck width of almost 37 feet, and an average structure length of slightly over 246 feet.

Table 3.9: Statistics of Five-Span NBI Code 202 Oregon Bridges on Chosen Highways

\begin{tabular}{l|c|c}
\hline Dimension & $\begin{array}{c}\text { Average } \\
\text { (ft) }\end{array}$ & $\begin{array}{c}\text { Std Deviation } \\
\text { (ft) }\end{array}$ \\
\hline Width & 40.5 & 16.2 \\
\hline Longest Span & 62.2 & 11.8 \\
\hline Total Structure Length & 246.1 & 38.1 \\
\hline
\end{tabular}

The five-span bridge 07628, having a span and overall length dimensions within one standard deviation, was chosen from the NBI database to be the typical five-span bridge. Bridge 07628 has a webwall that wasn't modeled. This can be justified since there is another Oregon bridge (07628A) that has similar dimensions and characteristics, but wasn't designed with the webwall. Table 3.10 gives the dimensions for the typical five-span bridge that was modeled, and an elevation view is shown in Figure 3.2.

Table 3.10: Bridge Used In Five-Span Study (Oregon Bridge 07628)

\begin{tabular}{l|c}
\hline Dimension & $\begin{array}{c}\text { Value } \\
\text { (ft) }\end{array}$ \\
\hline Width & 35.1 \\
\hline Main Span (S3) Length & 69.9 \\
\hline Secondary Span (S2/S4) Length & 60.0 \\
\hline Total Structure Length & 222.1 \\
\hline
\end{tabular}

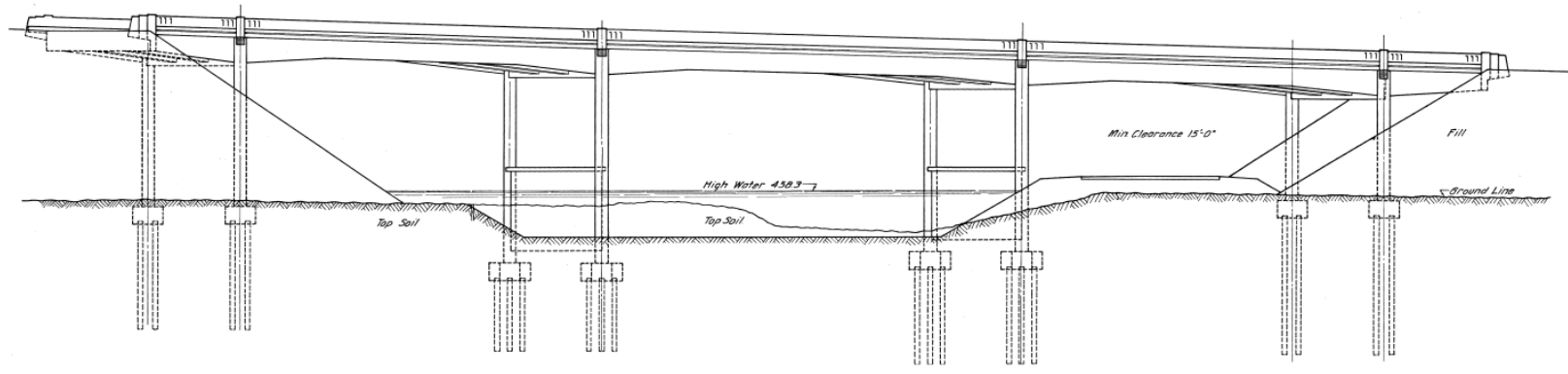

Figure 3.2: Elevation View of Oregon Bridge 07628 (Sutherlin Creek, Douglas County) 


\subsection{THREE-DIMENSIONAL MODELS OF TYPICAL BRIDGES}

The method used to generate fragility curves in this study relies on analytical models of the structures being considered. The modeling process can become very complicated and cumbersome, leading to the necessity of simplifying assumptions. For example, the choice of modeling in two dimensions or three dimensions can greatly impact the modeling process. However, choosing if the longitudinal direction or transverse direction controls the response of the structure can be difficult to determine. By minimizing these assumptions and modeling three dimensionally, the dominant direction will be accounted for, in addition to possible combination of the responses in the two directions.

The highway bridges being considered are of a continuous concrete design with integral bent caps and two columns per bent. The bridges all are constructed using a series of typical bridge components. The first component is the superstructure made up of girders/beams supporting the deck and wearing surface. Any parapets used could also be included with the superstructure. The superstructure in the modeling process was consolidated into an aggregate, and will be referred to as the deck. The components of a typical bridge are shown in Figure 4.1. The second primary set of components is used to support the superstructure and include the abutments and bents (columns and bent caps). As mentioned previously, the bridges being modeled all have integral bent caps.

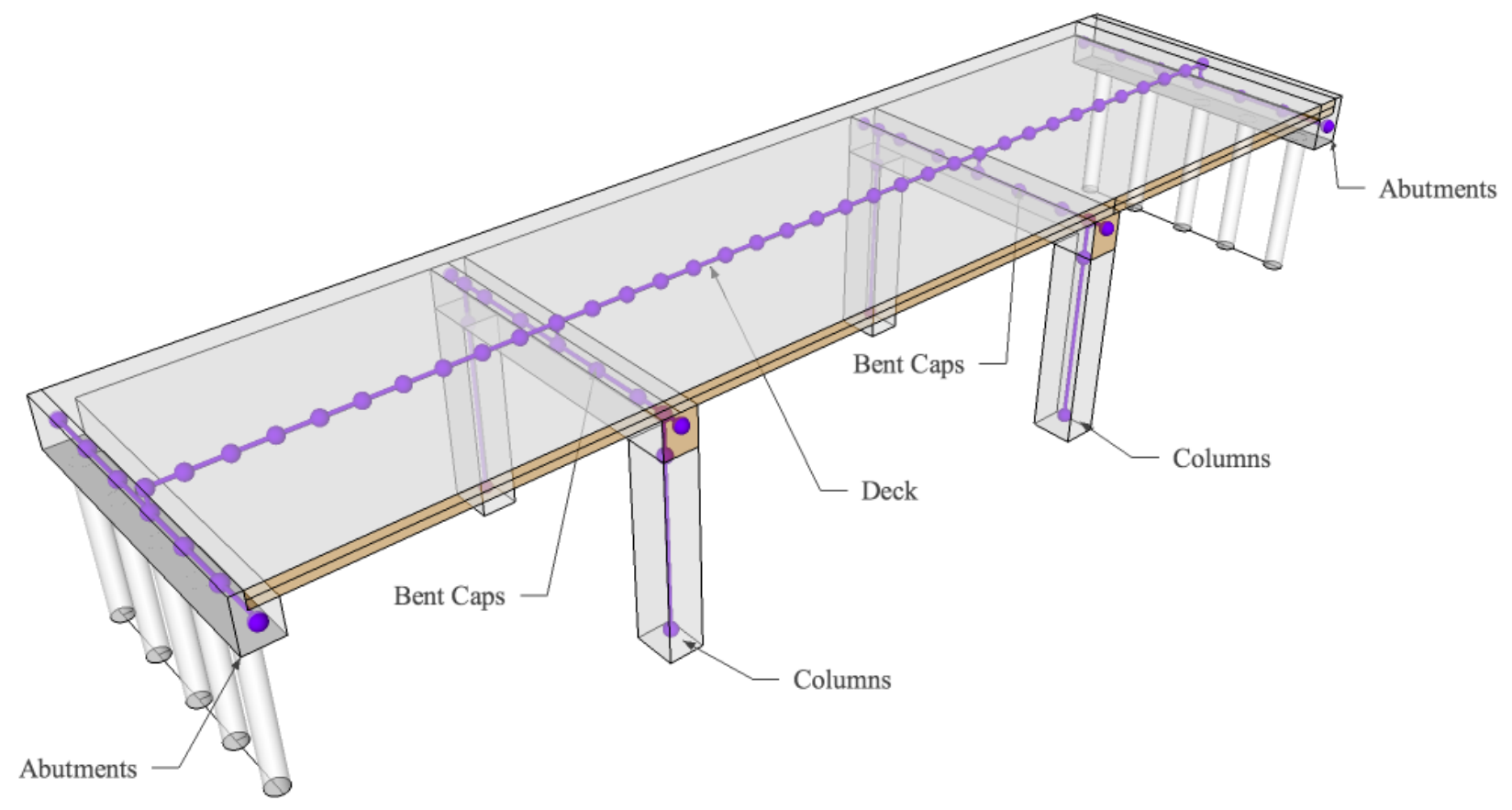

Figure 4.1: Typical Bridge Model 
In the following sections, the analytical models for the two types of bridges will be presented. Nonlinearities were taken into account when modeling some of the bridge components. Five percent Rayleigh damping was used in all models, and was calculated using the first mode as calculated by the eigenvalue analysis.

Examples of the seismic loads being considered are two ground-motion records showing two extremes of the PGA spectrum. The first, with a peak PGA of $0.135 \mathrm{~g}$ and a probability of exceedance of 10\%, was recorded at Long Beach, CA (SAC, 2010) and is shown in Figure 4.2. The time-history analyses conducted using records from the POE-of-10\% group used a time step of five milliseconds in the OpenSees model.

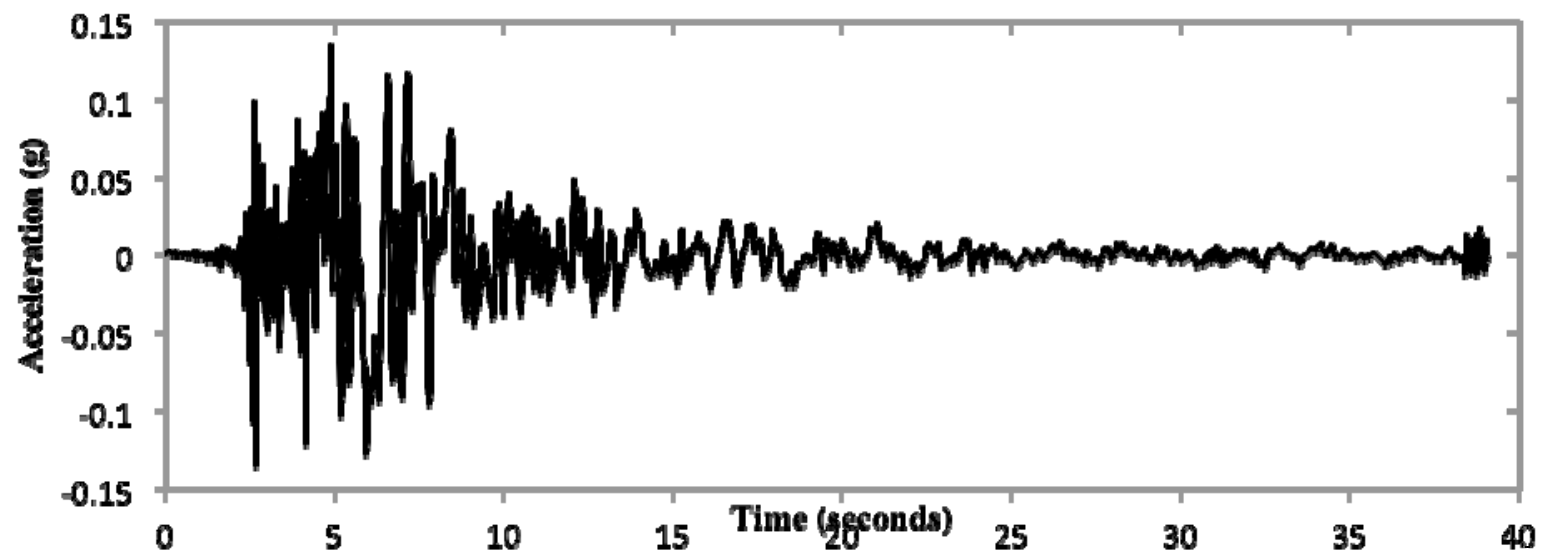

Figure 4.2: Ground-Motion Sample from POE-of-10\% Group

The second ground-motion record, with a peak PGA of $1.637 \mathrm{~g}$ and a probability of exceedance of 2\%, was recorded at Valparaiso, Chile, in 1985 (SAC, 2010) and is shown in Figure 4.3. This record also has a much longer duration, at almost 100 seconds.

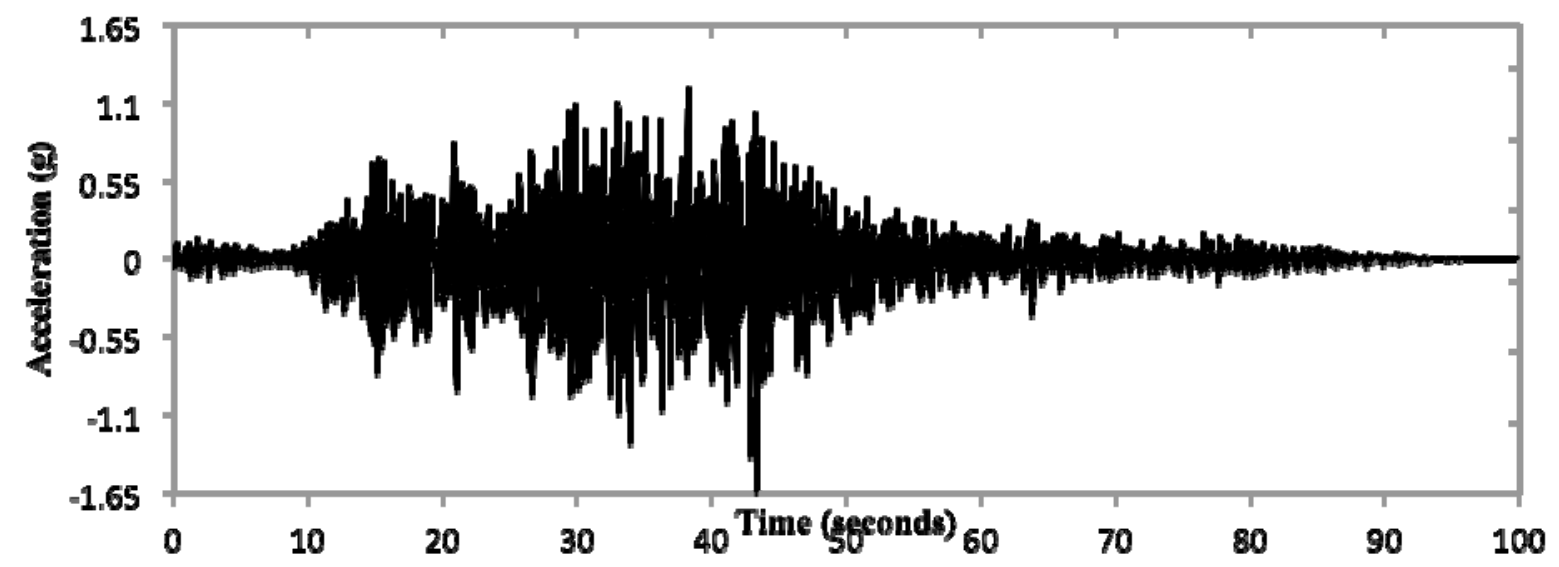

Figure 4.3: Ground-Motion Sample from POE-of-2\% Group 
The time-history analyses conducted using records from the POE-of-10\% group started with a time step of two milliseconds. This time step was reduced as necessary in order to accommodate numerical convergence problems. Having the script used by OpenSees to automatically change the time step, in addition to the specific numerical method used for a given time step, was found to be the most convenient.

\subsection{TYPICAL THREE-SPAN BRIDGE}

\subsubsection{BRIDGE LAYOUT}

Oregon Bridge 07865A East was used as the template for the typical three-span bridge to be used in this study, and an elevation view is shown in Figure 3.1. This bridge has three spans that are 36, 48 and 36 feet long, for a total structure length of 120 feet, with the width of each span being almost 34 feet. This bridge has a continuous concrete deck with the bents being integral. The heights of the four columns range from 19.8 feet to 22.0 feet.

The dual-column bent caps for this bridge are made up of a 16-inch-wide-by-60-inch-deep reinforced concrete bent beam supported by two 24-inch-by-24-inch rectangular reinforced concrete columns. The bent beam uses three \#10 bars at the top and a combination of three \#9 and three \#10 bars at the bottom of the beam. The reinforcement details are shown in Figure 4.4. The abutments used with this bridge are seat type abutments with pile supports. From the bridge plans, the abutments were assumed to use a 3.5-foot-high back wall, combined with seven piles.

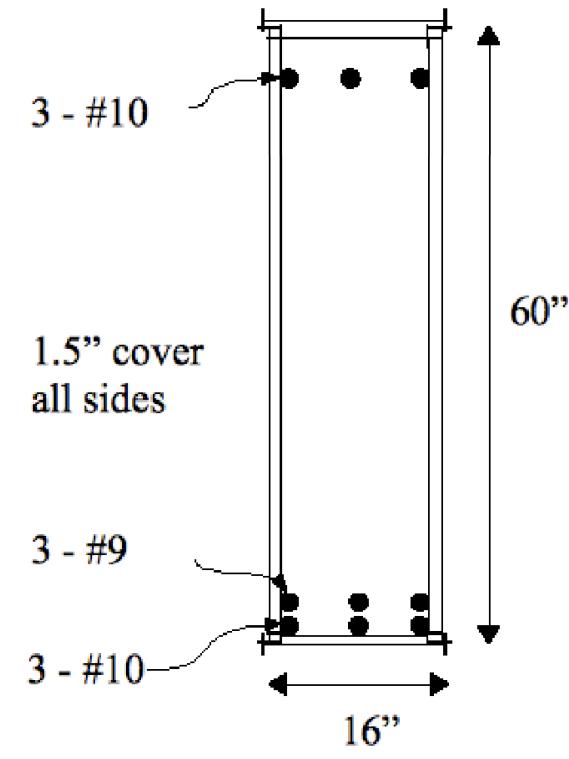

(a) Bents $2 / 3$

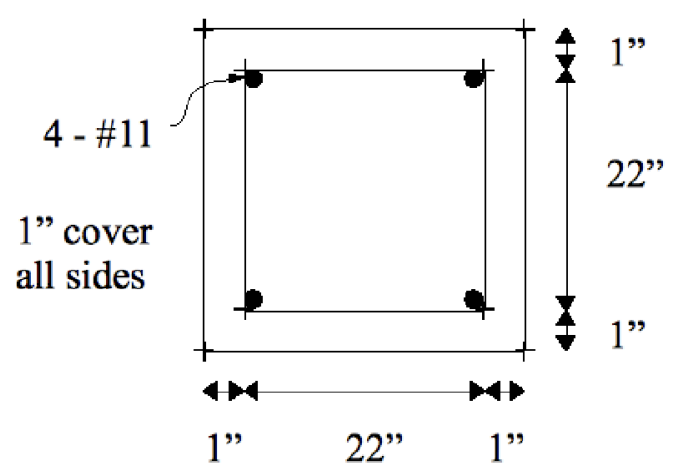

(b) Columns

Figure 4.4: Concrete Member Reinforcement for Three-Span Bridge 


\subsubsection{OPENSEES MODEL}

The typical three-span bridge was modeled using the OpenSees application. In order to take into account nonlinearities, several different element types were used when modeling some of the bridge components. An overview of the element and material types are shown in Table 4.1.

Table 4.1: Element Types Used With Three-Span Model

\begin{tabular}{l|l|l}
\hline Component & Material & Element \\
\hline $\begin{array}{l}\text { Abutments } \\
\text { (Bents 1/4) }\end{array}$ & Elastic properties & elasticBeamColumn \\
\hline Soil Interaction & ElasticPPGap & zeroLength \\
\hline Deck & Elastic properties & elasticBeamColumn \\
\hline $\begin{array}{l}\text { Bent Caps } \\
\text { (Bents 2/3) }\end{array}$ & $\begin{array}{l}\text { FiberSection, Concrete01, Hysteretic } \\
\text { Steel }\end{array}$ & dispBeamColumn \\
\hline Columns & $\begin{array}{l}\text { FiberSection, Concrete01, Concrete04, } \\
\text { Hysteretic Steel }\end{array}$ & beamWithHinges \\
\hline
\end{tabular}

The abutment-soil interaction was modeled as a combination of linear springs. The OpenSees zeroLength element was used in order to have only axial forces being applied to the abutment from the soil, with no bending. The ElasticPPGap material was used to allow the use of compressive loads only, and also to allow an initial gap to be present between the deck and the abutment. The material values used to define the gap material were derived from accepted design guidelines (Caltrans, 2006) and are provided in Table 4.2.

Table 4.2: ElasticPPGap Material Values for Three-Span Abutment-Soil Model

\begin{tabular}{l|l}
\hline Description & Value \\
\hline Stiffness of transverse spring & $381.8 \mathrm{kips} / \mathrm{in}$ \\
\hline Maximum compressive strength of transverse spring & $-334.1 \mathrm{kips}$ \\
\hline Initial gap of transverse spring & $-0.50 \mathrm{in}$ \\
\hline Total stiffness of longitudinal springs & $381.8 \mathrm{kips} / \mathrm{in}$ \\
\hline Total maximum compressive strength of longitudinal springs & $-334.1 \mathrm{kips}$ \\
\hline Initial gap of longitudinal spring & $-0.75 \mathrm{in}$ \\
\hline
\end{tabular}

The superstructure deck was assumed to be level with no skew relative to the abutment. The column base locations were moved slightly vertically to maintain appropriate column heights and a level deck. The deck was assumed to behave elastically and therefore was modeled using the elasticBeamColumn element. The element was defined using the values found in Table 4.3.

Table 4.3: Element Values for Three-Span Deck

\begin{tabular}{l|l}
\hline Description & Value \\
\hline Cross Sectional Area & $4436.25 \mathrm{in} 2$ \\
\hline Elastic Modulus $(\mathrm{E})$ & $3733.4 \mathrm{ksi}$ \\
\hline Shear Modulus $(\mathrm{G})$ & $1500.0 \mathrm{ksi}$ \\
\hline Torsional Moment of Inertia $(\mathrm{J})$ & $61.509 \times 10^{6} \mathrm{in}^{4}$ \\
\hline $\begin{array}{l}\text { Second Moment of Area about } \\
\text { the local y Axis }\left(\mathrm{I}_{\mathrm{y}}\right)\end{array}$ & $6.3344 \times 10^{7} \mathrm{in}^{4}$ \\
\hline $\begin{array}{l}\text { Second Moment of Area about } \\
\text { the local z Axis }\left(\mathrm{I}_{\mathrm{z}}\right)\end{array}$ & $4.2778 \times 10^{5} \mathrm{in}^{4}$ \\
\hline
\end{tabular}


Concrete and steel OpenSees material types were used to model the reinforced concrete portions of the bridges. The Concrete 01 material accounts for compression of the concrete, but doesn't allow for any tension load and was used for the cover concrete. The Concrete04 material was used for the confined concrete since the material will predict the crushing strength as a function of the crushing strain using the Mander model. The columns were modeled using both Concrete 01 and Concrete 04 materials, while the bent caps only used the Concrete 01 material. In order to prevent bending of the bent caps in the model about the global vertical axis, another element was introduced with large EI values that restricted bending only about the vertical axis. This approximates the behavior of the bent cap being integral to the superstructure.

The hysteretic material was used to model the reinforcement steel of all reinforced concrete members. The general behavior provided by these OpenSees material types is shown in Figure 4.5. When possible, material property values were found from Oregon Department of Transportation (ODOT) drawings of the bridges used in this study, such as maximum compressive strength of the concrete and yielding stress of the reinforcing steel. To model the stress-strain relationship of the column-confined concrete of the columns, an analytical model (Mander et al., 1988) was used. The specific values used to define the materials are given in tables Table 4.4 through Table 4.6.

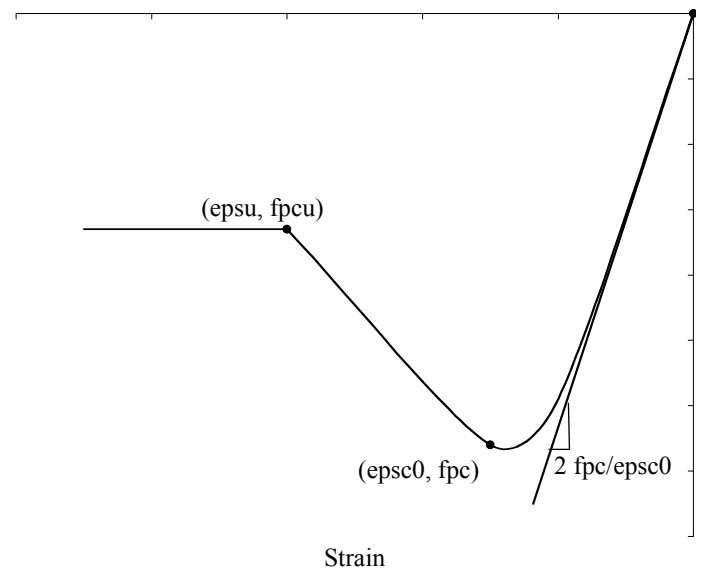

(a) General Concrete01 Material

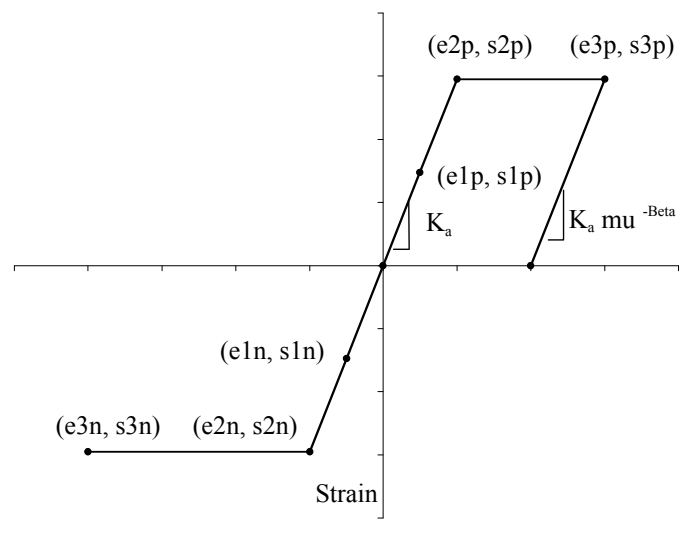

(b) General Hysteretic Material

Figure 4.5: OpenSees Material Types Used In Reinforced Concrete Models (from OpenSees 2009)

Table 4.4: Concrete04 Values for Confined Concrete Used With Three-Span Bridge

\begin{tabular}{l|l|l}
\hline Property & Description & Value \\
\hline $\mathrm{fpc}$ & maximum concrete compressive strength & $-4.464 \mathrm{ksi}$ \\
\hline epsc0 & concrete strain at maximum strength & $-0.002433 \mathrm{in} . / \mathrm{in}$. \\
\hline epsU & concrete strain at crushing strength & $-0.010 \mathrm{in} . / \mathrm{in}$. \\
\hline & Elastic modulus of concrete & $3733.4 \mathrm{ksi}$ \\
\hline & ratio of confined concrete strength to unconfined strength & 1.04 \\
\hline
\end{tabular}


Table 4.5: Concrete01 Values for Cover Concrete Used With Three-Span Bridge

\begin{tabular}{l|l|l}
\hline Property & Description & Value \\
\hline fpc & maximum concrete compressive strength & $-4.29 \mathrm{ksi}$ \\
\hline epsc0 & concrete strain at maximum strength & $-0.002023 \mathrm{in} . / \mathrm{in}$. \\
\hline fpcu & concrete crushing strength & $0.0 \mathrm{ksi}$ \\
\hline epsU & concrete strain at crushing strength (AASHTO, 2009) & $-0.005 \mathrm{in} . / \mathrm{in}$. \\
\hline
\end{tabular}

Table 4.6: Hysteretic Steel Values Used with Five-Span Bridge

\begin{tabular}{l|l|l}
\hline Property & Description & Value \\
\hline $\mathrm{s} 2 \mathrm{p}$ & $\begin{array}{l}\text { stress at second point of the envelope in the positive direction (yield } \\
\text { stress) }\end{array}$ & $40 \mathrm{ksi}$ \\
\hline $\mathrm{e} 2 \mathrm{p}$ & $\begin{array}{l}\text { strain at second point of the envelope in the positive direction (yield } \\
\text { strain) }\end{array}$ & 0.0013793 \\
\hline $\mathrm{s} 3 \mathrm{p}$ & stress at third point of the envelope in the positive direction & $40 \mathrm{ksi}$ \\
\hline $\mathrm{e} 3 \mathrm{p}$ & strain at third point of the envelope in the positive direction & 0.20 \\
\hline
\end{tabular}

There was a small increase ( $4 \%$ ) when comparing the confined strength to the unconfined strength of the concrete. These values are a result of the Mander model, and are fully expected since the level of transverse reinforcement for the columns is relatively poor, with the \#4 transverse bars spaced at 12 inches. This spacing is in contrast to transverse spacing using current design guidelines, which can be in the range of three to four inches.

The hysteretic material used to model the steel in the columns has the ability to use pinching factors and to model damage due to energy and ductility. The default values provided by OpenSees were used in this case. The typical bridge, modeled using OpenSees, is shown in Figure 4.6.

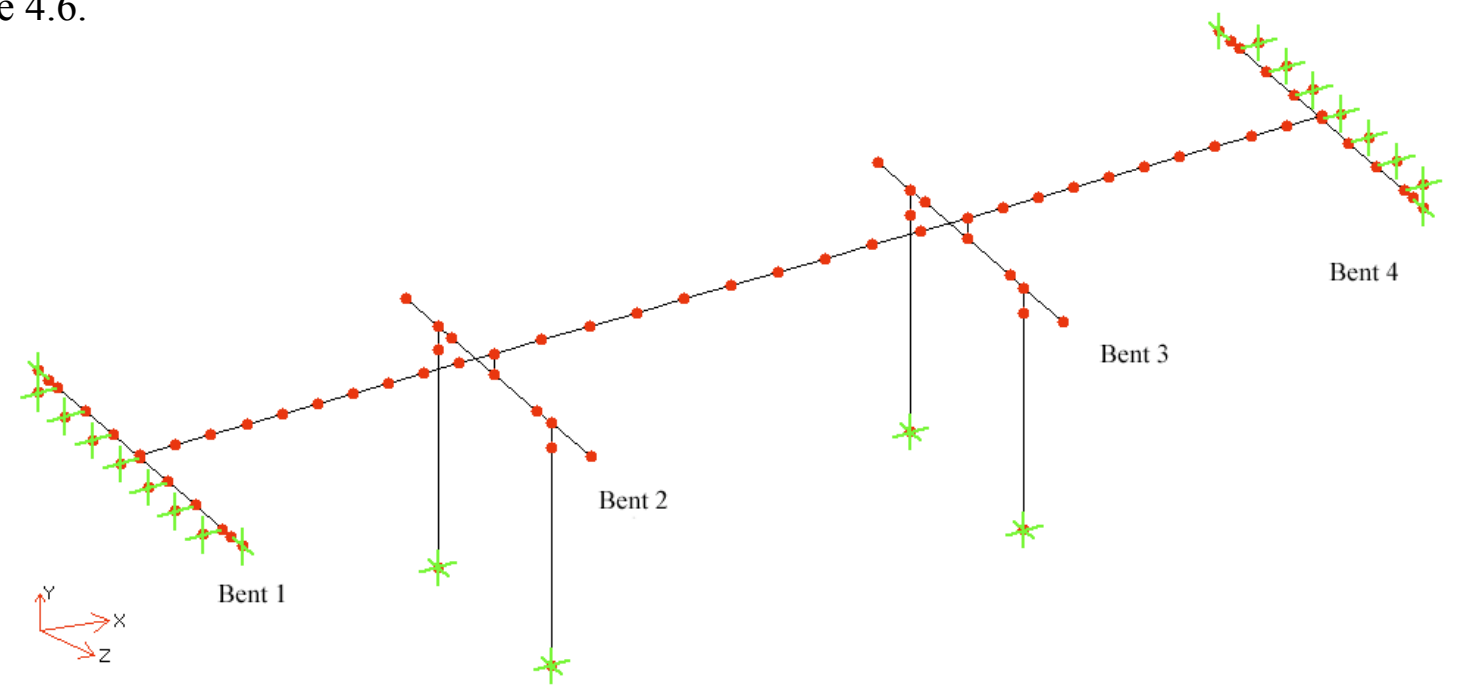

Figure 4.6: OpenSees Model for Three-Span Bridge

The boundary conditions applied to the OpenSees model, as indicated in Figure 4.6, are described in Table 4.7. The nodes representing the soil portion of the soil-abutment connection 
were fixed except to allow movement with the abutment in the direction normal to the connection. For example, the longitudinal soil node was allowed to move in the transverse direction to ensure the soil nodes and bent nodes were always aligned. This resulted in a normal force being applied to the bent, with no load due to soil friction being modeled.

Table 4.7: OpenSees Boundary Conditions for Three-Span Bridge

\begin{tabular}{l|l}
\hline Model Element & Boundary Condition \\
\hline Column Bases & Fixed in all directions \\
\hline Bents 1/4 & Fixed in vertical direction \\
\hline $\begin{array}{l}\text { Longitudinal Soil-Abutment } \\
\text { Connections }\end{array}$ & $\begin{array}{l}\text { Base of element (soil) fixed in all directions except transverse; } \\
\text { tied to move with Bent 1 in transverse direction }\end{array}$ \\
\hline $\begin{array}{l}\text { Transverse Soil-Abutment } \\
\text { Connections }\end{array}$ & $\begin{array}{l}\text { Base of element (soil) fixed in all directions except longitudinal; } \\
\text { tied to move with Bent 1 in longitudinal direction }\end{array}$ \\
\hline $\begin{array}{l}\text { All nodes fixed in the transverse } \\
\text { and longitudinal directions }\end{array}$ & Ground motions were applied to these nodes \\
\hline
\end{tabular}

\subsubsection{MODEL VERIFICATION}

In order to verify the proper usage of these concrete and hysteretic material types, several simple verification tests were used. The first verification test was performed by making an OpenSees model of a fixed-base RC column and subjecting it to a lateral force at the top of the column. The modeled column was identical to a column from the typical three-span bridge column, with the base being fixed and the top being free with no restraints. The column was subjected to a concentric axial load of 150 kips. While the column was being loaded by a lateral force, the overturning moment at the base was being recorded. The moment from the OpenSees model was determined to be $3727.6 \mathrm{kip} / \mathrm{inch}$ when the reinforcing steel being loaded in tension was just starting to yield. The same scenario was then considered, but using standard analytical techniques. The following equations were used:

$$
\begin{gathered}
a=\frac{P}{0.85 f_{c}^{\prime} b} \\
M=0.85 f_{c}^{\prime} a b\left(\bar{y}-\frac{a}{2}\right)+A_{s}^{\prime} f_{y}\left(d-d^{\prime}\right)
\end{gathered}
$$

where $\mathrm{a}$ is the depth of the equivalent rectangular stress block, $\mathrm{P}$ is the axial load, $f_{c}^{\prime}$ is the compressive strength of the concrete, $\mathrm{M}$ is the overturning moment, $\mathrm{b}$ is the width of the column, $\mathrm{d}$ is the depth of the beam measured from the extreme compression fiber to the centroid of the steel area in tension, and $\mathrm{d}^{\prime}$ is the distance from the extreme compression fiber to the centroid of the steel area in compression.

When equations 4-1 and 4-2 are solved, the overturning moment, $\mathrm{M}$, is found to be 3866.7 kip/inch. Comparing the two estimates of the overturning moment shows a $3.6 \%$ difference between the analytical and numerical methods.

The second test involved modeling a simple reinforced concrete column using information from the National Science Foundation Pacific Earthquake Engineering Research Center (PEER, 2009) 
structural performance database. Using the design data of the nosh96n1 square column, an OpenSees model was constructed and subjected to a cyclic load. This particular column was the smallest column available in the database, and closest to the actual column size of the modeled three-span bridge. The experimental column and OpenSees model had the following characteristics:

\begin{tabular}{|l|l|}
\hline 0.625 in long. bars (\#5), qty (4) & 0.25 in. bars transverse reinforcement \\
\hline 1 inch cover, 11 in $\mathrm{x} 11$ in column & 9 inch transverse spacing \\
\hline
\end{tabular}

A comparison of the experimental test results and the numerical OpenSees model is shown in Figure 4.7. Based upon this comparison, an argument could easily be made that the OpenSees model is a reasonable representation of the column and, therefore, similar efforts to model bridge columns should yield reasonable models.

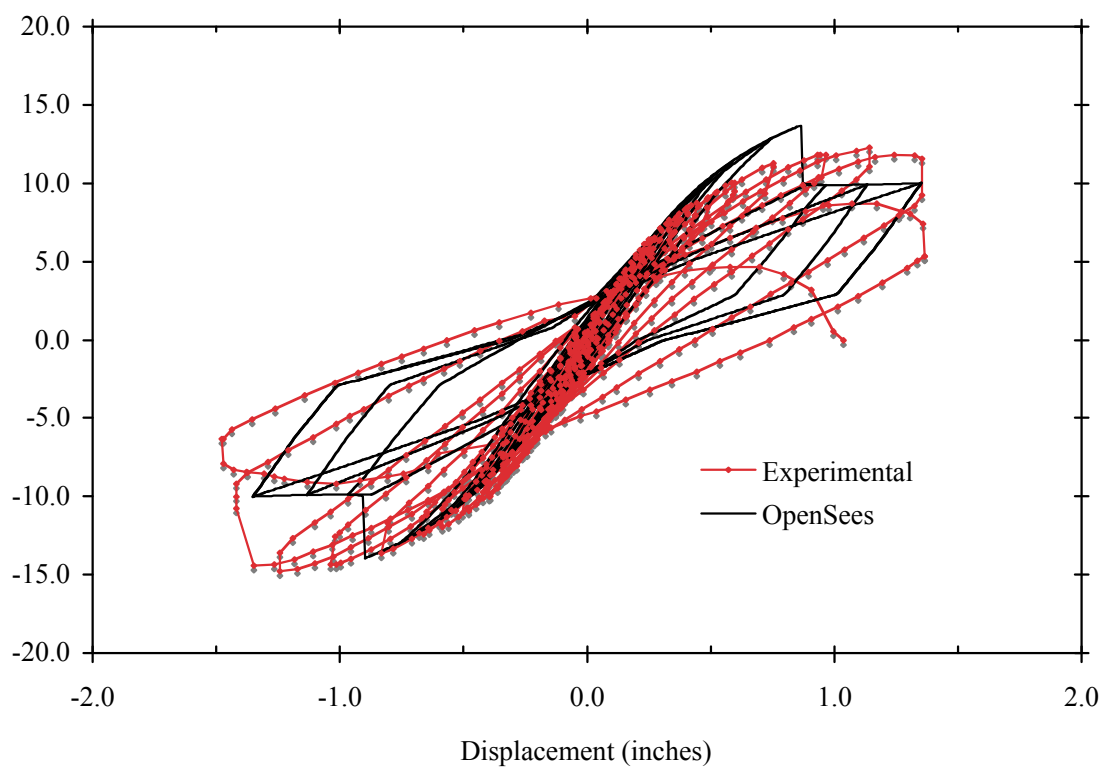

Figure 4.7: Comparison of Experimental and Modeled Hysteretic Behavior of Test Column

The OpenSees model for the test column used an assumed value of 1.05 for the ratio of confined concrete strength to unconfined strength.

Another simple, but effective, method of model verification is to ensure that the period of vibration predicted by the OpenSees model is reasonably close to the period of a simple, single degree of freedom system having the same mass and stiffness. The values used in this calculation were: $E=$ $3733 \mathrm{ksi}, I_{\mathrm{col}}=27,648 \mathrm{in}^{4}$ and weight of superstructure $=708.7 \mathrm{kips}($ mass $=708.7 / 386.4=1.834 \mathrm{kips}-$ $\sec ^{2} /$ in.). The stiffness of a fixed-fixed column was idealized to be $k_{c o l}=\frac{12 E I}{L^{3}}$. The stiffness associated with two columns for each bent was calculated and are shown in

Table 4.8

Table 4.8: Estimated Stiffness Values for Three-Span Bridge 


\begin{tabular}{r|c}
\hline Location & $\begin{array}{c}\text { Bent Stiffness } \\
\text { (kips/in) }\end{array}$ \\
\hline Bent 2 & 143.6 \\
\hline Bent 3 & 174.3 \\
\hline Total & 317.9 \\
\hline
\end{tabular}

The period of vibration can be calculated for the three-span bridge, in both the transverse and longitudinal directions, and with the soil-abutment interaction included and not included. As an example, for the case where the soil-abutment stiffness is not included, and for the longitudinal direction, the period of a simple SDOF system can be calculated to be:

$$
T=2 \pi \sqrt{\frac{m}{k}}=2 \pi \sqrt{\frac{1.834 \frac{\mathrm{kips} \cdot \mathrm{sec}^{2}}{\mathrm{in}}}{317.9 \frac{\mathrm{kips}}{\mathrm{in}}}}=0.477 \text { seconds }
$$

Similar calculations yield the data shown below in Table 4.9 for both directions of displacement.

Table 4.9: Calculated Periods of Vibration for Various Three-Span Bridge Models

\begin{tabular}{c|c|c}
\hline $\begin{array}{c}\text { Periods } \\
\text { (seconds) }\end{array}$ & $\begin{array}{c}\text { Soil-Abutment } \\
\text { Stiffness Included }\end{array}$ & $\begin{array}{c}\text { Soil-Abutment Stiffness } \\
\text { Not Included }\end{array}$ \\
\hline Longitudinal & 0.322 & 0.477 \\
\hline Transverse & 0.322 & 0.477 \\
\hline
\end{tabular}

The periods are identical for the three-span bridge for both directions since the abutment stiffness is the same in both directions, and the stiffness for the columns are also the same in both directions. Using the OpenSees model with the soil-abutment stiffness included, the period of vibration with a longitudinal motion was found to be 0.262 seconds. With the soil-abutment stiffness removed, the period of vibration with a longitudinal motion was found to be 0.484 seconds. The calculated approximations agree relatively well with the OpenSees numerical model.

\subsubsection{MODEL RESPONSE}

Using the provided dimensions from ODOT drawings and OpenSees material and element types, a numerical model was constructed with the geometry shown in Figure 4.6. Ground motions were applied to the soil nodes of the soil-abutment connections and to the bases of the columns. An eigenvalue analysis of this model, using OpenSees, has a fundamental period of 0.76 seconds with the associated motion being a twisting motion around the center of the structure. Mode shapes for the three-span bridge, and with no soil-abutment stiffness included, are shown in Figure 4.8. The second mode has a period of 0.66 seconds and the third mode has a period of 0.48 seconds and has a longitudinal motion, with good agreement with the simple SDOF system described in the previous section. 


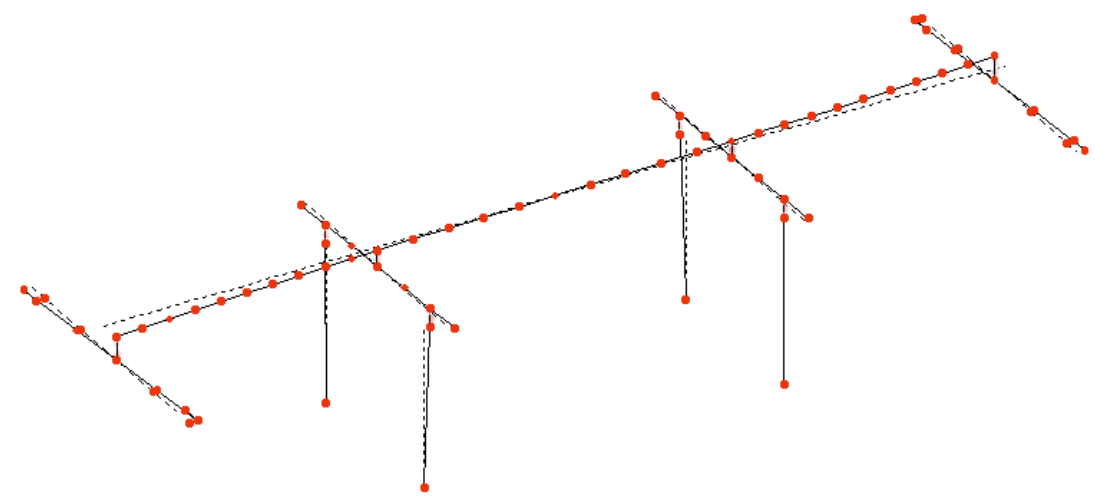

(a) Mode 1 with period of 0.76 seconds (rotating motion near the bridge center)

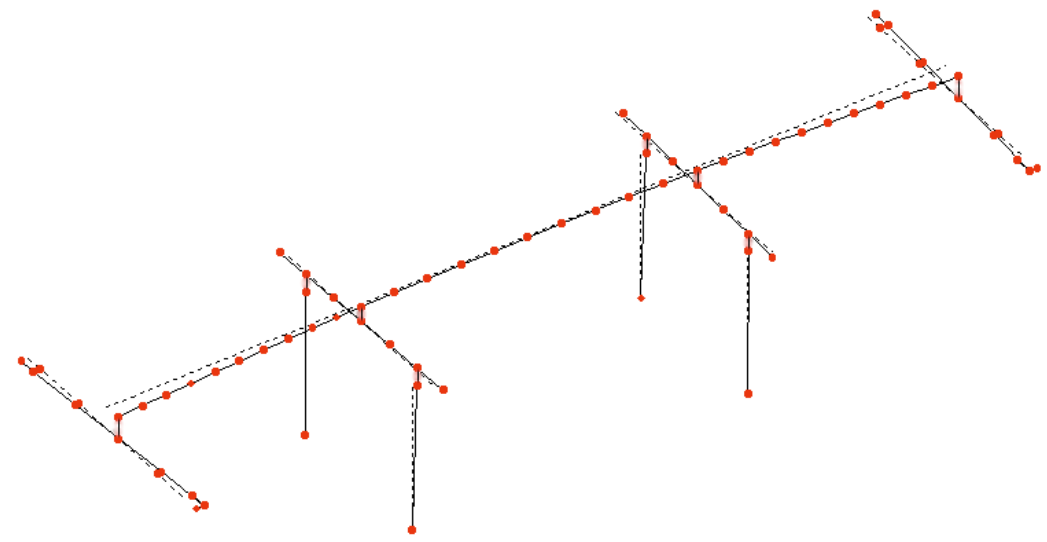

(b) Mode 2 with period of 0.66 seconds (bowing motion about bridge center)

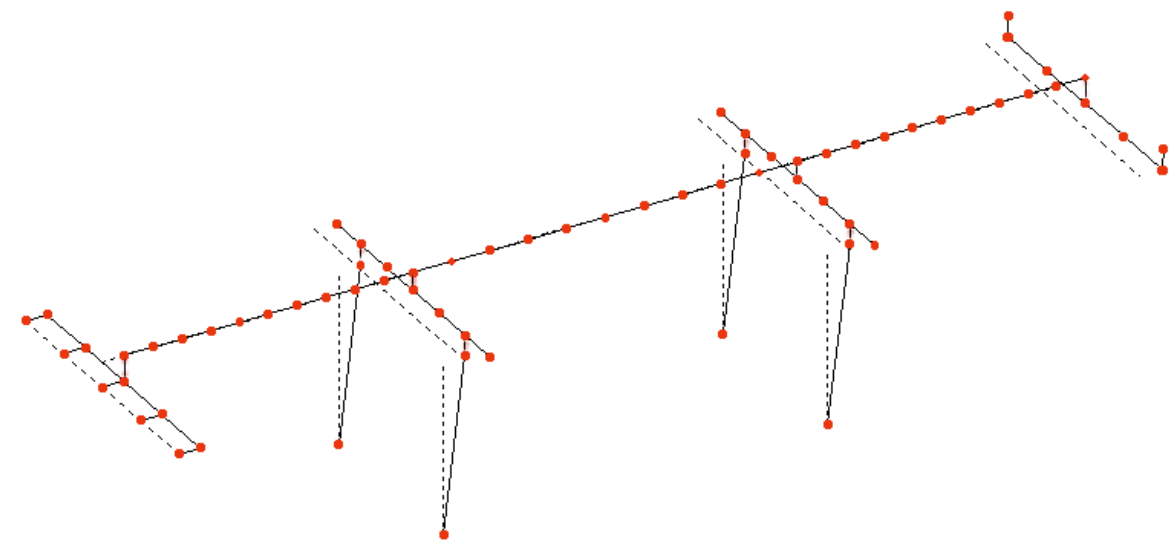

(c) Mode 3 with period of 0.48 seconds ( longitudinal motion)

Figure 4.8: Mode Shapes of Typical Three-Span Bridge with no Soil-Abutment Stiffness Included

Using the ground-motion records listed in tables 2.2 and 2.3 , and the previously defined OpenSees model, multiple time history analyses were run until completion. The ground-motion records (SAC, 2010) are provided as orthogonal pairs. The ground motions were oriented along the longitudinal (x) direction and transverse (z) direction of the bridge model. Each pair was used with two runs, one in the horizontal $x-z$ orientation, and then the records were reversed and rerun in the z-x direction. This resulted in a total of 40 runs with the three-span model. 
Maximum column displacements resulting from these 40 runs are provided in Table 4.10 and Table 4.11.

Table 4.10: Maximum Displacements Using POE-of-10\%-in-50-Years Group

\begin{tabular}{|c|c|c|c|c|c|c|}
\hline \multirow[t]{2}{*}{ Ground-Motion Record } & \multirow{2}{*}{$\begin{array}{c}\text { PGA } \\
\text { dir1 } \\
(\mathrm{g})\end{array}$} & \multirow{2}{*}{$\begin{array}{c}\text { PGA } \\
\text { dir2 } \\
\text { (g) }\end{array}$} & \multicolumn{2}{|c|}{ Orientation 1} & \multicolumn{2}{|c|}{ Orientation 2} \\
\hline & & & $\begin{array}{l}\text { Long. } \\
\text { Disp. } \\
\text { (in) }\end{array}$ & $\begin{array}{l}\text { Trans. } \\
\text { Disp. } \\
\text { (in) }\end{array}$ & $\begin{array}{l}\text { Long. } \\
\text { Disp. } \\
\text { (in) }\end{array}$ & $\begin{array}{l}\text { Trans. } \\
\text { Disp. } \\
\text { (in) }\end{array}$ \\
\hline Long Beach, Vernon CMD Bldg. & 0.174 & 0.135 & 1.7 & 1.1 & 1.7 & 1.4 \\
\hline Morgan Hill, 1984, Gilroy & 0.386 & 0.662 & 3.3 & 2.7 & 2.7 & 3.1 \\
\hline West. Washington, Olympia, 1949 & 0.383 & 0.352 & 2.7 & 2.0 & 2.5 & 2.9 \\
\hline West. Washington, Seattle Army B., 1949 & 0.295 & 0.388 & 5.4 & 5.9 & 4.5 & 5.4 \\
\hline North Palm Springs, 1986 & 0.587 & 0.599 & 3.3 & 3.6 & 2.6 & 2.2 \\
\hline Puget Sound, Wa., Olympia, 1949 & 0.752 & 0.596 & 4.7 & 3.3 & 4.1 & 5.9 \\
\hline Puget Sound, Wa., Federal OFC B., 1949 & 0.369 & 0.303 & 3.4 & 3.2 & 3.0 & 4.2 \\
\hline Eastern Wa., Tacoma County, 1949 & 0.290 & 0.574 & 3.8 & 5.9 & 5.1 & 2.3 \\
\hline Llolleo, Chile 1985 & 0.697 & 0.670 & 4.0 & 4.0 & 4.2 & 5.0 \\
\hline Vinadel Mar, Chile, 1985 & 0.541 & 0.384 & 6.3 & 5.1 & 7.4 & 8.9 \\
\hline
\end{tabular}

Table 4.11: Maximum Displacements Using POE-of-2\%-in-50-Years Group

\begin{tabular}{l|c|c|c|c|c|c}
\hline Ground-Motion Record & \multirow{2}{*}{$\begin{array}{c}\text { PGA } \\
\text { dir1 }\end{array}$} & \multirow{2}{*}{$\begin{array}{c}\text { PGA } \\
\text { dir2 }\end{array}$} & \multicolumn{2}{c|}{ Orientation 1 } & \multicolumn{2}{c}{ Orientation 2 } \\
\cline { 5 - 8 } & & (g) & $\begin{array}{c}\text { Long. } \\
\text { Disp. } \\
\text { (in) }\end{array}$ & $\begin{array}{c}\text { Trans. } \\
\text { Disp. } \\
\text { (in) }\end{array}$ & $\begin{array}{c}\text { Long. } \\
\text { Disp. } \\
\text { (in) }\end{array}$ & $\begin{array}{c}\text { Trans. } \\
\text { Disp. } \\
\text { (in) }\end{array}$ \\
\hline 1992 Mendocino & 0.755 & 0.485 & 10.0 & 5.2 & 9.7 & 13.0 \\
\hline 1992 Erzincan & 0.605 & 0.539 & 7.8 & 6.0 & 5.8 & 7.2 \\
\hline 1949 Olympia & 0.895 & 0.821 & 6.8 & 4.9 & 6.0 & 8.1 \\
\hline 1965 Seattle & 1.755 & 1.390 & 15.3 & 8.4 & 9.5 & 13.5 \\
\hline 1985 Valpariso & 1.636 & 1.573 & 10.8 & 8.8 & 10.3 & 13.2 \\
\hline 1985 Valpariso & 1.270 & 0.901 & 21.2 & 14.7 & 13.2 & 22.6 \\
\hline Deep Interplate (simulation) & 0.796 & 0.646 & 9.0 & 6.5 & 8.3 & 8.2 \\
\hline 1978 Miyagi-oki & 0.606 & 0.783 & 13.6 & 23.7 & 23.9 & 15.5 \\
\hline Shallow Interplate (simulation) & 0.563 & 0.534 & 6.0 & 6.6 & 6.4 & 5.6 \\
\hline Shallow Interplate (simulation) & 0.578 & 0.749 & 6.2 & 8.0 & 7.4 & 5.7 \\
\hline
\end{tabular}

The maximum displacement found in Table 4.6 is 8.9 inches for the structure being loaded by the group of ground motions having a POE of $10 \%$ in 50 years. This compares favorably to the 10.2 inches predicted by the response spectrum envelope from Figure 2.5 for a structure having a fundamental period of 0.76 seconds.

The maximum displacement found in Table 4.7 is 23.9 inches for the structure being loaded by the group of ground motions having a POE of $2 \%$ in 50 years. This compares favorably to the 24.0 inches predicted by the response spectrum envelope from Figure 2.4 for a structure having a fundamental period of 0.76 seconds.

These displacement values are used in subsequent sections to calculate displacement ductilities, and then ultimately build fragility curves. 


\subsection{TYPICAL FIVE-SPAN BRIDGE}

\subsubsection{BRIDGE LAYOUT}

Oregon Bridge 07628 was used as the template for the typical five-span bridge to be used in this study, and an elevation view is shown in Figure 3.2. This bridge has five spans that are 16, 60, 70,60 and 16 feet long, for a total structure length of 220 feet, with the width of each span being 30 feet. This bridge has a continuous concrete deck with the bents being integral. The heights of the eight columns range from 22.6 feet to 36.4 feet, with the shortest at bent 5 and the longest at bent 3 .

The dual-column bents for this bridge are made up of a 15-inch-wide-by-62-inch-deep reinforced concrete bent beam supported by two 24-inch-by-24-inch rectangular reinforced concrete columns. The as-designed bent beam uses three layers of three $1 \frac{1}{2} \mathrm{inch}^{2}$ bars at the bottom of the beam. The model is simplified by using one layer of larger $\left(4 \frac{1}{2} \mathrm{inch}^{2}\right)$ bars at the center of gravity of the second layer. The reinforcement as modeled is shown in Figure 4.9.

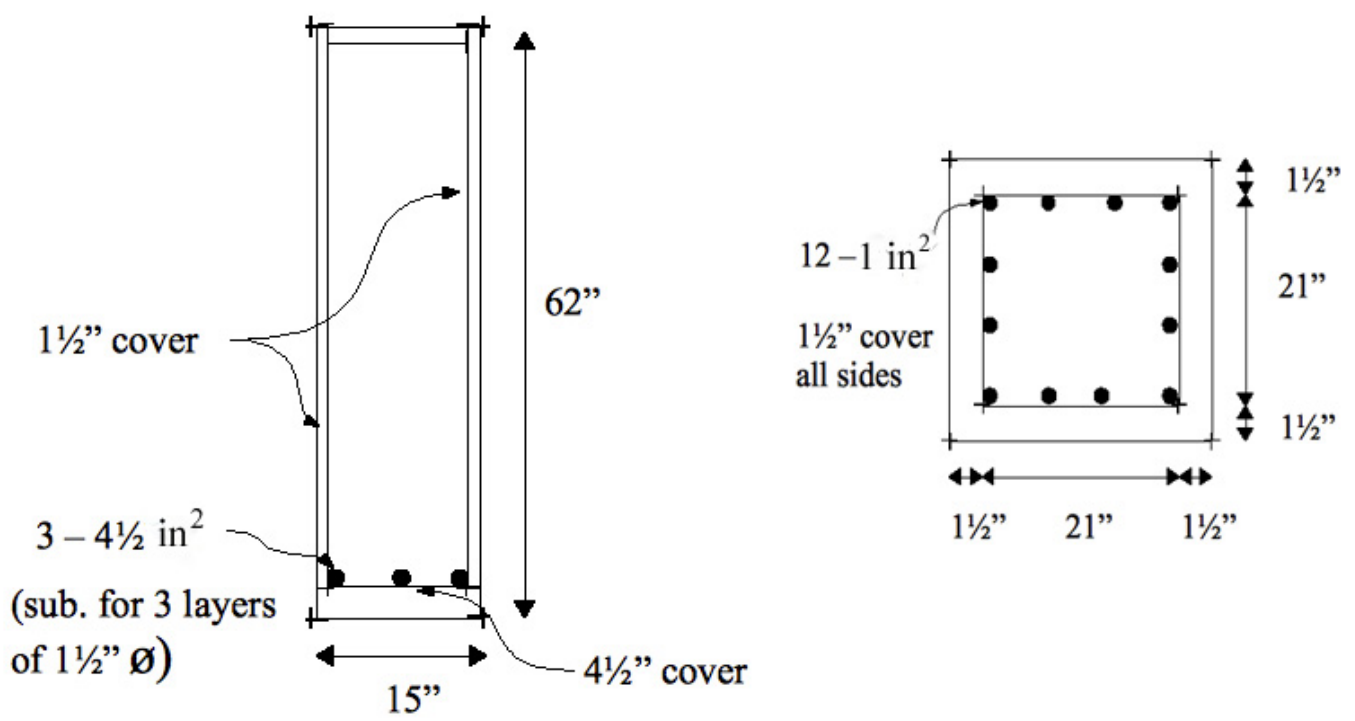

Figure 4.9: Concrete Member Reinforcement for Typical Five-Span Bridge

\subsubsection{OPENSEES MODEL}

The typical five-span bridge was modeled using the OpenSees application.

In order to take into account nonlinearities, several different element types were used when modeling some of the bridge components. An overview of the element and material types are shown in

Table 4.12. 
Table 4.12: Element Types Used With Five-Span Model

\begin{tabular}{l|l|l}
\hline Component & Material & Element \\
\hline $\begin{array}{l}\text { Abutments } \\
\text { (Bents 1/6) }\end{array}$ & Elastic properties & elasticBeamColumn \\
\hline Soil Interaction & ElasticPPGap & zeroLength \\
\hline Deck & Elastic properties & elasticBeamColumn \\
\hline $\begin{array}{l}\text { Bent Caps } \\
\text { Bents 2/3/4/5) }\end{array}$ & FiberSection, Concrete01, Hysteretic Steel & dispBeamColumn \\
\hline Columns & $\begin{array}{l}\text { FiberSection, Concrete01, Concrete04, } \\
\text { Hysteretic Steel }\end{array}$ & beamWithHinges \\
\hline
\end{tabular}

The soil-abutment interaction was modeled as a combination of linear springs. The ElasticPPGap material was used to allow the use of compressive loads only. In this model there was no gap between the abutments and deck. The material values used to define the gap material were derived from accepted design guidelines (Caltrans, 2006) and are provided in Table 4.13.

Table 4.13: ElasticPPGap Material Values for Five-Span Abutments

\begin{tabular}{l|l}
\hline Description & Value \\
\hline Stiffness of transverse spring & $40 \mathrm{kips} / \mathrm{in}$ \\
\hline Maximum compressive strength of transverse spring & $-10 \mathrm{kips}$ \\
\hline Initial gap of transverse spring & 0 in \\
\hline Total stiffness of longitudinal springs & $327.3 \mathrm{kips} / \mathrm{in}$ \\
\hline Total maximum compressive strength of longitudinal springs & $-245.5 \mathrm{kips}$ \\
\hline Initial gap of longitudinal spring & 0 in \\
\hline
\end{tabular}

The guidelines also suggest using a nominal transverse spring stiffness equal to $50 \%$ of the transverse stiffness of the adjacent bent. In the five-span bridge case, approximations of the adjacent stiffness are $31 \mathrm{kips} / \mathrm{inch}$ (Bent 2 ) and $62 \mathrm{kips} / \mathrm{inch}$ (Bent 5). The value used (40 kips/inch) can be considered near to an average of the two bent stiffnesses.

As a comparison, another model for a four-span bridge (Hwang et al., 2001) with a total length of 234 feet and width of almost 60 feet was designed to have more piers supporting the abutment and a higher back wall ( 6 feet) when compared to the Oregon typical five-span bridge. This resulted in a transverse stiffness that is over nine times the stiffness of the modeled Oregon fivespan bridge, and a longitudinal stiffness that is four times the stiffness of the Oregon bridge.

The superstructure deck was assumed to be level with no skew relative to the abutment. The column base locations were moved slightly vertically to maintain appropriate column heights and a level deck. The deck was assumed to behave elastically and therefore was modeled using the elasticBeamColumn element. The element was defined using the values found in Table 4.14.

Table 4.14: elasticBeamcolumn Element Values for Five-Span Deck

\begin{tabular}{l|l}
\hline Description & Value \\
\hline Cross Sectional Area & $4746 \mathrm{in}^{2}$ \\
\hline Elastic Modulus (E) & $3274 \mathrm{ksi}$ \\
\hline
\end{tabular}




\begin{tabular}{l|l}
\hline Description & Value \\
\hline Shear Modulus $(\mathrm{G})$ & $1500 \mathrm{ksi}$ \\
\hline Torsional Moment of Inertia $(\mathrm{J})$ & $38.38 \times 10^{6} \mathrm{in}^{4}$ \\
\hline Second Moment of Area about the local y Axis $\left(\mathrm{I}_{\mathrm{y}}\right)$ & $2.537 \times 10^{6} \mathrm{in}^{4}$ \\
\hline Second Moment of Area about the local z Axis $\left(\mathrm{I}_{\mathrm{z}}\right)$ & $6.230 \times 10^{7} \mathrm{in}^{4}$ \\
\hline
\end{tabular}

Concrete and steel OpenSees material types were used to model the reinforced concrete portions of the bridges. The Concrete01 material accounts for compression of the concrete, but doesn't allow for any tension load and was used for the cover concrete. The values used to define the concrete and reinforcing steel are shown below in tables Table 4.15 and Table 4.16, and were used only for the five-span bridge model. The 28-day compressive strength specified by ODOT drawings was given as $-3.3 \mathrm{ksi}$. To account for the time-related strength development property of concrete, the modeled compressive strength (AASHTO, 2009) was increased by $30 \%$ to $4.259 \mathrm{ksi}$. This is the compressive strength used for the cover concrete. To model the stressstrain relationship of the confined column concrete, an analytical model (Mander et al., 1988) was used to determine the confined concrete maximum strength and the cover strain at maximum strength. Typical values for the ultimate compressive strain (AASHTO, 2009) range from 0.008 to 0.025 , but the lowest value was chosen because of the relatively poor amount of transverse confinement reinforcement present in the modeled five-span bridge. Also because of the amount of transverse confinement, the Mander model predicts a modest strength increase of the confined concrete $(1.7 \%)$ when compared to the cover concrete.

Table 4.15: Concrete01 Values for Confined Concrete Used With Five-Span Bridge

\begin{tabular}{l|l}
\hline Description & Value \\
\hline maximum concrete compressive strength & $-4.333 \mathrm{ksi}$ \\
\hline concrete strain at maximum strength & $-0.0021999 \mathrm{in} / \mathrm{in}$ \\
\hline concrete crushing strength & $0 \mathrm{ksi}$ \\
\hline concrete strain at crushing strength (AASHTO, 2009) & -0.008 in/in \\
\hline
\end{tabular}

Table 4.16: Concrete01 Values for Cover Concrete Used With Five-Span Bridge

\begin{tabular}{l|l}
\hline Description & Value \\
\hline maximum concrete compressive strength & $-4.259 \mathrm{ksi}$ \\
\hline concrete strain at maximum strength & $-0.002023 \mathrm{in} / \mathrm{in}$ \\
\hline concrete crushing strength & $0 \mathrm{ksi}$ \\
\hline concrete strain at crushing strength (AASHTO, 2009) & $-0.005 \mathrm{in} / \mathrm{in}$ \\
\hline
\end{tabular}

The hysteretic steel material was used to model the reinforcement steel of all reinforced concrete members. The general behavior provided by these OpenSees material types are shown in figures 4.1 and 4.2. When possible, material property values were found from ODOT drawings of the bridges used in this study, such as maximum compressive strength of the concrete and yielding stress of the reinforcing steel. To model the stress-strain relationship of the column confined concrete of the columns, an analytical model (Mander et al., 1988) was used. The specific values used to define the hysteretic material are given in

Table 4.17. The typical bridge, modeled using OpenSees, is shown in Figure 4.10. 
Table 4.17: Hysteretic Steel Values Used With Five-Span Bridge

\begin{tabular}{l|l}
\hline Description & Value \\
\hline yield stress & $40 \mathrm{ksi}$ \\
\hline yield strain & 0.0013793 \\
\hline ultimate strain & 0.20 \\
\hline
\end{tabular}

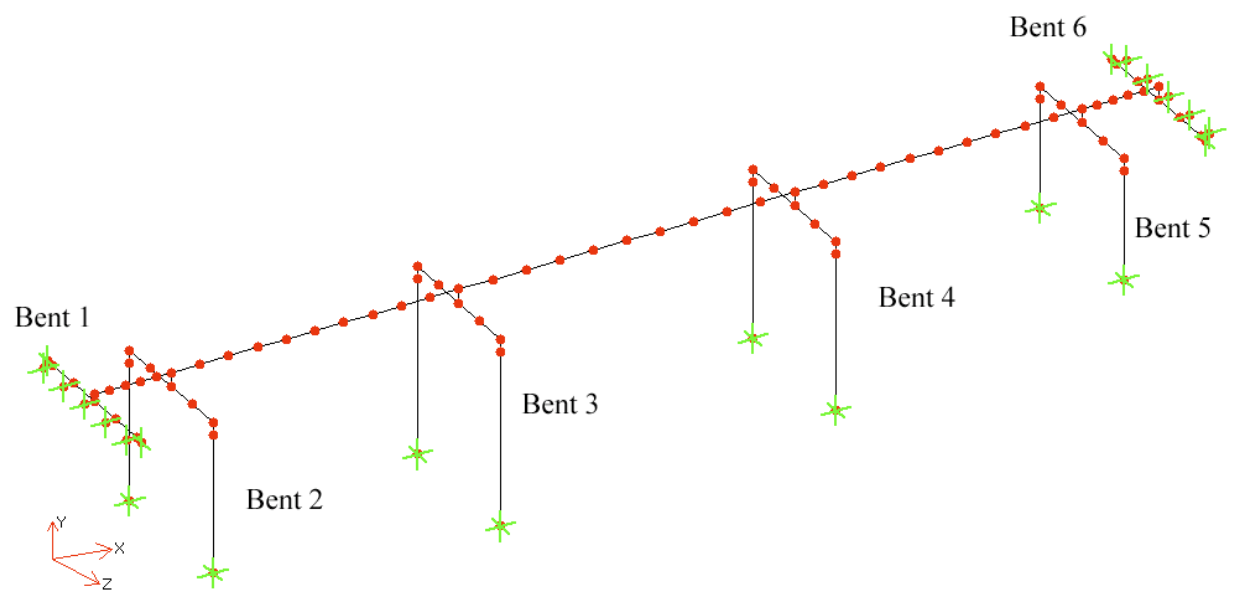

Figure 4.10: OpenSees Model for Typical Five-Span Bridge

\subsubsection{MODEL VERIFICATION}

The same verifications that were performed on the three-span model (Section 4.1.2.1) were also performed on the five-span model. A typical five-span modeled column was subjected to a concentric axial load of 170 kips. While the column was being loaded by a lateral force, the overturning moment at the base was being recorded. The moment from the OpenSees model was determined to be 2,933 in $\cdot k i p s$ when the reinforcing steel being loaded in tension was just starting to yield. The same scenario was then considered, but using standard analytical techniques. When equations 4-1 and 4-2 were solved, the overturning moment was found to be 3,048 in.kips. Comparing the two estimates of the overturning moment shows a $3.8 \%$ difference between the analytical and numerical methods.

Another simple, but effective, method of model verification is to ensure that the period of vibration predicted by the OpenSees model is reasonably close to the period of a simple, single degree of freedom system having the same mass and stiffness. The values used in this calculation were: $E=4300 \mathrm{ksi}, I_{\mathrm{col}}=$ $27,648 \mathrm{in}^{4}$, Weight of superstructure $=1187.3 \mathrm{kips}\left(\right.$ mass $=1187.3 / 386.4=3.0728 \mathrm{kips}^{-\mathrm{sec}^{2}} / \mathrm{in}$. $)$. The stiffness of a fixed-fixed column was idealized to be $k_{c o l}=\frac{12 E I}{L^{3}}$. The stiffness associated with two columns for each bent was calculated and are shown in

Table 4.18. 
Table 4.18: Estimated Stiffness Values for Five-Span Bridge

\begin{tabular}{c|c}
\hline Location & $\begin{array}{c}\text { Bent Stiffness } \\
\text { (kips/in) }\end{array}$ \\
\hline Bent 2 & 68.5 \\
\hline Bent 3 & 34.0 \\
\hline Bent 4 & 47.9 \\
\hline Bent 5 & 141.8 \\
\hline Total & \multicolumn{2}{|c}{292.2} \\
\hline
\end{tabular}

The period of vibration can be calculated for the five-span bridge, in both the transverse and longitudinal directions, and with the soil-abutment interaction both being included and not included. As an example, for the case where the soil-abutment stiffness is not included, and for the longitudinal direction, the period of a simple SDOF system can be calculated to be:

$$
T=2 \pi \sqrt{\frac{m}{k}}=2 \pi \sqrt{\frac{3.0728 \frac{\mathrm{kips} \cdot \mathrm{sec}^{2}}{\mathrm{in}}}{292.2 \frac{\mathrm{kips}}{\mathrm{in}}}}=0.644 \text { seconds }
$$

Similar calculations yield the data shown below in Table 4.19 for both directions of displacement.

Table 4.19: Calculated Periods of Vibration for Various Five-Span Bridge Models

\begin{tabular}{c|c|c}
\hline $\begin{array}{c}\text { Periods } \\
\text { (seconds) }\end{array}$ & $\begin{array}{c}\text { Soil-Abutment } \\
\text { Stiffness Included }\end{array}$ & $\begin{array}{c}\text { Soil-Abutment Stiffness } \\
\text { Not Included }\end{array}$ \\
\hline Longitudinal & 0.442 & 0.644 \\
\hline Transverse & 0.604 & 0.444 \\
\hline
\end{tabular}

Using the OpenSees model with the soil-abutment stiffness included, the period of vibration with a longitudinal motion was found to be 0.363 seconds. With the soil-abutment stiffness removed, the period of vibration with a longitudinal motion was found to be 0.660 seconds. The calculated approximations agree relatively well with the OpenSees numerical model.

\subsubsection{MODEL RESPONSE}

Using the provided dimensions from ODOT drawings and OpenSees material and element types, a numerical model was constructed with the geometry shown in Figure 4.10. Ground motions were applied to the soil nodes of the soil-abutment connections and to the bases of the columns. An eigenvalue analysis of this model, using OpenSees, shows a fundamental period of 0.72 seconds with the associated motion being a twisting motion near bent 5 . Mode shapes for the five-span bridge, and with no soil-abutment stiffness included, are shown in Figure 4.11. The second mode has a period of 0.66 seconds with a longitudinal motion, with good agreement with the simple SDOF system described in the previous section. The third mode has a period of 0.48 seconds. 


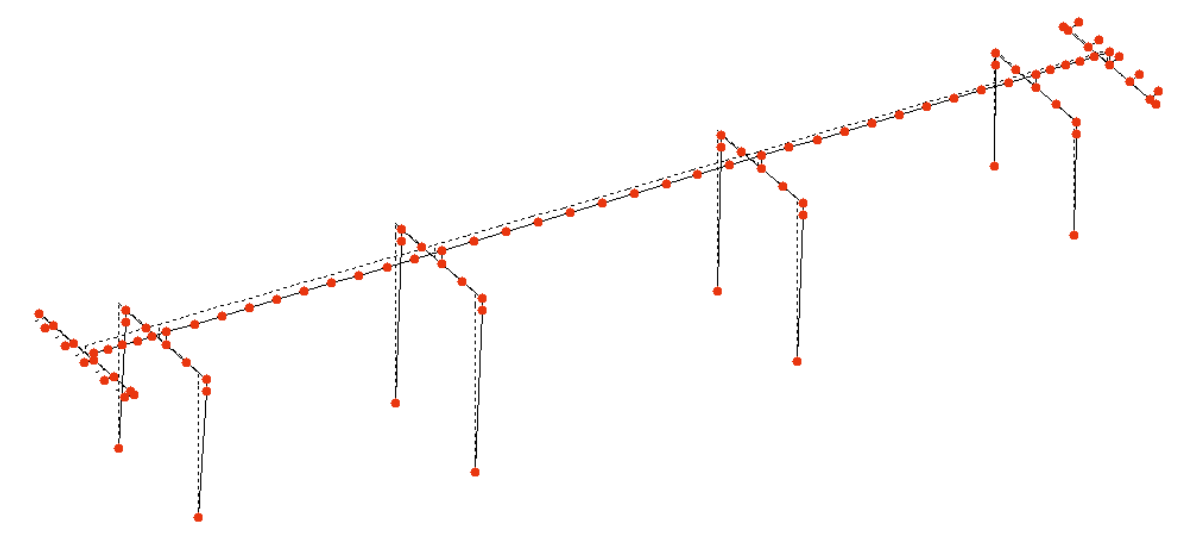

(a) Mode 1 With Period of 0.72 seconds With Twisting Motion Near Bent 5

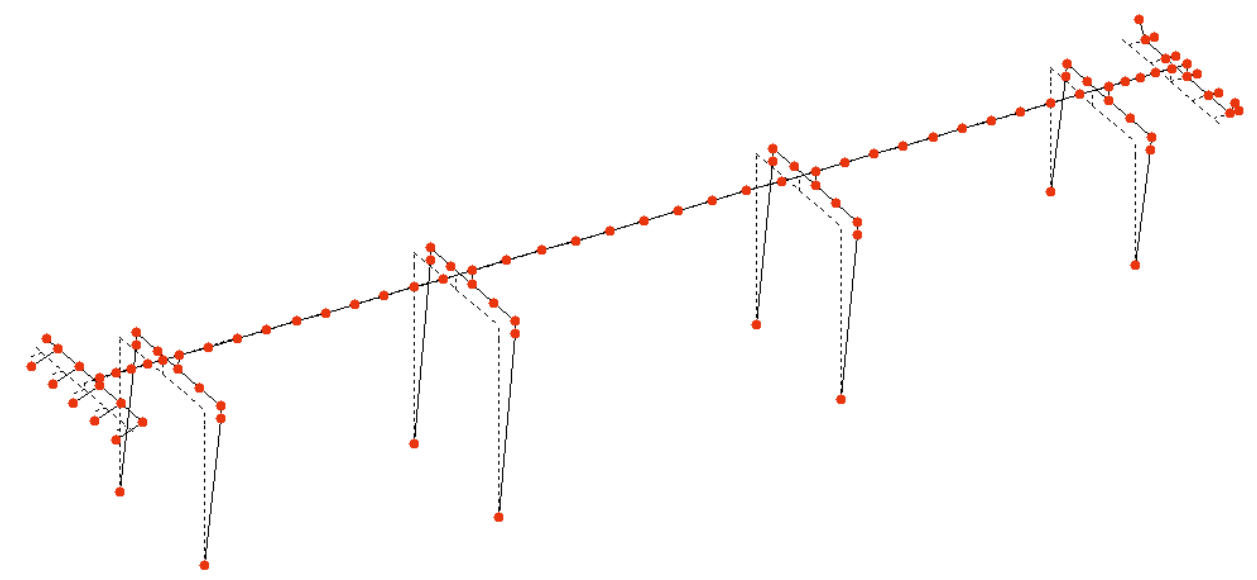

(b) Mode 2 With Period of 0.66 seconds With Longitudinal Motion

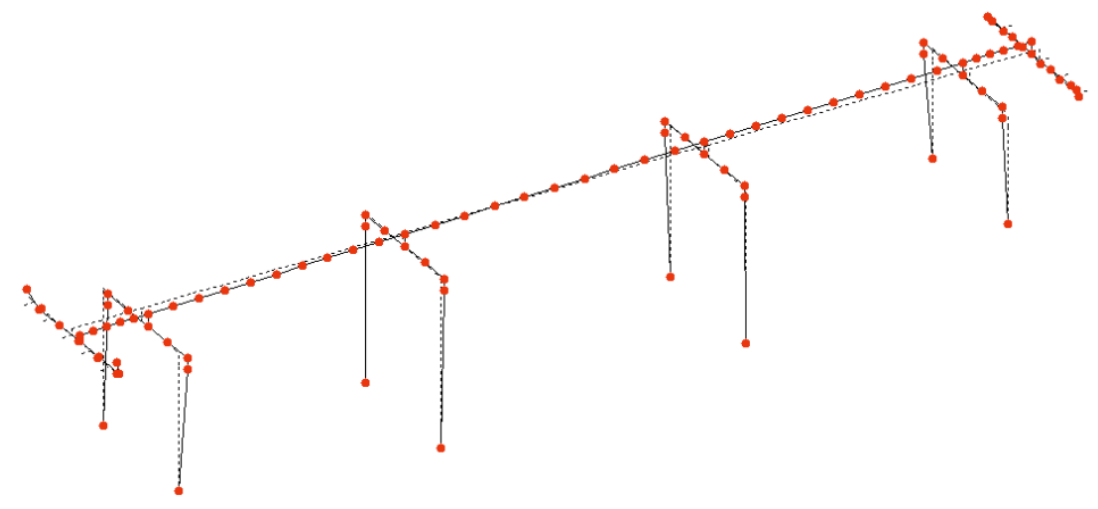

(c) Mode 3 With Period of 0.53 seconds With Rotating Motion Near Center

Figure 4.11: Mode Shapes of Typical Five-Span Bridge with no Soil-Abutment Stiffness Included

Using the ground-motion records listed in tables 2.2 and 2.3, and the previously defined OpenSees model, multiple time-history analyses were run until completion. The ground-motion records (SAC, 2010) are provided as orthogonal pairs. The ground motions were oriented along the longitudinal (x) direction and transverse (z) direction of the bridge model. Each pair was used with one run, one in the horizontal x-z orientation. This resulted in a total of 20 runs with 
the five-span model. Maximum column displacements resulting from these 20 runs are provided in tables 4.18 and 4.19 .

The maximum displacement found in Table 4.20 is 10.9 inches for the structure being loaded by the group of ground motions having a POE of $10 \%$ in 50 years. This compares favorably to the 8.0 inches predicted by the response spectrum envelope from Figure 2.5 for a structure having a fundamental period of 0.72 seconds.

Table 4.20: Maximum Displacements Using POE-of-10\%-in-50-Years Group

\begin{tabular}{|c|c|c|c|c|}
\hline \multirow[t]{2}{*}{ Ground-Motion Record } & \multirow{2}{*}{$\begin{array}{c}\text { PGA } \\
\text { dir1 } \\
(\mathbf{g})\end{array}$} & \multirow{2}{*}{$\begin{array}{c}\text { PGA } \\
\text { dir2 } \\
(\mathrm{g})\end{array}$} & \multicolumn{2}{|c|}{ Orientation 1} \\
\hline & & & $\begin{array}{l}\text { Long. } \\
\text { Disp. } \\
\text { (in) }\end{array}$ & $\begin{array}{c}\text { Trans. } \\
\text { Disp. } \\
\text { (in) }\end{array}$ \\
\hline Long Beach, Vernon CMD Bldg. & 0.174 & 0.135 & 1.0 & 3.1 \\
\hline Morgan Hill, 1984, Gilroy & 0.386 & 0.662 & 2.7 & 5.1 \\
\hline West. Washington, Olympia, 1949 & 0.383 & 0.352 & 2.4 & 5.3 \\
\hline West. Washington, Seattle Army B., 1949 & 0.295 & 0.388 & 4.5 & 7.1 \\
\hline North Palm Springs, 1986 & 0.587 & 0.599 & 1.5 & 10.9 \\
\hline Puget Sound, Wa., Olympia, 1949 & 0.752 & 0.596 & 5.6 & 5.6 \\
\hline Puget Sound, Wa., Federal OFC B., 1949 & 0.369 & 0.303 & 3.6 & 3.7 \\
\hline Eastern Wa., Tacoma County, 1949 & 0.290 & 0.574 & 0.9 & 6.2 \\
\hline Llolleo, Chile 1985 & 0.697 & 0.670 & 3.4 & 10.1 \\
\hline Vinadel Mar, Chile, 1985 & 0.541 & 0.384 & 9.5 & 3.9 \\
\hline
\end{tabular}

Table 4.21: Maximum Displacements Using POE-of-2\%-in-50-Years Group

\begin{tabular}{|c|c|c|c|c|}
\hline \multirow[t]{2}{*}{ Ground-Motion Record } & \multirow{2}{*}{$\begin{array}{c}\text { PGA } \\
\text { dir1 } \\
\text { (g) }\end{array}$} & \multirow{2}{*}{$\begin{array}{c}\text { PGA } \\
\text { dir2 } \\
\text { (g) }\end{array}$} & \multicolumn{2}{|c|}{ Orientation 1} \\
\hline & & & $\begin{array}{l}\text { Long. } \\
\text { Disp. } \\
\text { (in) }\end{array}$ & $\begin{array}{l}\text { Trans. } \\
\text { Disp. } \\
\text { (in) }\end{array}$ \\
\hline 1992 Mendocino & 0.755 & 0.485 & 15.3 & 12.0 \\
\hline 1992 Erzincan & 0.605 & 0.539 & 11.3 & 41.3 \\
\hline 1949 Olympia & 0.895 & 0.821 & 7.1 & 14.2 \\
\hline 1965 Seattle & 1.755 & 1.390 & 19.5 & 17.3 \\
\hline 1985 Valpariso & 1.636 & 1.573 & 8.6 & 16.1 \\
\hline 1985 Valpariso & 1.270 & 0.901 & 17.1 & 14.3 \\
\hline Deep Interplate (simulation) & 0.796 & 0.646 & 18.6 & 7.9 \\
\hline 1978 Miyagi-oki & 0.606 & 0.783 & 14.0 & 19.6 \\
\hline Shallow Interplate (simulation) & 0.563 & 0.534 & 7.9 & 18.7 \\
\hline Shallow Interplate (simulation) & 0.578 & 0.749 & 6.0 & 14.8 \\
\hline
\end{tabular}

The maximum displacement found in Table 4.21 is 41.3 inches for the structure being loaded by the group of ground motions having a POE of $2 \%$ in 50 years. When reviewing the data associated with run, material failure was found to have occurred. If this outlying data point is ignored, then the maximum displacement was 19.6 inches. This compares favorably to the 21 inches predicted by the response spectrum envelope from Figure 2.4 for a structure having a fundamental period of 0.72 seconds. 
These displacement values are used in subsequent sections to calculate displacement ductilities, and then to ultimately build fragility curves. 


\subsection{PROBABALISTIC SEISMIC DEMAND ANALYSIS}

\subsection{PROBABALISTIC SEISMIC DEMAND}

Within the framework of predicting the risk of damage to Oregon bridges, being able to quantify the seismic demand seen by those structures is fundamental to the effort to define fragility curves. A simple mathematical description of this loss estimation is provided by the following equation (Ellingwood et al, 2005):

$$
P[\text { Loss }]=\sum_{s} \sum_{L S} \sum_{d} P[\text { Loss } \mid D=d] P[D=d \mid L S] P[L S \mid I M=s] P[I M=s]
$$

where Loss is an appropriate metric such as number of deaths or injuries, damage expenses or lost opportunity costs. The last term $P[I M=s]$ represents a relevant measure of the hazard Intensity Measure (IM) such as Peak Ground Acceleration (PGA) or Spectral Acceleration $\left(\mathrm{S}_{\mathrm{a}}\right)$. Given that the structure experiences a hazard of intensity $s$, the third term $P[L S \mid I M=s]$ represents the probability that the structure exceeds a particular limit state given a certain Intensity Measure. If a specified limit state is exceeded, the second term $P[D=d \mid L S]$ represents the probability that the structure will sustain a damage state of $d$. If the structure sustains a damage state $d$, then the first term $P[$ Loss $\mid D=d]$ represents the probability that the structure will sustain a given level of loss. The product of these individual terms result in the probability the structure will sustain a given level of loss. The term $P[L S \mid I M=s]$ in Eq. (5-1) allows the seismic demand to be defined and can be thought of as a fragility term because the ability of the structure to withstand ground motions of a specified intensity is represented. The LS represent a specified structural limit state which is a measure of the structural response (e.g., displacement or curvature ductility), and is referred to as an engineering demand parameter (EDP).

The two parts of the fragility concept are capacity and demand where the damage states of a structure can be considered to be related to structural capacity (C) and the ground-motion intensity is a representation of structural demand (D). The probability of failure, $P_{f}$, can then be written as:

$$
P_{f}=P\left\lfloor\frac{C}{D} \leq 1\right\rfloor
$$

which gives the probability that the structural demand will exceed the structural capacity. Since both capacity and demand distributions are assumed to be lognormal (Wen, 2003), $P_{f}$ can be expressed (Melchers, 1999) using the standard normal distribution function $\Phi()$ : 


$$
\begin{aligned}
P_{f} & =\Phi(-\beta) \\
& =\Phi\left(\frac{-\ln \left(\frac{\mu_{C}}{\mu_{D}} \frac{\sqrt{1+V_{D}^{2}}}{\sqrt{1+V_{C}^{2}}}\right)}{\sqrt{\ln \left[\left(1+V_{C}^{2}\right)\left(1+V_{D}^{2}\right)\right]}}\right) \\
& =\Phi\left(\frac{-\ln \left(\frac{C_{m}}{D_{m}}\right)}{\sqrt{\ln \left[\left(1+V_{C}^{2}\right)\left(1+V_{D}^{2}\right)\right]}}\right) \\
& =\Phi\left(\frac{\ln \left(\frac{D_{m}}{C_{m}}\right)}{\sqrt{\ln \left(1+V_{C}^{2}\right)+\ln \left(1+V_{D}^{2}\right)}}\right)
\end{aligned}
$$

where $\mu_{C}$ and $\mu_{D}$ are the means of the capacity and demand distributions, $V_{C}$ and $V_{D}$ are the coefficients of variation (COV) of the capacity and demand distributions, and $C_{m}$ and $D_{m}$ are the median values of the capacity and demand distributions. Using the fact that for a lognormal distribution $\sigma_{\ln X}^{2}=\ln \left(1+V_{X}^{2}\right)$, Eq. (5-3) can be further simplified:

$$
P_{f}=\Phi\left(\frac{\ln \left(\frac{D_{m}}{C_{m}}\right)}{\sqrt{\ln \left(1+V_{C}^{2}\right)+\sigma_{\ln _{D}}^{2}}}\right)
$$

where $\sigma_{\ln _{D}}$ is the standard deviation of the lognormal demand distribution.

The median demand can be represented by a power model (Cornell et al., 2002) such that

$$
D_{m}=a\left(S_{a}\right)^{b}
$$

Assuming that this can be extended to include other intensity measures, a more general expression will be used:

$$
D_{m}=a(I M)^{b}
$$

Since two ground-motion records were used for each simulation, the geometric average of the PGA for each of the two records was used when specifying the IM. Research has shown that the dispersion of displacement data relative to spectral acceleration, in lognormal space, is less than the dispersion of displacement data relative to PGA, also in lognormal space (Hwang et al., 
2001). However, spectral acceleration is considered a structural parameter and is not directly related to ground shaking, and since PGA is easily derived from ground-motion records it was the only IM used in this study.

Transforming Equation 5-6 into lognormal space yields:

$$
\ln D_{m}=b \cdot \ln I M+\ln a
$$

An illustration from Padgett (2007) showing the transformation into lognormal space is shown in Figure 5.1.

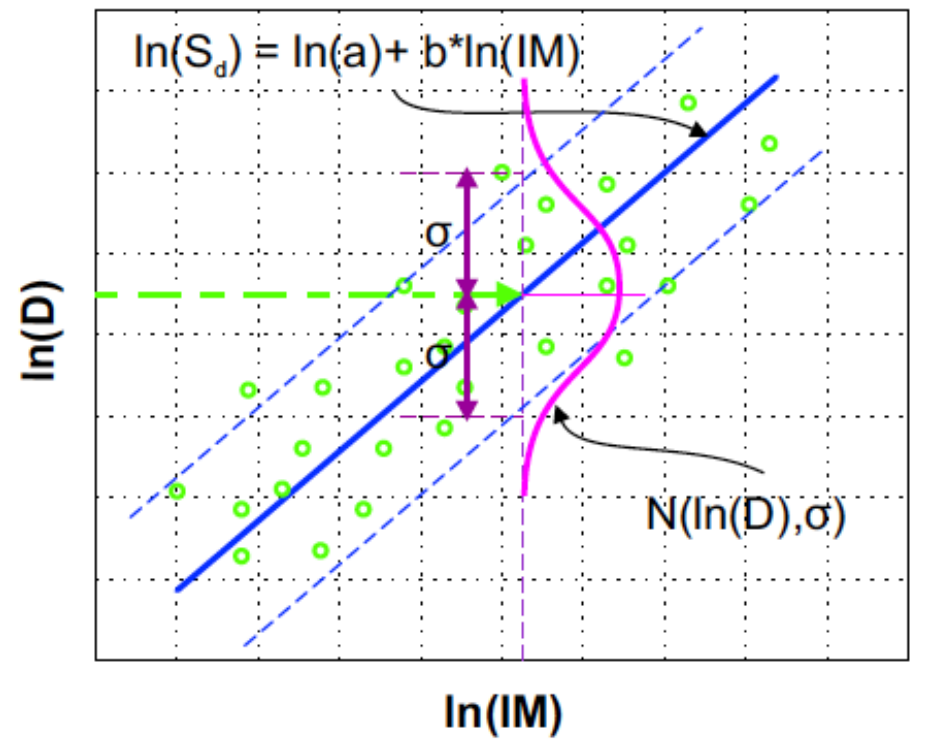

Figure 5.1: PSDM Illustration in Lognormal Space (Padgett, 2007)

The chart shows data from the nonlinear analyses being plotted in the $\ln (D)$ vs. $\ln (I M)$ space. A regression analysis yields the equation of the desired line: $\ln a+b \ln I M$. Additionally, the standard deviation of the transformed data is also shown; this is the standard deviation used in Equation 5-4.

Using Equation (5-6) in Equation (5-4), another expression for the failure probability $P_{f}$ can be derived:

$$
P_{f}=\Phi\left[\frac{\ln \left(\frac{D_{m L}}{C_{m}}\right)}{\sqrt{\ln \left(1+V_{c}^{2}\right)+\sigma_{\ln }^{2}}}\right]=\Phi\left[\frac{\ln D_{m}-\ln C_{m}}{\sqrt{\ln \left(1+V_{c}^{2}\right)+\sigma_{\ln _{D}}^{2}}}\right]
$$




$$
\begin{aligned}
& =\Phi\left[\frac{\ln \left(a M^{b}\right)-\ln C_{m}}{\sqrt{\ln \left(1+V_{t}^{2}\right)+\sigma_{\ln _{D}}^{2}}}\right]=\Phi\left[\frac{\ln a+b \ln I M-\ln C_{m}}{\sqrt{\ln \left(1+V_{c}^{2}\right)+\sigma_{\ln _{D}}^{2}}}\right]
\end{aligned}
$$

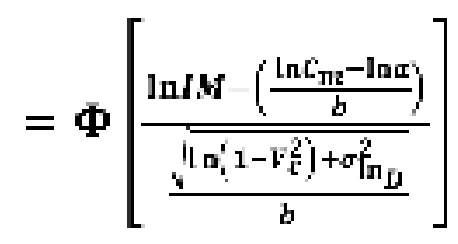

Rewriting Equation 5-8 in the form used in Equation 1-2:

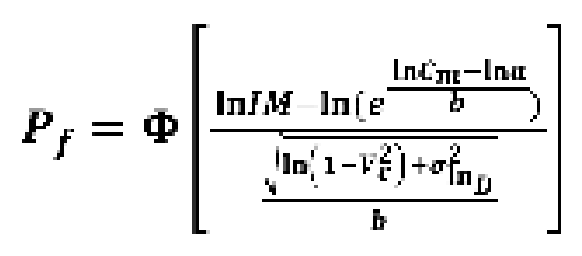

Since Equation 1-2 is the form of an equation that represents a lognormal cumulative distribution function, the second term of Equation 5-9, $e^{\frac{\ln C_{\mathrm{T} i}-\operatorname{lna}}{b}}$, is the median of the lognormal capacity distribution and the bottom term, $\frac{v^{\ln \left(11 V_{L}^{2}\right) \mid \sigma_{\operatorname{lng}}^{2}}}{b}$, is a measure of the dispersion.

The primary failure location of the bridges considered was expected to be the columns. Therefore, the only engineering demand parameter that was considered was the column displacement ductility.

Displacement ductility demand was used to evaluate the extent of loading of the columns and is defined as:

$$
\mu_{\mathrm{s}}=\frac{\dot{\Delta}_{\operatorname{mLx}}}{\dot{s}_{\text {titid }}}
$$

where $\Delta_{\max }$ is the maximum displacement throughout a given time history and $\Delta_{\text {yield }}$ is the displacement of the column at first yield of the outermost longitudinal reinforcement steel.

\subsection{PSDM FOR TYPICAL THREE-SPAN BRIDGE}

The displacement of a column resulting in the yielding of the outermost steel reinforcement for the three-span bridge was around 0.8 inches. This value was determined by doing a pushover 
analysis of the actual bridge model. Using Equation 5-10, the displacement ductilities were determined and are shown in tables 5.1 and 5.2.

Table 5.1: Displacement Ductilities Using POE-of-10\%-in-50-Years Group

\begin{tabular}{l|c|c|c|c}
\hline Ground-Motion Record & $\begin{array}{c}\text { PGA } \\
\mathbf{d i r 1} \\
\mathbf{( g )}\end{array}$ & $\begin{array}{c}\text { PGA } \\
\mathbf{d i r 2} \\
\mathbf{( g )}\end{array}$ & $\begin{array}{c}\text { Displacement } \\
\text { Ductility, } \boldsymbol{\mu}_{\mathcal{L}} \\
\text { Orientation 1 }\end{array}$ & $\begin{array}{c}\text { Displacement } \\
\text { Ductility, } \boldsymbol{\mu}_{\boldsymbol{s}} \\
\text { Orientation 2 }\end{array}$ \\
\hline Long Beach, Vernon CMD Bldg. & 0.174 & 0.135 & 2.17 & 2.08 \\
\hline Morgan Hill, 1984, Gilroy & 0.386 & 0.662 & 4.12 & 3.82 \\
\hline West. Washington, Olympia, 1949 & 0.383 & 0.352 & 3.37 & 3.65 \\
\hline West. Washington, Seattle Army B., 1949 & 0.295 & 0.388 & 7.31 & 6.70 \\
\hline North Palm Springs, 1986 & 0.587 & 0.599 & 4.52 & 3.21 \\
\hline Puget Sound, Wa., Olympia, 1949 & 0.752 & 0.596 & 5.87 & 7.34 \\
\hline Puget Sound, Wa., Federal OFC B., 1949 & 0.369 & 0.303 & 4.19 & 5.18 \\
\hline Eastern Wa., Tacoma County, 1949 & 0.290 & 0.574 & 7.42 & 6.33 \\
\hline Llolleo, Chile 1985 & 0.697 & 0.670 & 5.04 & 6.25 \\
\hline Vinadel Mar, Chile, 1985 & 0.541 & 0.384 & 7.86 & 11.07 \\
\hline
\end{tabular}

Table 5.2: Displacement Ductilities Using POE-of-2\%-in-50-Years Group

\begin{tabular}{l|c|c|c|c}
\hline Ground-Motion Record & $\begin{array}{c}\text { PGA } \\
\mathbf{d i r 1} \\
\mathbf{( g )}\end{array}$ & $\begin{array}{c}\text { PGA } \\
\mathbf{d i r 2} \\
\mathbf{( g )}\end{array}$ & $\begin{array}{c}\text { Displacement } \\
\text { Ductility, } \boldsymbol{\mu}_{\mathbf{S}} \\
\text { Orientation 1 }\end{array}$ & $\begin{array}{c}\text { Displacement } \\
\text { Ductility, } \boldsymbol{\mu}_{\mathbf{S}} \\
\text { Orientation 2 }\end{array}$ \\
\hline 1992 Mendocino & 0.755 & 0.485 & 12.5 & 16.2 \\
\hline 1992 Erzincan & 0.605 & 0.539 & 9.71 & 9.04 \\
\hline 1949 Olympia & 0.895 & 0.821 & 8.55 & 10.1 \\
\hline 1965 Seattle & 1.755 & 1.390 & 19.2 & 16.9 \\
\hline 1985 Valpariso & 1.636 & 1.573 & 13.4 & 16.4 \\
\hline 1985 Valpariso & 1.270 & 0.901 & 26.5 & 28.3 \\
\hline Deep Interplate (simulation) & 0.796 & 0.646 & 11.2 & 10.4 \\
\hline 1978 Miyagi-oki & 0.606 & 0.783 & 29.6 & 29.8 \\
\hline Shallow Interplate (simulation) & 0.563 & 0.534 & 8.19 & 8.05 \\
\hline Shallow Interplate (simulation) & 0.578 & 0.749 & 9.93 & 9.26 \\
\hline
\end{tabular}

Using the methodology described in Section 5.1, the probability seismic demand model (PSDM) was found and is shown below in Figure 5.2. The defining parameters are provided in Table 5.3.

The dispersion found during this analysis is comparable to that found from other researchers (Nielson, 2005 and Padgett, 2007) using this method.

Table 5.3: PSDM for Three-Span Bridge

\begin{tabular}{l|c}
\hline PSDM & $\begin{array}{c}\text { Dispersion } \\
\sigma_{\operatorname{lnD} m}\end{array}$ \\
\hline $\ln D_{m}=0.914 \cdot \ln I M+2.577$ & 0.643 \\
\hline
\end{tabular}




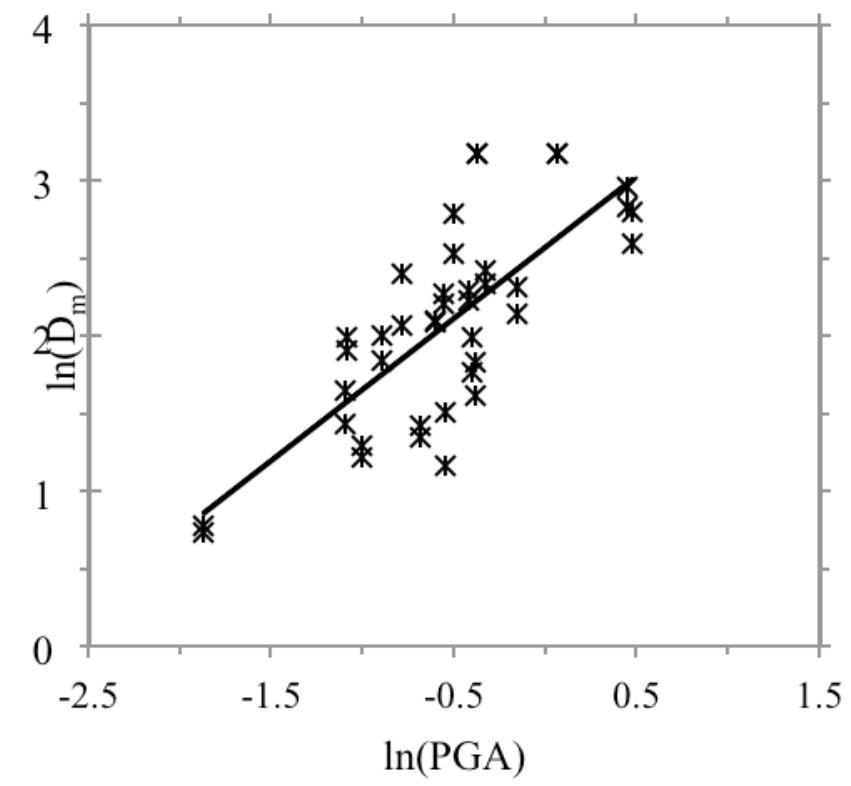

Figure 5.2: PSDM Plot for Three-Span Bridge

\subsection{PSDM FOR TYPICAL FIVE-SPAN BRIDGE}

The displacement of shortest column resulting in the yielding of the outermost steel reinforcement for the five-span bridge column was around 2.0 inches. This value was determined by doing a pushover analysis of the actual bridge model. Using Equation 5-10, the displacement ductilities were determined and are shown in tables 5.4 and 5.5.

Table 5.4: Displacement Ductilities Using POE-of-10\%-in-50-Years Group

\begin{tabular}{l|c|c|c}
\hline Ground-Motion Record & $\begin{array}{c}\text { PGA } \\
\mathbf{d i r} \mathbf{1} \\
\mathbf{( g )}\end{array}$ & $\begin{array}{c}\text { PGA } \\
\mathbf{d i r 2} \\
\mathbf{( g )}\end{array}$ & $\begin{array}{c}\text { Displacement } \\
\text { Ductility } \\
\mu_{\mathbf{L}}\end{array}$ \\
\hline Long Beach, Vernon CMD Bldg. & 0.174 & 0.135 & 1.55 \\
\hline Morgan Hill, 1984, Gilroy & 0.386 & 0.662 & 2.55 \\
\hline West. Washington, Olympia, 1949 & 0.383 & 0.352 & 2.65 \\
\hline West. Washington, Seattle Army B., 1949 & 0.295 & 0.388 & 3.55 \\
\hline North Palm Springs, 1986 & 0.587 & 0.599 & 5.45 \\
\hline Puget Sound, Wa., Olympia, 1949 & 0.752 & 0.596 & 2.80 \\
\hline Puget Sound, Wa., Federal OFC B., 1949 & 0.369 & 0.303 & 1.85 \\
\hline Eastern Wa., Tacoma County, 1949 & 0.290 & 0.574 & 3.10 \\
\hline Llolleo, Chile 1985 & 0.697 & 0.670 & 5.05 \\
\hline Vinadel Mar, Chile, 1985 & 0.541 & 0.384 & 4.75 \\
\hline
\end{tabular}

Table 5.5: Displacement Ductilities Using POE-of-2\%-in-50-Years Group

\begin{tabular}{l|c|c|c}
\hline Ground-Motion Record & $\begin{array}{c}\text { PGA } \\
\text { dir1 } \\
\text { (g) }\end{array}$ & $\begin{array}{c}\text { PGA } \\
\text { dir2 } \\
\text { (g) }\end{array}$ & $\begin{array}{c}\text { Displacement } \\
\text { Ductility } \\
\mu_{\text {L }}\end{array}$ \\
\hline 1992 Mendocino & 0.755 & 0.485 & 7.65 \\
\hline 1992 Erzincan & 0.605 & 0.539 & 20.7 \\
\hline
\end{tabular}




\begin{tabular}{l|c|c|c}
\hline Ground-Motion Record & $\begin{array}{c}\text { PGA } \\
\text { dir1 } \\
\mathbf{( g )}\end{array}$ & $\begin{array}{c}\text { PGA } \\
\mathbf{d i r 2} \\
\mathbf{( g )}\end{array}$ & $\begin{array}{c}\text { Displacement } \\
\text { Ductility } \\
\boldsymbol{\mu}_{\mathbf{2}}\end{array}$ \\
\hline 1949 Olympia & 0.895 & 0.821 & 7.10 \\
\hline 1965 Seattle & 1.755 & 1.390 & 9.75 \\
\hline 1985 Valpariso & 1.636 & 1.573 & 8.05 \\
\hline 1985 Valpariso & 1.270 & 0.901 & 8.55 \\
\hline Deep Interplate (simulation) & 0.796 & 0.646 & 9.30 \\
\hline 1978 Miyagi-oki & 0.606 & 0.783 & 9.80 \\
\hline Shallow Interplate (simulation) & 0.563 & 0.534 & 9.35 \\
\hline Shallow Interplate (simulation) & 0.578 & 0.749 & 7.40 \\
\hline
\end{tabular}

Using the methodology described in Section 5.1, the PSDM was found and is shown below in Figure 5.3. The defining parameters are provided in Table 5.6. The dispersion found during this analysis is larger comparable to that found from other researchers (Nielson, 2005 and Padgett, 2007) using this method.

Table 5.6: PSDM for Five-Span Bridge

\begin{tabular}{l|c}
\hline PSDM & $\begin{array}{c}\text { Dispersion } \\
\sigma_{\operatorname{lnD} m}\end{array}$ \\
\hline $\ln D_{m}=0.850 \cdot \ln I M+2.131$ & 0.670 \\
\hline
\end{tabular}

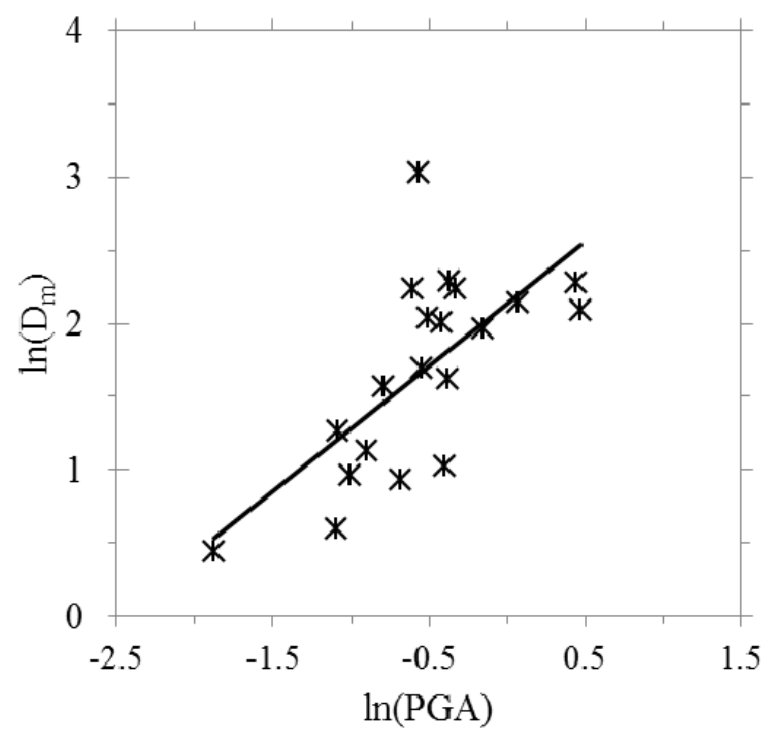

Figure 5.3: PSDM Plot for Five-Span Bridge 


\subsection{SEISMIC FRAGILITY ANALYSIS OF BRIDGES}

\subsection{LIMIT STATES}

The capacity limit states $\left(C_{m}\right)$ used in Equation (5-8) are conceptually the same qualitative limit states used in the FEMA loss assessment package HAZUS-MH MR3 (FEMA, 2003). Descriptions of these limit states are given in Table 6.1:

Table 6.1: FEMA Limit States

\begin{tabular}{l|l}
\hline Slight/Minor & $\begin{array}{l}\text { Minor cracking and spalling to the abutment, cracks in shear keys at } \\
\text { abutments, minor spalling and cracks at hinges, minor spalling at the column } \\
\text { (damage requires no more than cosmetic repair) or minor cracking to the deck }\end{array}$ \\
\hline Moderate & $\begin{array}{l}\text { Any column experiencing moderate (shear cracks) cracking and spalling } \\
\text { (column structurally still sound), moderate movement of the abutment (<2"), } \\
\text { extensive cracking and spalling of shear keys, any connection having cracked } \\
\text { shear keys or bent bolts, keeper bar failure without unseating, rocker bearing } \\
\text { failure or moderate settlement of the approach. }\end{array}$ \\
\hline Extensive & $\begin{array}{l}\text { Any column degrading without collapse - shear failure - (column structurally } \\
\text { unsafe), significant residual movement at connections, or major settlement } \\
\text { approach, vertical offset of the abutment, differential settlement at } \\
\text { connections, shear key failure at abutments. }\end{array}$ \\
\hline Complete & $\begin{array}{l}\text { Any column collapsing and connection losing all bearing support, which may } \\
\text { lead to imminent deck collapse, tilting of substructure due to foundation } \\
\text { failure. }\end{array}$ \\
\hline
\end{tabular}

But the real need is to have quantitative values which can be used in the generation of fragility curves. Other researchers dealing with the modeling of reinforced concrete bridges in the Central and Southeastern United States (CSUS) have recognized that the detailing for the typical reinforced concrete column will produce poor confinement due to the widely spaced transverse steel and also due to lap splices being located where a plastic hinge is expected to occur. From research related to the CSUS, Hwang et al. (2000) proposed quantitative limit states that roughly correspond to the limit states in Table 5.1. The median displacement ductilities of 1.0, 1.2, 1.76, and 4.76 were suggested, which correspond to yielding, cracking, spalling and reinforcement buckling, respectively. The values used to model bridge capacity are shown in Table 6.2.

Once the median displacement ductilities $(\mathrm{Cm})$ are available, then the amount of variability, or dispersion, of the capacity distribution needs to be estimated. The coefficient of variation (COV), when working with a single variable, is defined to be the ratio of the standard deviation to the mean of the distribution. Generally, a lower COV corresponds to a lower dispersion of the variable. Since the COV for the capacity distribution is unknown, an assumption was made about its value. Nielson (2007) assumed that the COV for the slight and moderate damage states was 0.25 , which corresponds to a relatively lower variation. The COV for the extensive and complete damage states had a value of 0.5 , which corresponds to a higher level of variation. Instead of a jump in values, a more gradual increase of variability was used so that the COV for 
the slight, moderate, extensive and complete damage states was $0.25,0.33,0.42$, and 0.5 . Bridge capacity values used are shown in Table 6.2. The increased variability is assumed since the higher damage states correspond to more nonlinear behavior of the bridge components, and the ability to model actual behavior of the bridges becomes more difficult at the higher levels of damage.

Table 6.2: Model Bridge Capacity Values

\begin{tabular}{c|c|c}
\hline Damage State & $\begin{array}{c}\text { Median Capacity } \\
\text { Displacement Ductility }\end{array}$ & Coefficient of Variation \\
\hline Slight & 1.0 & 0.25 \\
\hline Moderate & 1.2 & 0.33 \\
\hline Extensive & 1.76 & 0.42 \\
\hline Complete & 4.76 & 0.50 \\
\hline
\end{tabular}

Research has shown that natural, physical processes can frequently be represented using lognormal distributions. Typical values of the standard deviation, $\mathrm{s}^{*}$, of these natural processes can range from $\mathrm{s}^{*}=1.2$ to 3.0 (Eckhard et al., 2001). The following equation relating the coefficient of variation and the lognormal standard deviation can be used:

$s^{*}=e^{\sqrt{1+1\left(1+c+c r^{2}\right)}}$

Using the assumed standard deviation values, the $\mathrm{COV}$ is found to range from 0.18 to 1.53 , and the assumed $\mathrm{COV}$ values used in this study fall within the lower portion of this range.

\subsection{FRAGILITY CURVE GENERATION}

At this point of the discussion, all of the elements needed to calculate fragility curves are available. These are:

- A method to predict the median of the lognormal demand distribution in terms of the chosen intensity measure. In the current research, this takes the form of the PSDM.

- Quantitative values of the median value of the capacity lognormal distribution. As mentioned previously, these values are assumed to be 1.0,1.2, 1.76, and 4.73, which correspond to yielding, cracking, spalling and reinforcement buckling, respectively.

- An estimate of the dispersion of the capacity distribution: The COV is used to estimate the dispersion, $\beta=\sqrt{\ln \left(1+\operatorname{CoV}^{2}\right)}$.

- An estimate of the dispersion of the demand distribution. The standard deviation of the displacement ductility values in the lognormal space was taken to be a measure of the dispersion.

- A mathematical model which links the above elements. This function is served by Equation 5-9. 
Once these values are known, any standard spreadsheet software package can plot the fragility curve associated with the calculated demand median and dispersion.

\subsection{THREE-SPAN BRIDGE FRAGILITY CURVES}

Using Equation 5-9, the following median and dispersion values were calculated for the threespan bridge and are provided in Table 6.3 and Figure 6.1.

Table 6.3: Fragility Curves Values for Typical Three-Span Bridge

\begin{tabular}{l|l|l}
\hline Damage State & Median & Dispersion \\
\hline Slight & 0.06 & 0.64 \\
\hline Moderate & 0.07 & 0.68 \\
\hline Extensive & 0.11 & 0.73 \\
\hline Complete & 0.33 & 0.78 \\
\hline
\end{tabular}

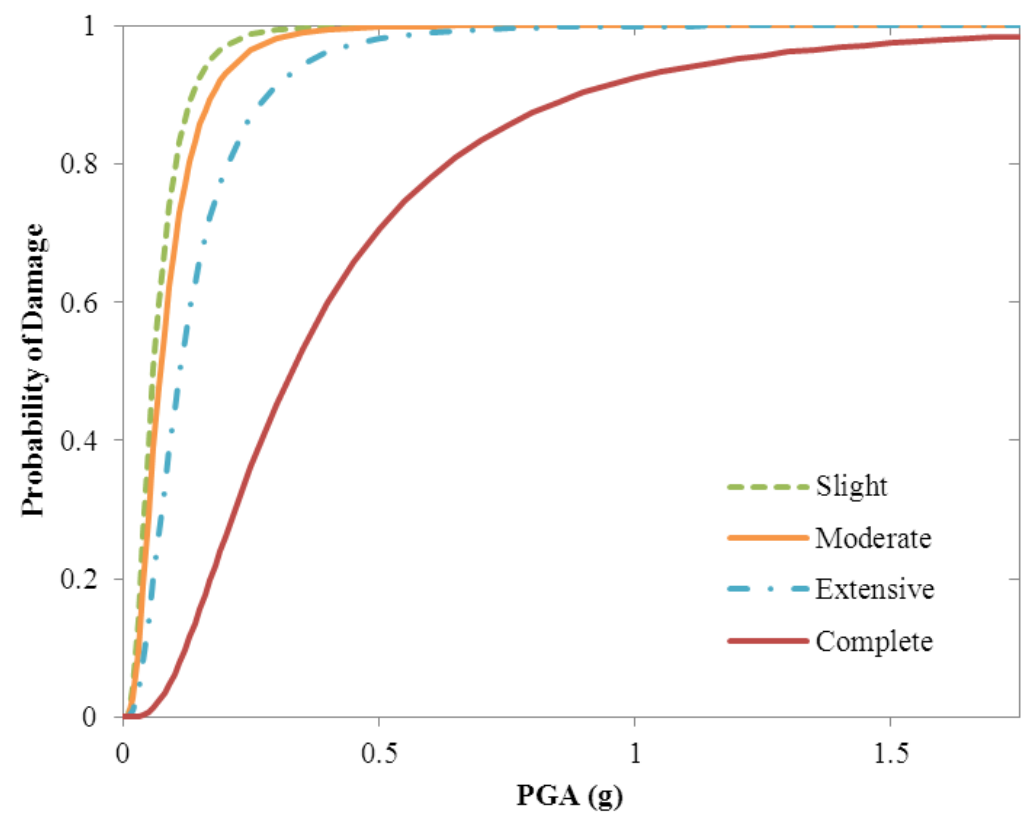

Figure 6.1: Fragility Curves for Three-Span Bridge

For a comparison, the fragility curves specified in HAZUS (2003) were calculated. The fragility curves currently being used in HAZUS were developed using a nonlinear static analysis method described in Section 1.2.3. This method attempts to take into account nonlinear behavior and doesn't have the computational overhead of the nonlinear time-history method, but should be considered a coarser approximation.

The procedure found in HAZUS was followed to modify the fragility medians for a "standard bridge" for local conditions. The location was chosen to be Portland, OR, and from the USGS website, the spectral acceleration values were determined to be $\mathrm{S}_{1}=0.339 \mathrm{~g}$ and $\mathrm{S}_{s}=0.963 \mathrm{~g}$. All 
values from the USGS website were based upon the 2003 NEHRP design provisions. The USGS specifies the short-period spectral acceleration at 0.2 seconds, but the HAZUS procedure requires the spectral acceleration at 0.3 seconds. The following equation is provided by HAZUS to convert: $\mathrm{S} a(0.3)=\mathrm{S}_{s} / 1.1=0.963 / 1.1=0.876 \mathrm{~g}$.

To allow for local soil conditions, these spectral accelerations were modified by the soil amplification factors, $\mathrm{F}_{\mathrm{A}}$ and $\mathrm{F}_{\mathrm{V}}$. The spectral acceleration values then become $\mathrm{S} a(0.3)=1.00565$ $\mathrm{g}$ and $\mathrm{S} a(1.0)=0.584 \mathrm{~g}$.

Several other modifications were also made. The $\mathrm{K}_{\text {shape }}$ factor is the modifier that converts cases for short periods to an equivalent spectral amplitude at $\mathrm{T}=1.0$ second and $\mathrm{K}_{3 \mathrm{D}}$ accommodates the three-dimensional movement of the deck. $\mathrm{K}_{\text {shape }}$ and $\mathrm{K}_{3 \mathrm{D}}$ were found to be 1.451 and 1.110 , respectively. $\mathrm{K}_{\text {skew }}$ has a value of unity because no deck skew was modeled.

The median values for the "standard bridge" type 202 are:

$$
\mathrm{a}_{2}=0.62 \mathrm{~g} ; \mathrm{a}_{3}=0.79 \mathrm{~g} ; \mathrm{a}_{4}=1.05 \mathrm{~g} ; \mathrm{a}_{5}=1.38 \mathrm{~g}
$$

The final step is to modify these median values to reflect the local structural and soil conditions using the following equations:

$$
\begin{aligned}
& \Lambda_{2}=\boldsymbol{K}_{\text {shapc }} \boldsymbol{a}_{2}=\mathbf{0 . 8 7 1} \mathrm{g} \\
& \Lambda_{3}=\boldsymbol{K}_{s k \mathrm{kH}} \boldsymbol{K}_{3 \nu} \boldsymbol{a}_{3}=0.999 \mathrm{~g} \\
& A_{1}=K_{s k E H^{\prime}} K_{3 D} a_{4}=1.221 g \\
& A_{\Xi}=K_{s k \varepsilon \mu^{\prime}} K_{3 \nu} a_{I}=1.665 g
\end{aligned}
$$

where $\mathrm{A}_{i}$ is the modified median value for the slight, moderate, extensive and complete damage states. HAZUS specifies the reference median values, $\mathrm{a}_{2}-\mathrm{a}_{5}$, to be $0.60 \mathrm{~g}, 0.90 \mathrm{~g}, 1.10 \mathrm{~g}$, and $1.50 \mathrm{~g}$, respectively, for a continuous concrete, pre-1990, non-CA, conventionally built bridge. HAZUS also specifies a dispersion of 0.6 for all damage states to be used for bridges.

The median values and dispersions for the four damage states from the three-span bridge model, from HAZUS, and Nielson (2007) are shown below in Table 6.4.

Table 6.4: Fragility Curves Values for Typical Three-Span Bridge and Reference Values

\begin{tabular}{l|c|c|c|c|c|c}
\hline \multirow{2}{*}{ Damage } & \multicolumn{2}{|c|}{ 3-Span Model } & \multicolumn{2}{c|}{ Nielson } & \multicolumn{2}{c}{ HAZUS } \\
\cline { 2 - 7 } & Median & Dispersion & Median & Dispersion & Median & Dispersion \\
\hline Slight & 0.06 & 0.64 & 0.16 & 0.7 & 0.87 & 0.6 \\
\hline Moderate & 0.07 & 0.68 & 0.53 & 0.7 & 1.00 & 0.6 \\
\hline Extensive & 0.11 & 0.73 & 0.75 & 0.7 & 1.22 & 0.6 \\
\hline Complete & 0.33 & 0.78 & 1.01 & 0.7 & 1.67 & 0.6 \\
\hline
\end{tabular}


As can be seen, the medians from the model are significantly lower than both Nielson and HAZUS. However, the dispersion of the model is similar to the other two sources. For simplicity, the dispersion of the model could be distilled to an average value of 0.7 .

\subsubsection{EFFECT OF ABUTMENTS}

The three-span model used the ElasticPPGap OpenSees material type, which allowed a gap between the abutment and deck to be specified. When the gap is modified to a large value, this effectively removes any effect from the abutments. The median and dispersion values from this model are shown in Table 6.5, and the fragility curves for the extensive and complete damage states are shown in Figure 6.2.

Table 6.5: Fragility Curve Values With and Without Abutments

\begin{tabular}{l|c|c|c|c|c}
\hline Damage State & \multicolumn{2}{|c|}{ With Abutments } & \multicolumn{2}{c|}{ Without Abutments } & \multirow{2}{*}{$\begin{array}{c}\text { Median } \\
\text { Percent } \\
\text { Difference }\end{array}$} \\
\cline { 2 - 5 } & Median & Dispersion & Median & Dispersion & -66.7 \\
\hline Slight & 0.06 & 0.64 & 0.02 & 0.74 & -57.1 \\
\hline Moderate & 0.07 & 0.68 & 0.03 & 0.79 & -54.5 \\
\hline Extensive & 0.11 & 0.73 & 0.05 & 0.84 & -45.5 \\
\hline Complete & 0.33 & 0.78 & 0.18 & 0.90 & \\
\hline
\end{tabular}

From this data, the impact of just the abutments on the damage state of the structure, as a whole, can be seen. The median values, for all damage states, were decreased by $45 \%$ or more showing a large increase in bridge fragility with no abutments.

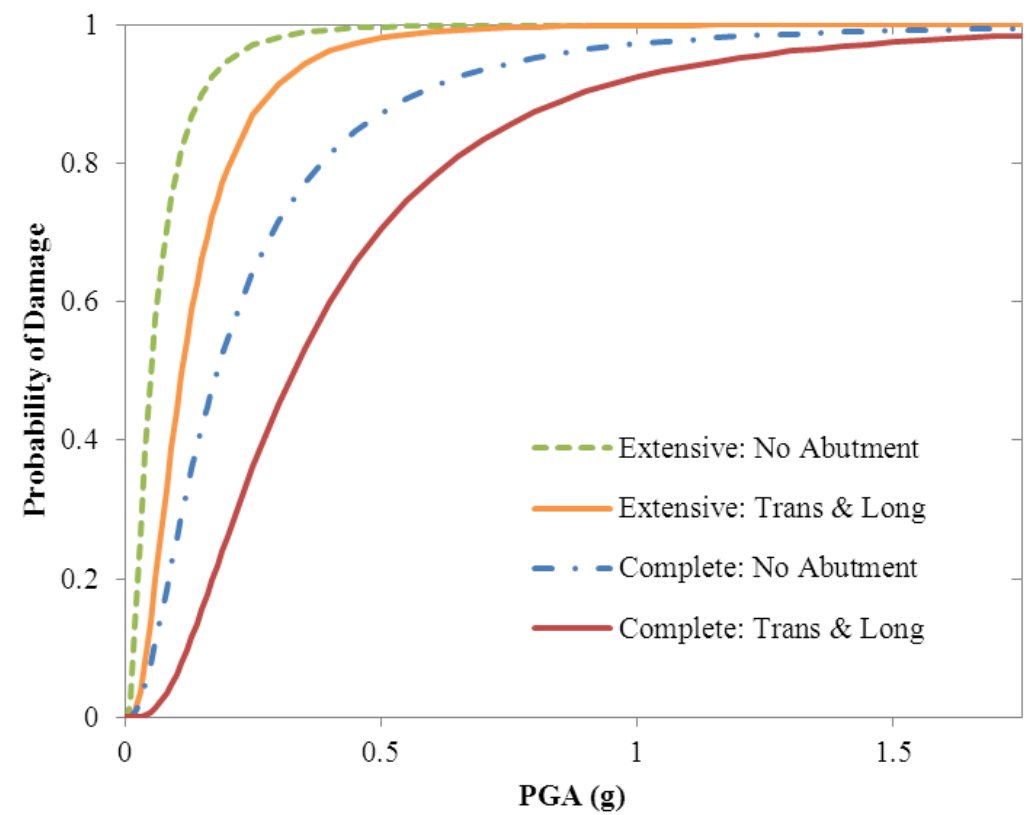

Figure 6.2: Complete and Extensive Damage Fragility Curve for Three-Span Bridge without Abutments 
When the only effect is in the longitudinal direction, the median values are again changed. The median and dispersion values are shown in Table 6.6.

Table 6.6: Fragility Curve Values with All Abutments and Longitudinal Abutments Only

\begin{tabular}{l|c|c|c|c|c}
\hline Damage State & \multicolumn{2}{|c|}{ With Abutments } & \multicolumn{2}{c}{$\begin{array}{c}\text { With Long. Abutment } \\
\text { Only }\end{array}$} & $\begin{array}{c}\text { Median } \\
\text { Percent } \\
\text { Difference }\end{array}$ \\
\cline { 2 - 6 } & Median & Dispersion & Median & Dispersion & -50.0 \\
\hline Slight & 0.06 & 0.64 & 0.03 & 0.70 & -42.9 \\
\hline Moderate & 0.07 & 0.68 & 0.04 & 0.74 & -36.4 \\
\hline Extensive & 0.11 & 0.73 & 0.07 & 0.79 & -36.4 \\
\hline Complete & 0.33 & 0.78 & 0.21 & 0.84 & \\
\hline
\end{tabular}

When comparing the data from tables 6.4 and 6.5, the largest impact came from introducing the transverse soil-abutment interaction, with the longitudinal soil-abutment interaction being less significant but still useful in reducing bridge movement. For example, when using only the longitudinal soil-abutment interaction, the median value for the complete damage state increased by $18.8 \%$. By using both the longitudinal and transverse interactions, the median value for the complete damage state increased by over $83 \%$ compared to when no soil-abutment interactions were modeled.

\subsubsection{EFFECT OF GROUND-MOTION SUITE CHANGE}

The original three-span model was evaluated using the entire ground-motion suite described in Section 2.2. That model was then modified such that only the ground motions from the POE10\%-in-50-years suite were used. The median and dispersion values from this new model are shown in Table 6.7, and the fragility curves for the extensive and complete damage states are shown in Figure 6.3.

Table 6.7: Fragility Medians Using POE-10\%-in-50-Years Ground-Motion Suite

\begin{tabular}{l|c|c|c|c}
\hline \multirow{2}{*}{ Damage State } & \multicolumn{2}{|c|}{ Complete Suite } & \multicolumn{2}{c}{ POE-10-in-50 suite only } \\
\cline { 2 - 5 } & Median & Dispersion & Median & Dispersion \\
\hline Slight & 0.06 & 0.64 & 0.02 & 0.90 \\
\hline Moderate & 0.07 & 0.68 & 0.03 & 0.98 \\
\hline Extensive & 0.11 & 0.73 & 0.06 & 1.07 \\
\hline Complete & 0.33 & 0.78 & 0.39 & 1.17 \\
\hline
\end{tabular}

The POE-10\%-in-50-years ground-motion suite is centered near $0.4 \mathrm{~g}$ with a maximum of 0.68 $\mathrm{g}$, whereas the full suite is centered near $0.6 \mathrm{~g}$ with a maximum of $1.76 \mathrm{~g}$. With this downwards shift of ground-motion acceleration, the columns are displaced less, leading to the lower median values. Also, with the smaller column displacements comes a smaller dispersion. 


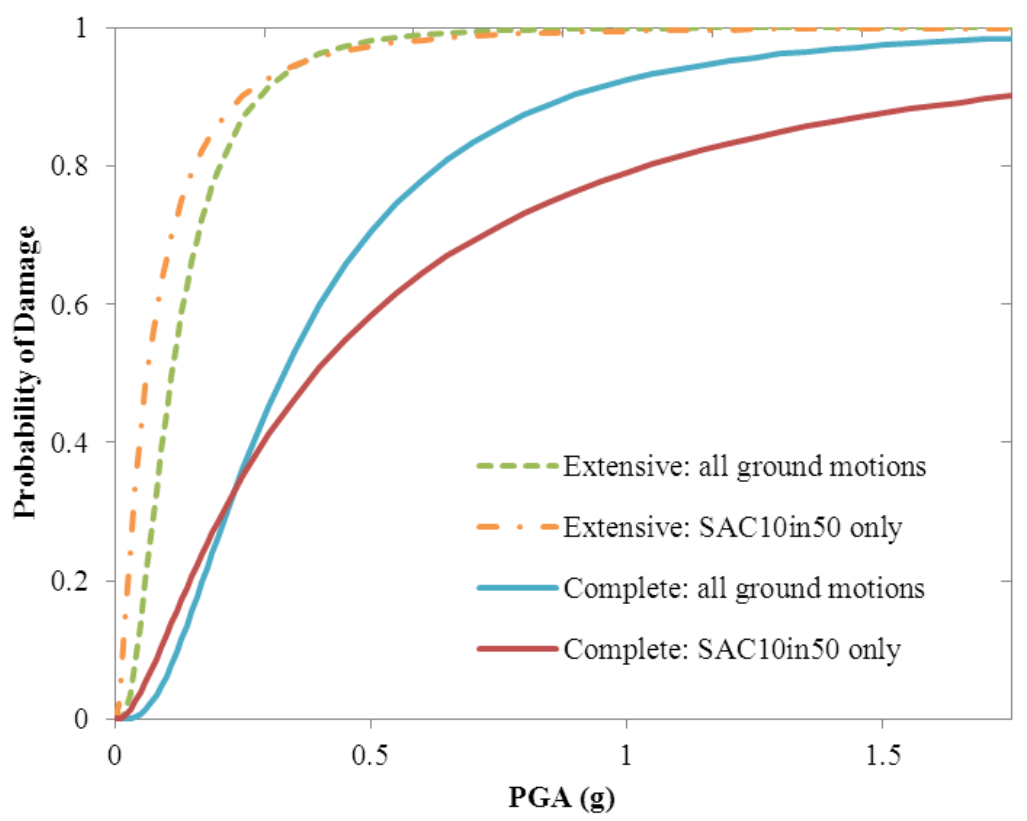

Figure 6.3: Complete and Extensive Damage Fragility Curve for Three-Span Bridge Suite Change

\subsubsection{EFFECT OF DECREASING THE NUMBER OF RUNS}

The original three-span model was evaluated using the entire ground-motion suite described in Section 2.2, with each ground-motion pair being applied in two orientations: the longitudinal and transverse directions, and then reversed to be applied in the transverse and longitudinal directions, resulting in a total of 40 runs. The data from this larger data set was then simplified to just include the runs which used the ground motions in first orientation, resulting in data from 20 runs being evaluated. The motivation in doing this was to justify using a reduced groundmotion suite, thus reducing computational time in half.

The median and dispersion values from this new, smaller data set are shown in Table 6.8, and the fragility curves for the extensive and complete damage states are shown in Figure 6.4.

Table 6.8: Fragility Medians Using Reduced Data Set

\begin{tabular}{l|c|c|c|c}
\hline \multirow{2}{*}{ Damage State } & \multicolumn{2}{|c|}{ Complete Suite } & \multicolumn{2}{c}{ Reduced Data Set } \\
\cline { 2 - 5 } & Median & Dispersion & Median & Dispersion \\
\hline Slight & 0.06 & 0.64 & 0.05 & 0.65 \\
\hline Moderate & 0.07 & 0.68 & 0.07 & 0.69 \\
\hline Extensive & 0.11 & 0.73 & 0.11 & 0.74 \\
\hline Complete & 0.33 & 0.78 & 0.33 & 0.79 \\
\hline
\end{tabular}




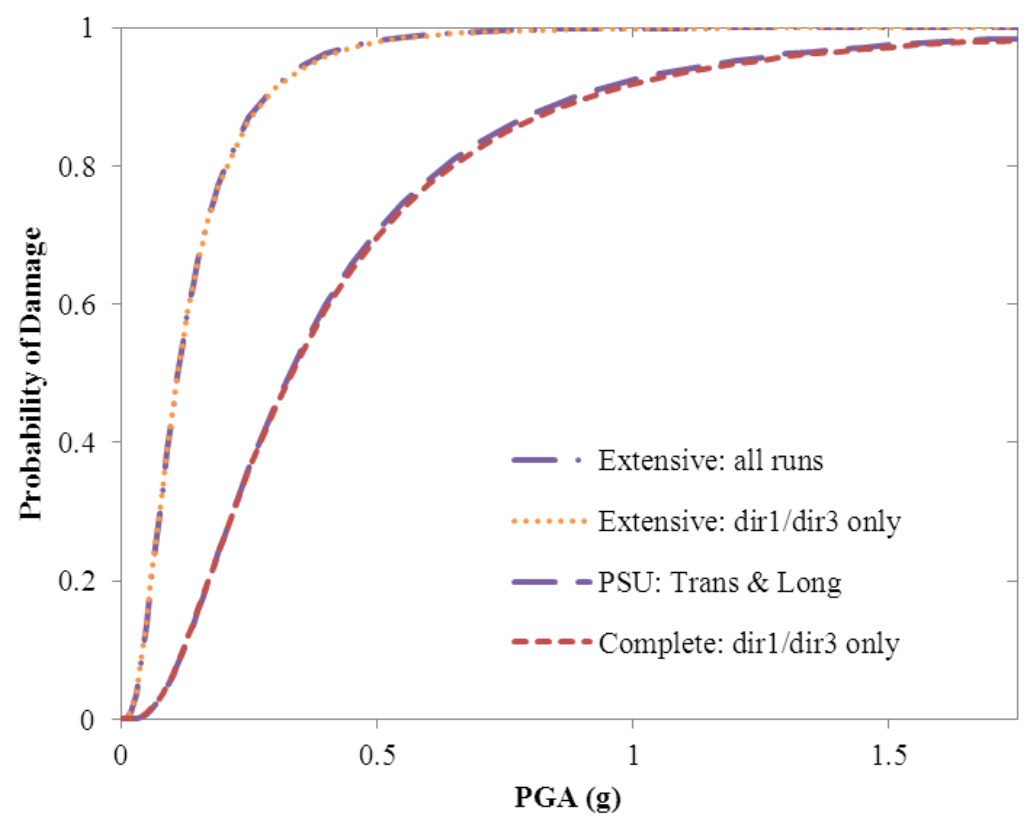

Figure 6.4: Complete and Extensive Damage Fragility Curves for Three-Span Bridge without Abutments

The results show that there is very little practical difference when comparing the results using the full data set to the smaller 20-run data set. Therefore, future models using the SAC groundmotion suite will only be applied in just one bi-directional orientation, without the groundmotion reversal.

\subsubsection{EFFECT OF GROUND-MOTION ORIENTATION}

The fragility curves presented in Section 6.3 were based upon ground motions being applied to the columns and abutments in the transverse and longitudinal directions. The ground-motion records were then modified using a transformation so that the direction of the ground motions were rotated $45^{\circ}$. The simple transformation used was:

$\left.\mid \begin{array}{l}x^{\prime} \\ y^{\prime}\end{array}\right]=\left|\begin{array}{cc}\cos \theta & -\sin \theta \\ \sin \theta & \cos \theta\end{array}\right|\left|\begin{array}{l}x \\ y\end{array}\right|$

where $\mathrm{x}$ and $\mathrm{y}$ are the transverse and longitudinal acceleration components, $\theta$ is the groundmotion rotation angle, and $\mathrm{x}^{\prime}$ and $\mathrm{y}^{\prime}$ are the transformed values.

The POE-10\%-in-50-years ground-motion suite was modified using this transformation for $\theta=$ $45^{\circ}$. The median and dispersion values using the rotated ground motions are shown in Table 6.9, and the fragility curves for the extensive and complete damage states are shown in Figure 6.5. 
For practical purposes, there was little effect on how the three-span bridge model reacted to rotated ground motions.

Table 6.9: Fragility Medians after Ground-Motion Rotation $\left(\theta=45^{\circ}\right)$ Using POE-10\%-in-50-Years Suite

\begin{tabular}{l|c|c|c|c}
\hline \multirow{2}{*}{ Damage State } & \multicolumn{2}{|c|}{ Without Rotation } & \multicolumn{2}{c}{ With $\mathbf{4 5}^{\circ}$ Rotation } \\
\cline { 2 - 5 } & Median & Dispersion & Median & Dispersion \\
\hline Slight & 0.02 & 0.90 & 0.03 & 0.81 \\
\hline Moderate & 0.03 & 0.98 & 0.04 & 0.89 \\
\hline Extensive & 0.06 & 1.07 & 0.07 & 0.97 \\
\hline Complete & 0.39 & 1.17 & 0.38 & 1.05 \\
\hline
\end{tabular}

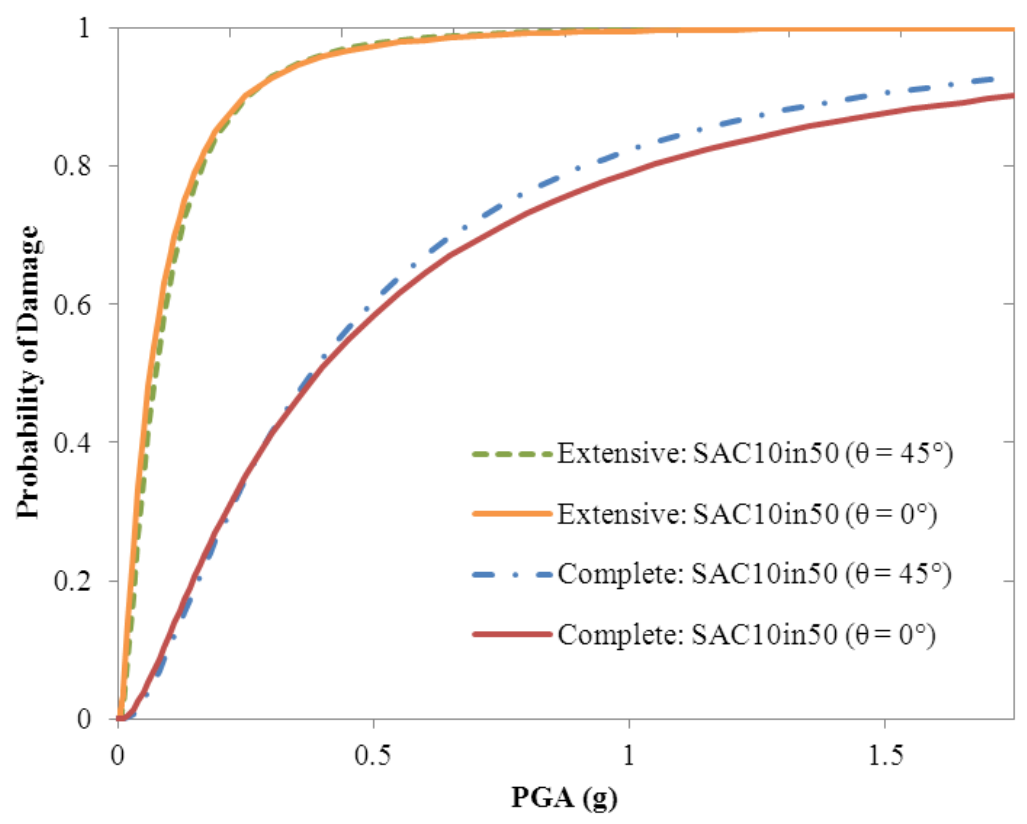

Figure 6.5: Complete and Extensive Damage Fragility Curves for Three-Span Using Rotated Ground-Motion Suite

\subsubsection{EFFECT OF CONCRETE CONFINEMENT RETROFIT}

The most common retrofit method used in California (Caltrans, 2010) is to encase the column with a steel jacket. The intent of this retrofit technique is to increase the confinement, which results in improving the flexural ductility of the column. The use of steel jacketing was originally developed for circular columns, but has been extended to include columns with square and rectangular cross sections (FHWA, 2006). Two steel plates are rolled to a radius equal to the column radius, or the diagonal of a square column, plus 0.5 to 1.0 inches for clearance. For a rectangular column, an oval jacket is used. After the vertical seams are welded, the gap between the column and the steel jacket is filled with grout. When working with rectangular columns with the larger space between the jacket and column, small aggregate is added to the grout. To prevent the jacket from bearing on the supporting member, such as the footing, at large drift angles a vertical gap of about two inches is usually used between the end of the jacket and the member. This technique is effective to increase confinement performance, but does not occur 
until the radial expansion of the concrete column induces circumferential stresses in the steel shell.

The minimum steel shell thickness can be estimated by using:

$$
t \geq \frac{f_{1} D}{58}(\text { in })
$$

where $\mathrm{f}_{l}$ is the confinement stress and $\mathrm{D}$ is the diameter of the column. $\mathrm{f}_{l}$ is assumed to be approximately 300 psi which is the value used (Chai et al., 1991) during the development of this method. The minimum steel jacket thickness was calculated to be 0.18 inches, suitable for the typical three-span bridge.

The value of $t_{: c}$, the ultimate confined concrete stress capacity, can be related to shell thickness (Caltrans, 2010):

$$
f_{t x}=f_{c}\left[-1.254+2.254 \sqrt{1-\frac{15.01 t_{s}}{D f_{s}}}-\frac{1 t f_{s}}{D f_{\mathrm{t}}}\right]
$$

where t: is the ultimate unconfined concrete stress capacity and $f_{s}$ is the stress induced in the steel jacket. Using $4.290 \mathrm{ksi}$ for the unconfined strength, and $36 \mathrm{ksi}$ for the stress induced in the steel jacket, t:c was found to be $6.448 \mathrm{ksi}$.

By equating the strain energy in the confined concrete to the strain energy in the confining steel jacket, the ultimate strains in the concrete based on the ultimate achievable strains in the confining steel can be found (Mander et al., 1988). Applying this principle to a circular steel shell of constant thickness results in the ultimate concrete strain capacity (Caltrans, 2010):

$$
\varepsilon_{c u}=0.004+\frac{3.6 t f_{y s z_{s a}}}{D f_{c z}}
$$

where $\mathrm{f}_{\mathrm{ys}}$ is the yield stress in the steel shell, $\varepsilon_{\mathrm{su}}$ is the ultimate strain in the steel shell, $\mathrm{D}$ is the diameter of the steel shell, and $\dot{t}: \mathrm{i}$ is the ultimate confined concrete stress capacity. The ultimate strain capacity was found to be $0.022 \mathrm{in} / \mathrm{in}$.

Using full-scale laboratory tests (Priestley et al., 1994a and Priestley et al., 1994b), the performance of as-built and retrofitted columns were tested. The columns were subjected to both lateral and axial loads. The as-built columns all displayed limited-ductile shear failures, followed by the rapid reduction of strength and stiffness. When retrofitted with steel jackets, the columns displayed an improved ductility, with capacities greater than or equal to $\mu_{\Delta}=8$. Also, the failure mode changed from predominantly shear failure for the as-built columns to predominately flexural deformation for the retrofitted columns.

Using these new concrete capacity values, the three-span OpenSees model was again used with the ground motions from the POE-of-10\%-in-50-years group.

The increased capacity from the steel jacket retrofit was then reflected in different capacity median, $C_{m}$, values used in Equation 5-9. The new values used were 3.1, 5.2, 7.2, and 8.3 for the 
slight, moderate, extreme and complete damage states, respectively. These were derived from the curvature ductility values used in Padgett 2007.

Using Equation 5-9 and the results from the OpenSees model, new fragility median and dispersion values were calculated. These are provided in Table 6.10. The new fragility curves are shown in figures Figure 6.6 and Figure 6.7.

Table 6.10: Fragility Medians after Steel Retrofit Using POE-10-in-50 Suite

\begin{tabular}{l|c|c|c|c}
\hline \multirow{2}{*}{ Damage State } & \multicolumn{2}{|c|}{ Without Retrofit } & \multicolumn{2}{c}{ With Retrofit } \\
\cline { 2 - 5 } & Median & Dispersion & Median & Dispersion \\
\hline Slight & 0.02 & 0.90 & 0.11 & 0.83 \\
\hline Moderate & 0.03 & 0.98 & 0.26 & 0.90 \\
\hline Extensive & 0.06 & 1.07 & 0.45 & 0.98 \\
\hline Complete & 0.39 & 1.17 & 0.57 & 1.07 \\
\hline
\end{tabular}

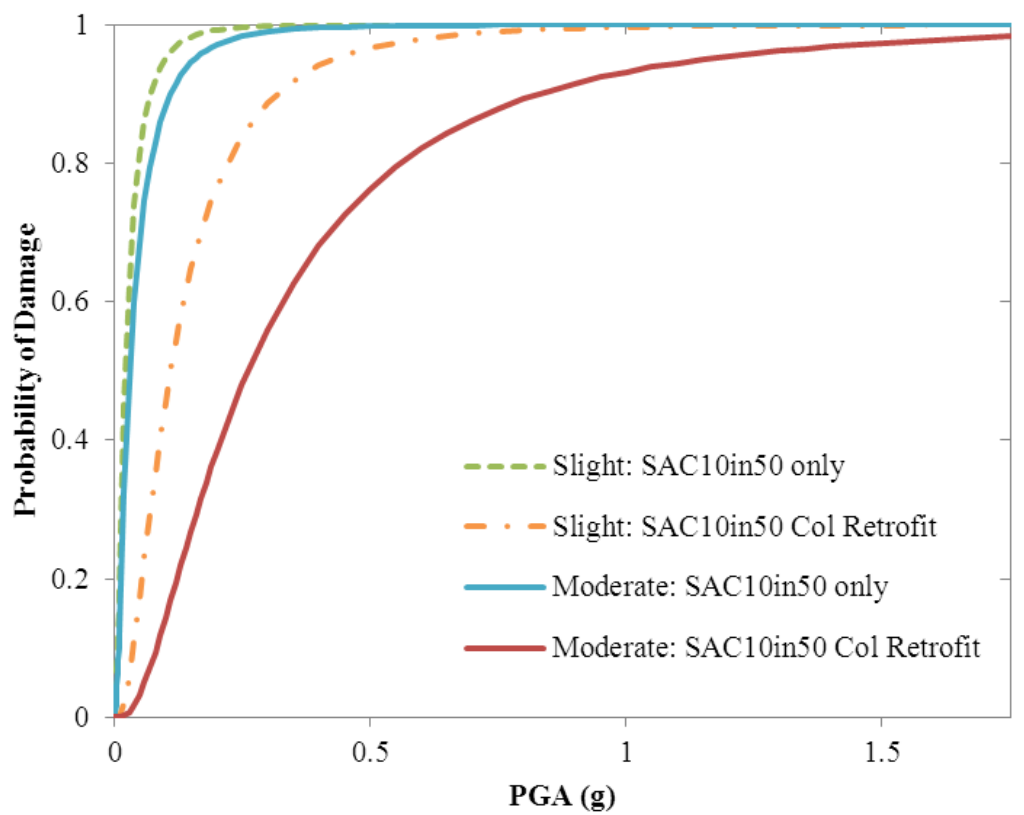

Figure 6.6: Slight and Moderate Damage Fragility Curves for Three-Span Using Retrofitted Columns 


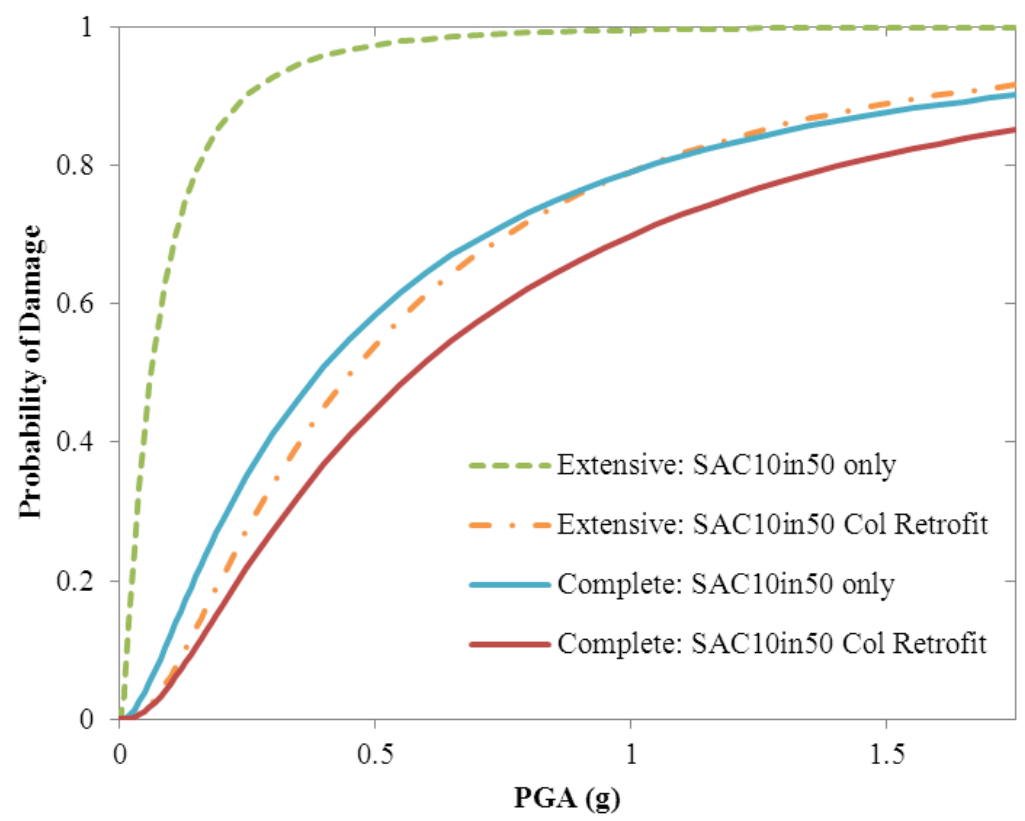

Figure 6.7: Extensive and Complete Damage Fragility Curves for Three-Span Using Retrofitted Columns

The medians for the slight, moderate and extensive damage states experienced the greatest improvement when using retrofitted columns, with improvements ranging from five times to almost nine times. The dispersion values decreased slightly, which were expected since the displacements experienced by the columns decreased with the retrofit jackets.

\subsection{FIVE-SPAN BRIDGE FRAGILITY CURVES}

The original five-span model was evaluated using the entire ground-motion suite described in Section 2.2, with each ground-motion pair being applied in the manner described in Section 6.3.3. This resulted in a total of 20 runs with the model resulting in column displacement data. Using this data and Equation 5-9, the following median and dispersion values were calculated for the five-span bridge and are provided in Table 6.11. The fragility curves are shown in Figure 6.8 .

Table 6.11: Fragility Curves Values for Typical Five-Span Bridge

\begin{tabular}{l|l|l}
\hline Damage State & Median & Dispersion \\
\hline Slight & 0.08 & 0.70 \\
\hline Moderate & 0.10 & 0.74 \\
\hline Extensive & 0.16 & 0.79 \\
\hline Complete & 0.51 & 0.84 \\
\hline
\end{tabular}


These median values indicate that the five-span bridge is somewhat less fragile when compared to the three-span bridge model (reduced data set in Table 6.6). The dispersions are very similar, so comparison of the fragility curves is appropriate.

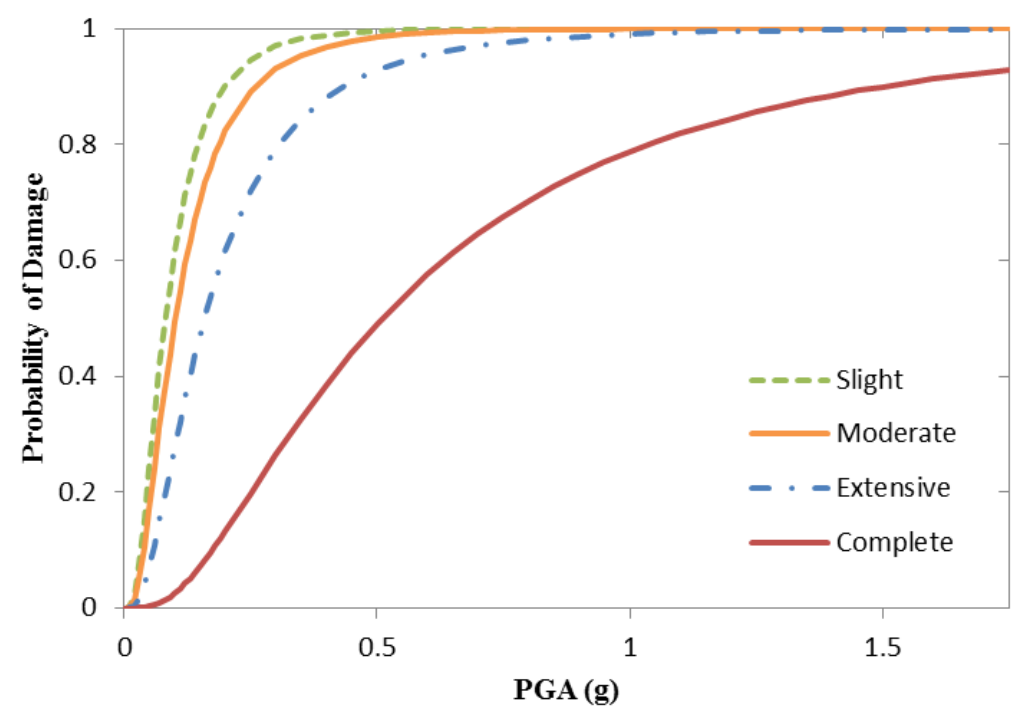

Figure 6.8: Fragility Curves for Five-Span Bridge 


\subsection{DISCUSSION AND CONCLUSIONS}

All bridges in Oregon vary in length, width, materials, site conditions and general design. This means that each bridge may react differently when exposed to a given earthquake. Prior to the 1970s, minimal consideration was given to seismic loads in the Northwest. Because of increased awareness, bridges designed after the 1980s have a lower risk of experiencing damage from a moderate to large earthquake compared to those bridges designed before 1980. However, much of the interstate highway system in the Pacific Northwest was designed in the mid- to late 1960s. Therefore, there are a large number of bridges that have minimal seismic resistance.

As stated in Chapter 5, ground-motion intensity was used in this study as a representation of structural demand. Two sets of ground motions were used which were developed for the Seattle area by the SAC Joint Venture. The suites are a combination of actual and synthetic ground motions, in which the first is a collection of ground motions having a probability of exceedance (POE) of $2 \%$ in 50 years and the second having a POE of $10 \%$ in 50 years. Using the two separate suites allowed the development of distinct fragility curves based upon suite. By assuming that each suite was equally important, the combined effects of both suites were also used to develop aggregate fragility curves. This study determined that the ground-motion suite, with overall PGA values ranging from $0.13 \mathrm{~g}$ to $1.7 \mathrm{~g}$, had a significant effect on the developed fragility curves.

The two parts of the fragility concept are capacity and demand, where the damage states of a structure can be considered to be related to structural capacity and the ground-motion intensity is a representation of structural demand. Numerous researchers have investigated the use of fragility curves to describe the vulnerability to seismic loading. This study used the more precise but more costly method, in terms of computation time, of nonlinear time-history analysis.

The other requisite to developing fragility curves of a structure is the ability to model the capacity of that structure. To do this, an inventory of a subset of Oregon bridges was made, from which a typical three-span and five-span bridge was identified using average attributes. Using these attributes, the two bridge types were modeled as spine models, focusing only on Oregon bridges designed prior to 1960. The continuous concrete bridge type was found to be the most common type for both three-span and five-span bridges. The intent was to quantify the vulnerability of these older, but common, Oregon bridge types. The bridges were then analyzed using the research-oriented finite element program called OpenSees.

The finite element models assumed that the bridge deck would behave elastically, and the columns would behave inelastically. Because of the expected inelastic behavior the columns were modeled using the OpenSees beamWithHinges element. This specialized element considers plasticity to be concentrated over specified hinge lengths at the element ends. In this study, the plastic hinge position was assumed to be located at $10 \%$ of the column lengths, which agrees well to available predictive equations. 
The abutment-soil interaction was modeled using a gap element which allows for the specification of a gap between the abutment and soil. When a sufficient amount of movement is experienced, a linear spring then applies a compressive load to the abutment. With the original model, which included both longitudinal and transverse abutment-soil interactions, the fragility medians for the typical three-span bridge were found to be $0.06 \mathrm{~g}, 0.07 \mathrm{~g}, 0.11 \mathrm{~g}$, and $0.33 \mathrm{~g}$ for the slight, moderate, extensive and complete damage states, respectively. For the five-span typical bridge, the fragility medians were found to be near $0.08 \mathrm{~g}, 0.10 \mathrm{~g}, 0.16 \mathrm{~g}$, and $0.51 \mathrm{~g}$ for the slight, moderate, extensive and complete damage states, respectively. When compared to predicted values from other researchers, these median values are very low, for both types of bridges. This can be predicted by looking at the relative sizes of the columns typically considered from other studies. In these studies, a common circular column diameter was 36 inches, which translates to an area moment of inertia of 82,406 in ${ }^{4}$. For both Oregon typical bridges, the square columns had a side length of 24 inches, which translates to an area moment of inertia of 27,648 $\mathrm{in}^{4}$. Given two equal bridges, but with the first with the larger moment of inertia for its columns, and the second bridge with the smaller inertia for its columns, the first bridge would have an initial stiffness of about three times of the second. If the two bridges weren't equal, where the first bridge had four columns per bent and the second still had the original three columns per bent, then the first bridge would have an initial stiffness of about five times of the second. In both of these cases, the bridge with the larger columns would displace less, especially before extensive cracking occurred, and would therefore experience less damage if subjected to a given ground motion. The smaller displacements would translate to larger fragility medians.

If the columns for the typical Oregon bridges were made larger, with the accordingly larger moment of inertia, what would be the impact? This can be estimated by calculating the period of a single degree of freedom system with the same mass as the three-span bridge, but with an increase of stiffness by a factor of five. This calculation results in a reduction of period of about $55 \%$, or a period of 0.35 seconds. Using the response spectrums from Section 2, the maximum displacements would be estimated to decrease by about 79\%. The fragility medians, when using the estimated reduced displacements, were found to be $0.32 \mathrm{~g}, 0.40 \mathrm{~g}, 0.61$, and $1.83 \mathrm{~g}$ for the slight, moderate, extensive and complete damage states, respectively. Thus, the estimated reduction in displacements yields significantly larger fragility medians. When compared to results from Nielson (2007) and HAZUS, there is still disagreement. In all cases except for the complete damage state, the modified three-span medians were less (50-60\%) than those predicted by HAZUS. For the complete damage state, the modified median was almost $10 \%$ greater than that predicted by HAZUS. For all damage states, the modified medians were closer to HAZUS values compared to the non-modified medians. But, in general, HAZUS still underestimates the fragility for the bridges considered in this study.

Several iterations were run where the three-span model was modified with the soil-abutment influence removed in both the longitudinal and transverse directions, and then removed only in the transverse direction. When all soil-abutment interaction was removed, the fragility medians were decreased, in most cases, by at least 50\%. This means that the likelihood of damage was significantly increased. For example, at a ground motion PGA of $0.25 \mathrm{~g}$, the probability of complete damage is $36 \%$ when taking into account the effect of the soil-abutment interaction in both directions, and $64 \%$ without taking into account the interaction. When the transverse soilabutment interaction was removed, the fragility medians were decreased, in most cases, by at 
least $36 \%$. This illustrates that the transverse soil-abutment interaction had the most influence on the degree of bridge damage. This also indicates the importance of abutment wing-walls (or other methods such as shear keys) for restricting transverse movement to improve the resiliency of bridges that are exposed to seismic loads.

Several other changes were made to how the original three-span bridge model was analyzed. The first was to determine the effect of individual ground-motion suites. The full suite included actual and synthetic ground motions that have probabilities of exceedance of both $2 \%$ and $10 \%$ in 50 years. The second suite only included ground motions having a POE of $10 \%$ in 50 years. Using Peak Ground Acceleration (PGA) as the measure of demand usually results in a larger spread in the displacement data set, or data dispersion. This means that a larger data set is necessary in order to reduce its dispersion. This is confirmed by the model results, since the dispersion values for all damage states significantly increased by at least $40 \%$. The fragility medians decreased, except the median for the complete damage state, which increased by $18 \%$. However, since the smaller suite resulted in a larger set of dispersions, either the suite size should be increased, or another measure of demand should be considered, such as spectral acceleration.

A second change was to decrease the number of runs applied to the three-span model. The original test scheme used the ground motions applied in the longitudinal and transverse directions, and then reversed to be applied in the transverse and longitudinal directions. To reduce the number of runs, the set of runs which used the reverse ground motions were not used in the analysis. The result of this was that both the dispersions and fragility medians, for all damage states, were changed very little. For future modeling, the extra runs can be removed, resulting in a large time savings.

The third change was to vary the orientation of the ground motions applied to the three-span model. The original model called for the ground motions to be applied in the longitudinal and transverse directions. This was changed so that the ground motions were applied at an angle $45^{\circ}$ from the longitudinal axis. This change, however, produced very little impact upon the fragility medians.

A single change was made to the three-span model itself, which was to model a column retrofit. The retrofit consisted of a circular steel jacket mounted along the length of the column. The space between the steel jacket and the existing column was assumed to be filled with a small aggregate and grout. The intent of this retrofit is to improve the ductility of the column by increasing the confinement experienced by the concrete. This increase of confinement is modeled by increasing the maximum strength of the concrete. In addition to the model change, the displacement ductility at which damage occurs is also assumed to increase. These two changes resulted in a significant increase of fragility medians. The fragility medians increased, at least by a factor of 4.5 , for the slight, moderate and extensive damage states. The median increased by $46 \%$ for the complete damage state. The largest increase in fragility median occurs with the moderate damage state. This corresponds with the largest increase in $\mathrm{C}_{m}$ value (the assumed median value of the capacity distribution), which also occurs with the moderate damage state. Therefore, the results are highly dependent upon the improvement of ductility resulting from the physical retrofit, which was reflected by the larger $\mathrm{C}_{m}$ values. 
The final stage of this study was to model a typical Oregon five-span bridge. The same methodology used with the three-span model was used with the five-span bridge. The fragility medians found were similar in scale as those found for the three-span bridge. All of the medians are relatively low, with the medians for the slight, moderate and extensive damage states being almost 50\% greater than of those for the three-span bridge. Although the medians were larger, the fact that they are relatively low still points to the relative fragility of the typical five-span bridge.

In general, the results of this study show that the typical three-span and five-span bridges found in Oregon are relatively fragile structures. The results from other researchers and HAZUS underestimate bride fragility in these types of bridges. HAZUS deviates from the methods used in this study in two important aspects. The first is that a static analysis procedure was used when modeling the bridges, versus a time-dependent procedure. The second is that multiple bridge types are aggregated into more generalized and all-encompassing bridge classes. This will make the HAZUS results less applicable to specific bridge subclasses.

Other numerical models used for other U.S. regions have used relatively large column cross sections, which will dramatically change the magnitude of displacements seen by the columns, directly affecting the fragility medians. Also, other models have included soil interactions at the column bases in addition to including bearings in the model. Previous research has found that changing parameters relating to the coefficient of friction values for elastomeric pads and the initial stiffness of foundations may have minimal impact (Padgett, 2007) on the behavior of a multi-span continuous concrete bridge. This may also imply that disregarding these design features may also have minimal impact.

Several assumptions made during this study could potentially impact the fragility results. The first set of assumptions all pertain to the values used when calculating the probability of failure (Equation 5-9). The median values of the capacity distribution $\left(\mathrm{C}_{m}\right)$ were all derived using results from previous research. Although this previous research involved actual test specimens, for both non-retrofitted and retrofitted columns, the tests consisted of relatively small numbers of specimens. The amount of deviation, and whether the results pertain directly to the columns found in the typical Oregon bridge, is unknown. Additionally, the coefficient of variation (COV) for the capacity distribution was also assumed. Although the COV values used in this study ranged from 0.25 to 0.50 , which lie within reasonable bounds for physical processes, the values were still somewhat arbitrary.

The final point to be stressed is to highlight the relative fragility of the bridges considered in this study. Retrofitting the columns with a steel jacket to increase concrete confinement significantly improved the performance of the columns. Without the retrofit measure, the columns were very susceptible to damage, experiencing slight to extensive damage at very low levels of ground motion. 


\subsection{FUTURE WORK}

The ability to model specific types of Oregon bridges was the primary outcome of this study. Some extensions of this work would be very beneficial and are summarized below.

1. The major assumption was regarding the hysteretic behavior of the sections typical to Oregon. The primary response used in the current study was displacement ductility demand of the structure columns. In order to calibrate and fully evaluate the model, several large-scale tests should be conducted to obtain actual response data of a typical column. These results could also be compared to another column retrofitted.

2. Numerous assumptions were made when defining the OpenSees models. The values used to define the hysteretic behavior of the reinforcing steel were designed to result in very simple behavior of the steel. Studies should be performed to vary the hysteretic behavior of the steel, in addition to other properties used in the model.

3. While each major portion of this study was implemented with either $t c l$ or MATLAB scripts, the scripts currently must be executed individually. These individual scripts should be combined in a manner such that incorporation into the Oregon transportation seismic hazard model, that is currently being developed, is possible.

4. The models in this study assumed that the ground motion was directly applied to the abutments and column bases. Soil and liquefaction effects should be incorporated into the models, which would result in a more realistic representation of demand on the structures.

5. The run time of each OpenSees model, using a given pair of ground motion records, was on the magnitude of several hours to a day. The models should be simplified, possibly by reducing the number of nonlinear elements used, in order to reduce run times.

6. Other types of bridges (e.g., steel, pre-stressed R/C, curved superstructure) should be modeled and investigated. This could also include more modern designs currently being used in Oregon.

7. Data from the Loma Prieta and Northridge earthquakes imply that high bridge skew has an effect on damage levels (Basoz et al., 1998). Bridge skew is accounted for in the HAZUS-HM technical manual by using modification factors applied to fragility medians. The current model should be modified to account for bridge skew, and the model output could then be compared to the effect of the HAZUS modification factors.

8. The OpenSees models should be extended to include the use of various types of bearings. 
9. The uncertainty of specific material parameters (e.g., steel strength) was ignored in the current models. There have been studies that show that these parameters hold to various distributions with known means and deviations. This information should be integrated into the OpenSees models. 


\subsection{REFERENCES}

AASHTO (2009). AASHTO LRFD Bridge Design Specifications. American Association of State Highway and Transportations Officieals, Washington, D.C.

Atwater, B.F., Nelson, A.R., Clague, J.J., Carver, G.A., Yamaguchi, D.K., Bobrowsky, P.T., Bourgeois, J., Darienzo, M.E., Grant, W.C., Hemphill-Haley, E., Kelsey, H.M., Jacoby, G.C., Nishenko, S.P., Palmer, S.P., Peterson, C.D., and Reinhart, M.A. (1995). "Summary of coastal geologic evidence for past great earthquakes at the Cascadia subduction zone." Earthquake Spectra, 11, 1-18.

Basoz N. and Kiremidjian A. (1998), "Evaluation of Bridge Damage Data from the Loma Prieta and Northridge, California Earthquakes". Report MCEER-98-0004, University at Buffalo, State University at New York.

Caltrans (2006). Caltrans Seismic Design Criteria. California Department of Transportation, Sacramento, CA, Version 1.4.

Caltrans (2010). Earthquake Retrofit Guidelines for Bridges Memo to Designers 20-4.

California Department of Transportations, Sacramento, CA.

Chai, Y.H., Priestley, M.J.N., and Seible, F., 1991, Flexural Retrofit of Circular Reinforced Concrete Bridge Columns by Steel Jackets," Report Number SSRP-91/06, Department of Applied Mechanics and Engineering Sciences, University of California, San Diego.

Chopra, A. K. (2007). Dynamics of Structures, 167-170. Pearson, third edition.

Cornell, A. C., Jalayer, F., Hamburger, R. O., and Foutch, D. A. (2002). "Probabilistic Basis for 2000 SAC Federal Emergency Management Agency Steel Moment Frame Guidelines.” Journal of Structural Engineering, 128(4), 526-533.

Ellingwood, B. R. and Wen, Y.-K. (2005). "Risk-Benefit-Based Design Decisions for LowProbability/High Consequence Earthquake Events in Mid-America." Progress in Structural Engineering and Materials, 7(2), 56-70.

FEMA (2003). HAZUS-MH MR3: Technical Manual, Vol. Earthquake Model. Federal Emergency Management Agency, Washington DC.

FHWA (1995). Recording and Coding Guide for the Structure Inventory and Appraisal of the Nation's Bridges: Report No. FHWA-PD-96-001, Federal Highway Administration, Washington DC.

FHWA (1995). Seismic Retrofitting Manual for Highway Bridges, FHWA-RD-94-052. Office of Engineering and Highway Operations R\&D, Federal Highway Administration, McLean, VA. 
FHWA (2004). "Nation Bridge Inspection Standards." Title 23 Code of Federal Regulations, Highways, Section 650.311, http://ecfr.gpoaccess.gov (accessed October 12, 2010).

FHWA (2006). Seismic Retrofitting Manual for Highway Structures: Part I - Bridges, FHWAHRT-06-032. Office of Engineering and Highway Operations R\&D, Federal Highway Administration, McLean, VA.

Filliben J. J., Gurley K., Pinelli, J. P. and Simiu E. "Fragility Curves, damage matrices, and wind induced loss estimation". Proceedings from the Third International Conference on Computer Simulation in Risk Analysis and Hazard Mitigation, June 19-21, 2002, Sintra, Portugal, 119-126.

Heaton, T. H. and Hartzell, S. H. (1987). "Earthquake Hazards on the Cascadia Subduction Zone." Science, 236, 162-168.

Hwang, H., Liu, J.B., and Chiu, Y.H. (2000). "Seismic Fragility Analysis of Highway Bridges." Report No. MAEC RR-4, Center for Earthquake Research Information.

Hwang, H., Liu, J.B., and Chiu, Y.H. (2001). "Seismic Fragility Analysis of Highway Bridges.” Report No. MAEC RR-4, Mid-America Earthquake Center.

Limpert E., Stahel W. and Abbt M. (2001). "Log-normal Distributions across the Sciences: Keys and Clues." BioScience, 51(5), 341-352.

Ludwin, R.S., A.I. Qamar, S.D. Malone, R.S. Crosson, S. Moran, G,C. Thomas, and W.P. Steele. 1996, Scotts Mills Earthquake Summary, http://www.pnsn.org/SEIS/EQ Special/ScottsMills/scottsmills.html (accessed December 30, 2010).

Mander, J. B., Priestley M. J. N., Park R. (1988). "Theoretical Stress-Strain Model for Confined Concrete." Journal of Structural Engineering, 114(8), 1804-1826.

Mander, J. B. (1999). Fragility Curve Development for Assessing the Seismic Vulnerability of Highway Bridges, Research Progress and Accomplishments: 1997-1999, Multidisciplinary Center for Earthquake Engineering Research, Buffalo, NY.

Mander, J. B., Kim, D. K., Chen, S. S., and Premus, G. J. (1996). "Response of Steel Bridge Bearings to the Reversed Cyclic Loading." Report No. NCEER 96-0014, NCEER.

Melchers, R. E. (1999). Structural Reliability Analysis and Prediction. John Wiley \& Sons Ltd., West Sussex, England, second edition.

Nielson, B. (2005). "Analytical Fragility Curves for Highway Bridges in Moderate Seismic Zones," PhD thesis, Georgia Institute of Technology.

Nowak, A. S. and Collins, K. R. (2000). Reliability of Structures. McGraw-Hill Company, Boston, MA. 
Open System for Earthquake Engineering Simulation, The Open System for Earthquake

Engineering Simulation Online, http://opensees.berkeley.edu/ (accessed December 30, 2010).

Oregon Coastal Management Program, Types of Coastal Hazards, http://www.oregon.gov/LCD/OCMP/ShorHaz_HazType.shtml (accessed December 30, 2010).

Pacific Earthquake Engineering Research Center, Structural Performance Database, http://www.ce.washington.edu/ peera1/ (accessed December 30, 2010).

Padgett, J. (2007). "Seismic Vulnerability Assessment of Retrofitted Bridges Using Probabilistic Methods," PhD thesis, Georgia Institute of Technology.

Porter, K., Kennedy R. and Bachman R. (2007). "Creating Fragility Functions for PerformanceBased Earthquake Engineering." Earthquake Spectra, 23, 471-489.

Priestley, M. J. N., Seible, F., Xiao, Y., and Verma, R. (1994a). "Steel Jacket Retrofitting of Reinforced Concrete Bridge Columns for Enhanced Shear Strength-Part 1: Theoretical Considerations and Test Design.” ACI Structural Journal, 91(4), 394-405.

Priestley, M. J. N., Seible, F., Xiao, Y., and Verma, R. (1994b). "Steel Jacket Retrofitting of Reinforced Concrete Bridge Columns for Enhanced Shear Strength-Part 2: Test Results and Comparison with Theory." ACI Structural Journal, 91(5), 537-551.

SAC, Develop Suite of Time Histories - SAC Venture Steel Project Phase 2 Task 5.4.1, http://nisee.berkeley.edu/data/strong motion/sacsteel/draftreport.html (accessed December 30, 2010).

Saxena, V., Deodatis G., Shinozuka M., Feng M. Q. (2000). Development of Fragility Curves for Multi-Span Reinforced Concrete Bridges. Proceedings of the International Conference on Monte Carlo Simulation. Principality of Monaco.

United States Geological Survey, Historic United States Earthquakes Online, http://earthquake.usgs.gov/regional/states/historical_mag.php/ (accessed: December 30, 2010).

Wen Y. K., Ellingwood B. R., Veneziano D., and Bracci J. (2003), “Uncertainty Modeling in Earthquake Engineering”. MAE Center Project FD-2 Report, Mid-America Earthquake Center, University of Illinois at Urbana-Champagne.

Werner S. D., Taylor C. E., Cho S., Lavoie J-P., Huyck C., Eitzel C., Chung H. and R.T. Eguchi R. T. (2006), "REDARS 2 Methodology and Software for Seismic Risk Analysis of Highway Systems". Report MCEER-06-SP08, University at Buffalo, State University at New York. 


\subsection{APPENDICES}

The OpenSees tcl files used in this study were separated into three broad categories. The first was the geometry file, which defines the geometry, boundary conditions, and nodal masses used in the model. The second file defines all of the gravity loads being applied to each node. The third file applies the ground motion to the appropriate nodes.

\subsection{OPENSEES SCRIPT FOR THREE-SPAN GEOMETRY}

source units.tcl;

\#

\# Define the properties of a generic elastic rigid element.

\# These values are only used for the abutment elements. RigidLink elements

\# are used elsewhere, but eigenvalues couldn't be found when using them for

\# the abutments. The reason is unknown, but the large values should work for

\# the abutments.

\#

set ge_A 1.E8;

set ge E 1.e10;

set ge_G 1.e10;

set ge_J 1.e10;

set ge_Iy 1.e10;

set ge_Iz 1.e10;

set S1 432.0; \# length of span 1

set S2 576.0; \# length of span 2

set S3 432.0; \# length of span 3

\#

\# Bent 1 Nodes/Masses

\#

node $100 \quad 0.000 \quad 277.850 \quad 0.000$;

node $101 \quad 0.000 \quad 277.850 \quad 99.750$;

node $102 \quad 0.000 \quad 277.850 \quad 199.500$;

node $103 \quad 0.000 \quad 277.850 \quad 299.250$;

node $104 \quad 0.000 \quad 277.850 \quad 399.000$;

mass $100 \quad 0.01207100 .01207100 .01207100 .00 .00 .0$;

set mass 1000.0120710

mass $101 \quad 0.02414200 .02414200 .02414200 .00 .00 .0$;

set mass101 0.0241420;

mass $102 \quad 0.02414200 .02414200 .02414200 .00 .00 .0$;

set mass102 0.0241420;

mass $103 \quad 0.02414200 .02414200 .02414200 .00 .00 .0$; 
set mass103 0.0241420;

mass $104 \quad 0.01207100 .01207100 .01207100 .00 .00 .0$;

set mass 1040.0120710

fix 1000100000 ;

fix 1010100000 ;

fix 102010000 ;

fix 103010000 ;

fix 104010000 ;

equalDOF 10011 ;

equalDOF 10023 ;

equalDOF 10133 ;

equalDOF 10243 ;

equalDOF 10353 ;

equalDOF 10463 ;

equalDOF 1047 ;

\#

\# A1 Longitudinal Nodes used with zeroLength elements

\#

node $2 \quad 0.000 \quad 277.850 \quad 0.000$;

node $3 \quad 0.000 \quad 277.850 \quad 99.750$;

node $4 \quad 0.000 \quad 277.850 \quad 199.500$;

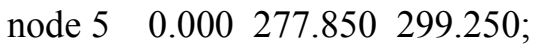

node $6 \quad 0.000 \quad 277.850 \quad 399.000$;

fix 21110111 ;

fix 31110111 ;

fix 411101111 ;

fix 5111010111 ;

fix 6110111 ;

\#

\# A1 Transverse Nodes used with zeroLength elements

\#

$\begin{array}{lllll}\text { node } & 1 & 0.000 & 277.850 & 0.000 ;\end{array}$

node $7 \quad 0.000 \quad 277.850 \quad 399.000$

fix 100111111 ;

fix 7011111 ;

\#

\# B2 Bent Nodes/Masses

\#

node $200432.000 \quad 290.250 \quad 0.000$;

node $201 \quad 432.000 \quad 290.250 \quad 63.500$;

node $202432.000 \quad 290.250 \quad 131.500$;

node $203432.000 \quad 290.250 \quad 199.500$;

node $204432.000 \quad 290.250 \quad 267.500$;

node $205432.000 \quad 290.250 \quad 335.500$;

node $206432.000 \quad 290.250 \quad 399.000$;

mass $200 \quad 0.00677240 .00677240 .00677240 .00 .00 .0$; set mass200 0.0067724;

mass $201 \quad 0.01402480 .01402480 .01402480 .00 .00 .0$; 
set mass201 0.0140248;

mass $202 \quad 0.01450470 .01450470 .01450470 .00 .00 .0$;

set mass202 0.0145047;

mass $203 \quad 0.01450470 .01450470 .01450470 .00 .00 .0$;

set mass203 0.0145047;

mass $204 \quad 0.01450470 .01450470 .01450470 .00 .00 .0$; set mass204 0.0145047;

mass $205 \quad 0.01402480 .01402480 .01402480 .00 .00 .0$; set mass205 0.0140248;

mass $206 \quad 0.00677240 .00677240 .00677240 .00 .00 .0$; set mass206 0.0067724;

\#

\# B3 Bent Nodes/Masses

\#

node $3001008.000 \quad 290.250 \quad 0.000$;

node $3011008.000 \quad 290.250 \quad 63.500$;

node 3021008.000290 .250131 .500 ;

node $3031008.000 \quad 290.250 \quad 199.500$;

node $3041008.000290 .250 \quad 267.500$;

node $3051008.000 \quad 290.250335 .500$;

node $3061008.000 \quad 290.250 \quad 399.000$;

mass $300 \quad 0.00677240 .00677240 .00677240 .00 .00 .0$; set mass 300 0.0067724;

mass 3010.01402480 .01402480 .01402480 .00 .00 .0 ; set mass301 0.0140248;

mass $302 \quad 0.01450470 .01450470 .01450470 .00 .00 .0$; set mass302 0.0145047;

mass $303 \quad 0.01450470 .01450470 .01450470 .00 .00 .0$; set mass303 0.0145047;

mass $304 \quad 0.01450470 .01450470 .01450470 .00 .00 .0$; set mass304 0.0145047;

mass $305 \quad 0.01402480 .01402480 .01402480 .00 .00 .0$; set mass305 0.0140248;

mass $306 \quad 0.00677240 .00677240 .00677240 .00 .00 .0$; set mass306 0.0067724;

$\#$

\# Bent 4 Nodes/Masses

\#

node $4001440.000277 .850 \quad 0.000$;

node $401 \quad 1440.000 \quad 277.850 \quad 99.750$;

node $4021440.000 \quad 277.850 \quad 199.500$;

node $4031440.000 \quad 277.850 \quad 299.250$;

node $4041440.000277 .850 \quad 399.000$;

mass $400 \quad 0.0120710 .01207100 .01207100 .00 .00 .0$; set mass400 0.0120710;

mass $401 \quad 0.0241420 .02414200 .02414200 .00 .00 .0$; set mass401 0.0241420;

mass $402 \quad 0.0241420 .02414200 .02414200 .00 .00 .0$; set mass402 0.0241420; 


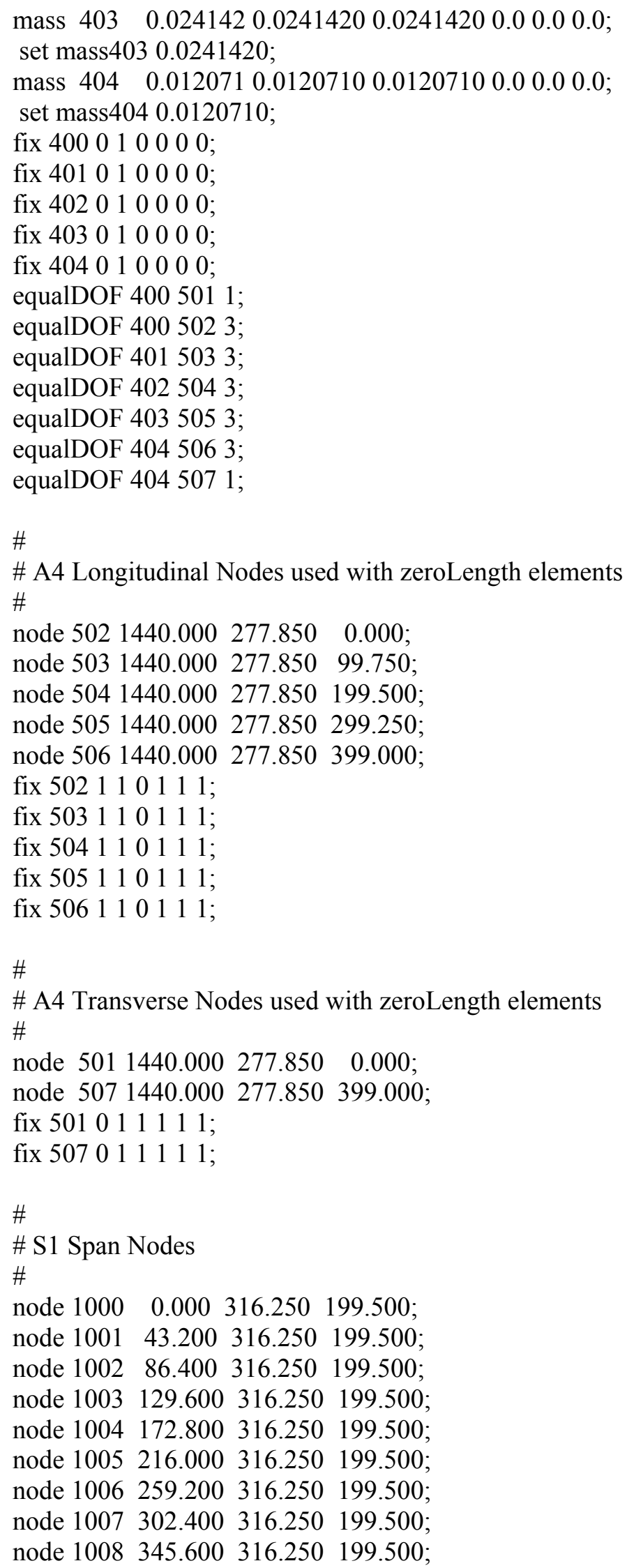


node $1009388.800316 .250 \quad 199.500$;

mass $1000 \quad 0.0211220 .02112200 .02112200 .00 .00 .0$; set mass 1000 0.0211220;

mass $1001 \quad 0.0422440 .04224400 .04224400 .00 .00 .0$; set mass 10010.0422440 ;

mass $1002 \quad 0.0422440 .04224400 .04224400 .00 .00 .0$; set mass 1002 0.0422440;

mass $1003 \quad 0.0422440 .04224400 .04224400 .00 .00 .0$; set mass 10030.0422440 ;

mass $1004 \quad 0.0422440 .04224400 .04224400 .00 .00 .0$; set mass 10040.0422440 ;

mass $1005 \quad 0.0422440 .04224400 .04224400 .00 .00 .0$; set mass 10050.0422440 ;

mass $1006 \quad 0.0422440 .04224400 .04224400 .00 .00 .0$; set mass 10060.0422440 ;

mass $1007 \quad 0.0422440 .04224400 .04224400 .00 .00 .0$; set mass 10070.0422440 ;

mass $1008 \quad 0.0422440 .04224400 .04224400 .00 .00 .0$; set mass 10080.0422440 ;

mass $1009 \quad 0.0422440 .04224400 .04224400 .00 .00 .0$; set mass 10090.0422440 ;

\#

\# S2 Span Nodes

\#

node $2000 \quad 432.000 \quad 316.250 \quad 199.500$;

node $2001 \quad 489.600 \quad 316.250 \quad 199.500$;

node $2002 \quad 547.200 \quad 316.250 \quad 199.500$;

node $2003 \quad 604.800 \quad 316.250 \quad 199.500$;

node $2004 \quad 662.400 \quad 316.250 \quad 199.500$;

node $2005720.000 \quad 316.250 \quad 199.500$;

node $2006777.600 \quad 316.250 \quad 199.500$;

node $2007 \quad 835.200 \quad 316.250 \quad 199.500$;

node $2008 \quad 892.800 \quad 316.250 \quad 199.500$;

node $2009 \quad 950.400 \quad 316.250 \quad 199.500$;

mass $2000 \quad 0.0492840 .04928400 .04928400 .00 .00 .0$; set mass2000 0.0492840;

mass $2001 \quad 0.0563240 .05632400 .05632400 .00 .00 .0$; set mass2001 0.0563240;

mass $2002 \quad 0.0563240 .05632400 .05632400 .00 .00 .0$; set mass2002 0.0563240;

mass $2003 \quad 0.0563240 .05632400 .05632400 .00 .00 .0$; set mass2003 0.0563240;

mass $2004 \quad 0.0563240 .05632400 .05632400 .00 .00 .0$; set mass2004 0.0563240;

mass $2005 \quad 0.0563240 .05632400 .05632400 .00 .00 .0$; set mass2005 0.0563240;

mass $2006 \quad 0.0563240 .05632400 .05632400 .00 .00 .0$; set mass2006 0.0563240;

mass $2007 \quad 0.0563240 .05632400 .05632400 .00 .00 .0$; set mass2007 0.0563240; 
mass $2008 \quad 0.0563240 .05632400 .05632400 .00 .0 \quad 0.0$; set mass2008 0.0563240;

mass $2009 \quad 0.0563240 .05632400 .05632400 .00 .00 .0$; set mass2009 0.0563240;

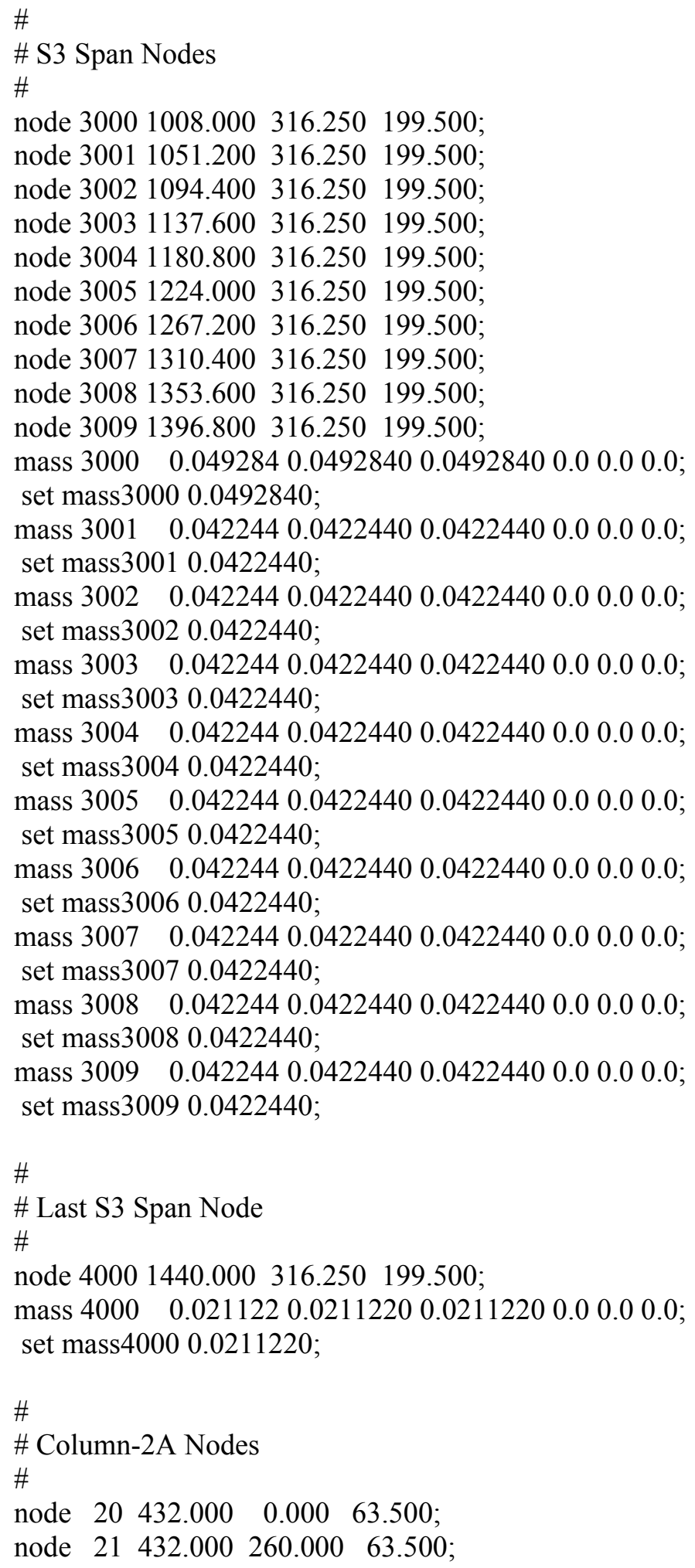


mass $20 \quad 0.01626120 .01626120 .0162612 \quad 0.00 .00 .0$; set mass20 0.0162612;

mass $21 \quad 0.01626120 .01626120 .01626120 .00 .00 .0$; set mass21 0.0162612;

fix 20111111 ;

\#

\# Column-2B Nodes

\#

node $22 \quad 432.000 \quad 0.000 \quad 335.500$;

node 23432.000260 .000335 .500 ;

mass $22 \quad 0.01626120 .01626120 .01626120 .00 .00 .0$; set mass22 0.0162612;

mass $23 \quad 0.01626120 .01626120 .01626120 .00 .00 .0$; set mass23 0.0162612;

fix 22111111 ;

\#

\# Column-3A Nodes

\#

node $301008.000 \quad 0.000 \quad 63.500$;

node $311008.000 \quad 260.000 \quad 63.500$;

mass $30 \quad 0.01626120 .01626120 .01626120 .00 .00 .0$; set mass30 0.0162612;

mass $31 \quad 0.01626120 .01626120 .01626120 .00 .00 .0$; set mass31 0.0162612;

fix 30111111 ;

\#

\# Column-3B Nodes

\#

node $321008.000 \quad 0.000 \quad 335.500$;

node $331008.000 \quad 260.000 \quad 335.500$;

mass $32 \quad 0.01626120 .01626120 .01626120 .00 .00 .0$; set mass32 0.0162612;

mass 330.01626120 .01626120 .01626120 .00 .00 .0 ; set mass 330.0162612 ;

fix 32111111 ;

set long_abut_tag 1;

set trans_abut_tag 2;

set IDconcCore 3;

set IDconcCover 4;

set IDreinf 5;

\# Longitudinal abutment material

uniaxialMaterial ElasticPPGap $1 \quad 76.360$-66.820 -0.75

\# Transverse abutment material

uniaxialMaterial ElasticPPGap $2381.800-334.100-0.50$ 


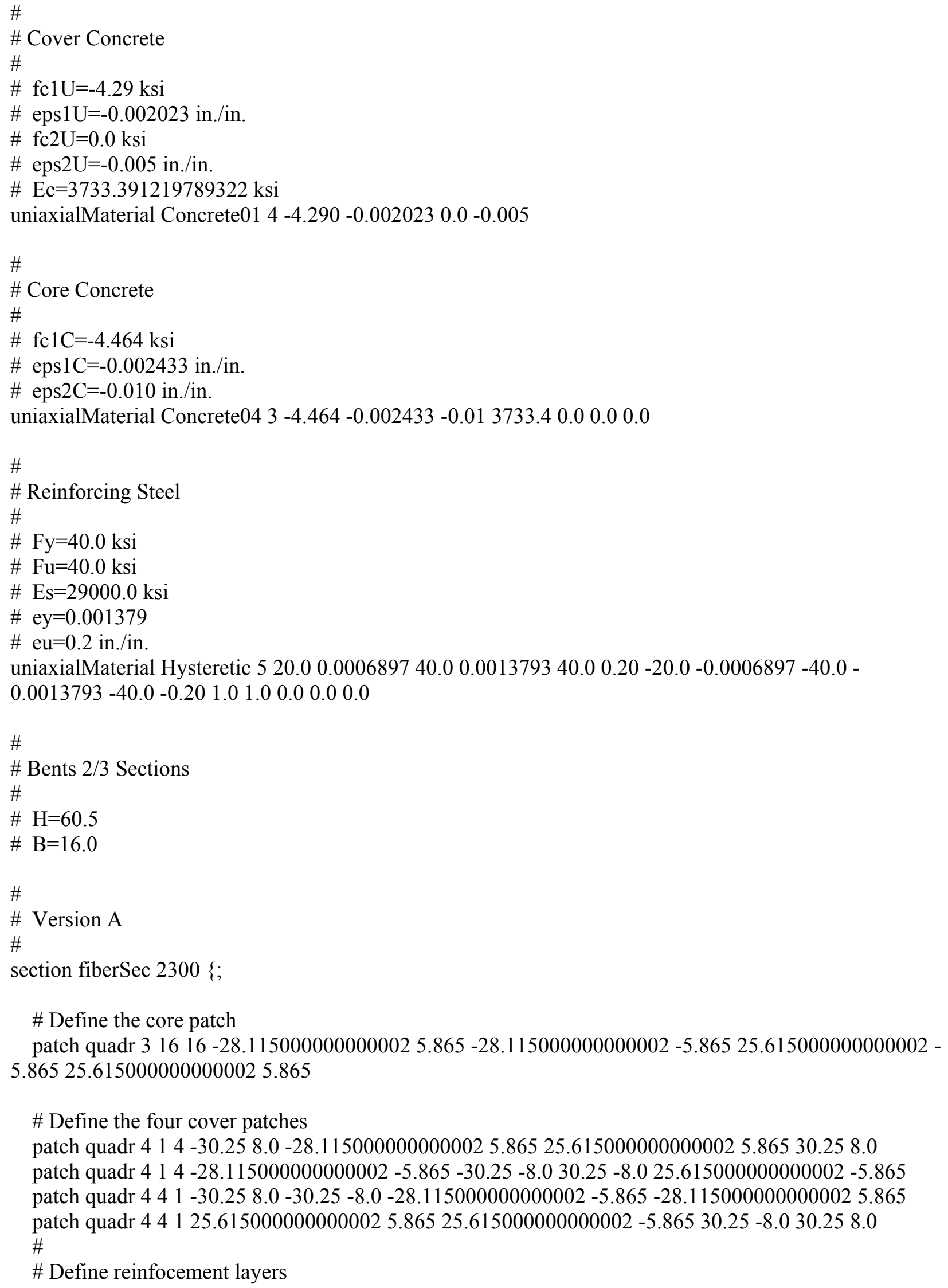




\section{\#}

\# Top layer

layer straight 531.27 25.615000000000002 5.865 25.615000000000002 -5.865; \# top layer reinforcement

\# Top middle layer

layer straight 52 0.2 7.949999999999999 5.865 7.949999999999999 -5.865; \# top layer reinforcement \# Bottom middle layer

layer straight 52 20.2 -10.45 5.865-10.45-5.865; \# top layer reinforcement

\# Bottom layer

layer straight 53 1.27 -28.115000000000002 5.865-28.115000000000002 -5.865; \# bottom layer reinfocement

\}; \# end of fibersection definition

uniaxialMaterial Elastic $23101.0 \mathrm{e}+010$

section Aggregator $23202310 \mathrm{~T}$-section 2300

geomTransf Linear 2330 -1 00

\# Version B

$\#$

section fiberSec 2340 ;

\# Define the core patch

patch quadr $31616-27.90355 .6535-27.9035-5.653525 .615000000000002-5.6535$

25.6150000000000025 .6535

\# Define the four cover patches

patch quadr $414-30.258 .0-27.90355 .653525 .6150000000000025 .653530 .258 .0$

patch quadr $414-27.9035-5.6535-30.25-8.030 .25-8.025 .615000000000002-5.6535$

patch quadr $441-30.258 .0-30.25-8.0-27.9035-5.6535-27.90355 .6535$

patch quadr $44125.6150000000000025 .653525 .615000000000002-5.653530 .25-8.030 .258 .0$

\#

\# Define reinfocement layers

\#

\# Top layer

layer straight 531.27 25.615000000000002 5.6535 25.615000000000002 -5.6535; \# top layer reinforcement

\# Top middle layer

layer straight 52 0.2 7.949999999999999 5.6535 7.949999999999999 -5.6535; \# top layer reinforcement

\# Bottom middle layer

layer straight $520.2-10.455 .6535-10.45-5.6535$; \# top layer reinforcement

\# Bottom layer

layer straight 532.25 -27.9035 5.6535 -27.9035 -5.6535; \# bottom layer reinfocement

\}; \# end of fibersection definition

uniaxialMaterial Elastic $23501.0 \mathrm{e}+010$

section Aggregator $23602350 \mathrm{~T}$-section 2340

$\#$

\# Columns 2/3 Sections

\#

section fiberSec 2000 ; 
\# Define the core patch

patch quadr $31616-9.2959 .295-9.295-9.2959 .295-9.2959 .2959 .295$

\# Define the four cover patches

patch quadr $414-12.012 .0-9.2959 .2959 .2959 .29512 .012 .0$

patch quadr $414-9.295-9.295-12.0-12.012 .0-12.09 .295-9.295$

patch quadr $441-12.012 .0-12.0-12.0-9.295-9.295-9.2959 .295$

patch quadr $4419.2959 .2959 .295-9.29512 .0-12.012 .012 .0$

\# Define reinfocement layers

\# top layer reinforcement

layer straight 521.569 .2959 .2959 .295 -9.295;

\# bottom layer reinfocement

layer straight 52 1.56 -9.295 9.295 -9.295 -9.295;

\}; \# end of fibersection definition

uniaxialMaterial Elastic 2001 1.0e+010

section Aggregator $20022001 \mathrm{~T}$-section 2000

geomTransf Linear $200300-1$

geomTransf PDelta $200400-1$

\#

\# Span Elements

\#

set Deck_Area 4436.25;

set Deck_E 3733.391;

set Deck_G 1500.0;

set Deck_J 61509000.0;

set Deck_Iy 63344000.0;

set Deck_Iz 427780.0;

geomTransf Linear 1000010 ;

element elasticBeamColumn 1000100010014436.33733 .41500 .061509000 .063344000 .0427780 .0

1000

element elasticBeamColumn 1001100110024436.33733 .41500 .061509000 .063344000 .0427780 .0

1000

element elasticBeamColumn 1002100210034436.33733 .41500 .061509000 .063344000 .0427780 .0

1000

element elasticBeamColumn 1003100310044436.33733 .41500 .061509000 .063344000 .0427780 .0 1000

element elasticBeamColumn 1004100410054436.33733 .41500 .061509000 .063344000 .0427780 .0 1000

element elasticBeamColumn 1005100510064436.33733 .41500 .061509000 .063344000 .0427780 .0 1000

element elasticBeamColumn 1006100610074436.33733 .41500 .061509000 .063344000 .0427780 .0 1000

element elasticBeamColumn 1007100710084436.33733 .41500 .061509000 .063344000 .0427780 .0 1000

element elasticBeamColumn 1008100810094436.33733 .41500 .061509000 .063344000 .0427780 .0 1000 
element elasticBeamColumn 1009100920004436.33733 .41500 .061509000 .063344000 .0427780 .0 1000

element elasticBeamColumn 2000200020014436.33733 .41500 .061509000 .063344000 .0427780 .0 1000

element elasticBeamColumn 2001200120024436.33733 .41500 .061509000 .063344000 .0427780 .0 1000

element elasticBeamColumn 2002200220034436.33733 .41500 .061509000 .063344000 .0427780 .0 1000

element elasticBeamColumn 2003200320044436.33733 .41500 .061509000 .063344000 .0427780 .0 1000

element elasticBeamColumn 2004200420054436.33733 .41500 .061509000 .063344000 .0427780 .0 1000

element elasticBeamColumn 2005200520064436.33733 .41500 .061509000 .063344000 .0427780 .0 1000

element elasticBeamColumn 2006200620074436.33733 .41500 .061509000 .063344000 .0427780 .0 1000

element elasticBeamColumn 2007200720084436.33733 .41500 .061509000 .063344000 .0427780 .0 1000

element elasticBeamColumn 2008200820094436.33733 .41500 .061509000 .063344000 .0427780 .0 1000

element elasticBeamColumn 2009200930004436.33733 .41500 .061509000 .063344000 .0427780 .0 1000

element elasticBeamColumn 3000300030014436.33733 .41500 .061509000 .063344000 .0427780 .0 1000

element elasticBeamColumn 3001300130024436.33733 .41500 .061509000 .063344000 .0427780 .0 1000

element elasticBeamColumn 3002300230034436.33733 .41500 .061509000 .063344000 .0427780 .0 1000

element elasticBeamColumn 3003300330044436.33733 .41500 .061509000 .063344000 .0427780 .0 1000

element elasticBeamColumn 3004300430054436.33733 .41500 .061509000 .063344000 .0427780 .0 1000

element elasticBeamColumn 3005300530064436.33733 .41500 .061509000 .063344000 .0427780 .0

1000

element elasticBeamColumn 3006300630074436.33733 .41500 .061509000 .063344000 .0427780 .0 1000

element elasticBeamColumn 3007300730084436.33733 .41500 .061509000 .063344000 .0427780 .0 1000

element elasticBeamColumn 3008300830094436.33733 .41500 .061509000 .063344000 .0427780 .0 1000

element elasticBeamColumn 3009300940004436.33733 .41500 .061509000 .063344000 .0427780 .0 1000

\#

\# Rigid Elements linking bents to spans

\#

rigidLink beam 1000 102;

rigidLink beam 2000 203;

rigidLink beam 3000 303;

rigidLink beam 4000 402; 


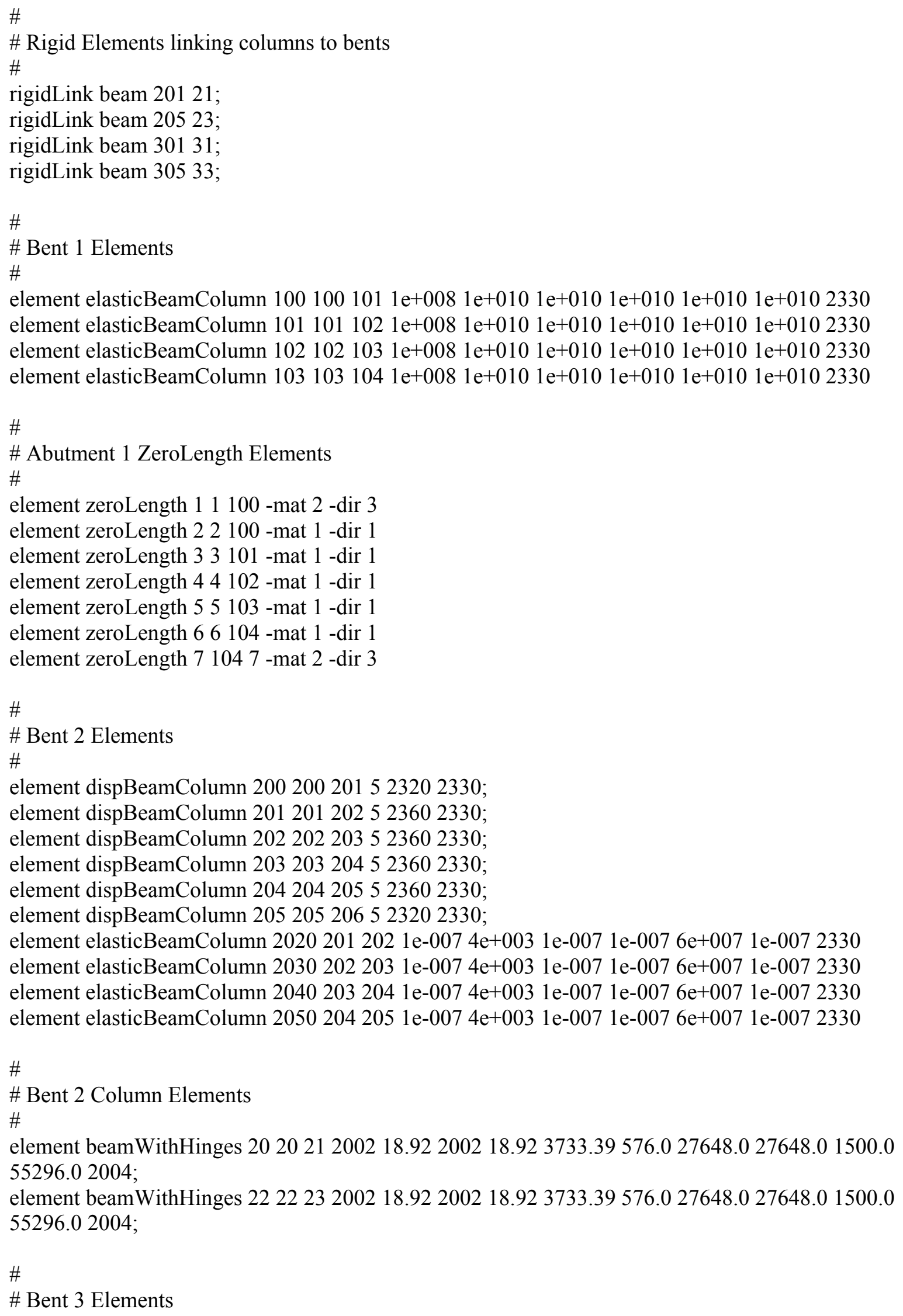




\section{\#}

element dispBeamColumn 30030030152320 2330;

element dispBeamColumn 30130130252360 2330;

element dispBeamColumn 30230230352360 2330;

element dispBeamColumn 30330330452360 2330;

element dispBeamColumn 30430430552360 2330;

element dispBeamColumn 30530530652320 2330;

element elasticBeamColumn 3020301302 1e-007 4e+003 1e-007 1e-007 6e+007 1e-007 2330

element elasticBeamColumn 3030302303 1e-007 4e+003 1e-007 1e-007 6e+007 1e-007 2330

element elasticBeamColumn 3040303304 1e-007 4e+003 1e-007 1e-007 6e+007 1e-007 2330

element elasticBeamColumn 3050304305 1e-007 4e+003 1e-007 1e-007 6e+007 1e-007 2330

\#

\# Bent 3 Column Elements

\#

element beamWithHinges 303031200218.92200218 .923733 .39576 .027648 .027648 .01500 .0 55296.0 2004;

element beamWithHinges 323233200218.92200218 .923733 .39576 .027648 .027648 .01500 .0

55296.0 2004;

\#

\# Bent 4 Elements

\#

element elasticBeamColumn $4004004011 \mathrm{e}+0081 \mathrm{e}+0101 \mathrm{e}+0101 \mathrm{e}+0101 \mathrm{e}+0101 \mathrm{e}+0102330$

element elasticBeamColumn $4014014021 \mathrm{e}+0081 \mathrm{e}+0101 \mathrm{e}+0101 \mathrm{e}+0101 \mathrm{e}+0101 \mathrm{e}+0102330$

element elasticBeamColumn $4024024031 \mathrm{e}+0081 \mathrm{e}+0101 \mathrm{e}+0101 \mathrm{e}+0101 \mathrm{e}+0101 \mathrm{e}+0102330$

element elasticBeamColumn $4034034041 \mathrm{e}+0081 \mathrm{e}+0101 \mathrm{e}+0101 \mathrm{e}+0101 \mathrm{e}+0101 \mathrm{e}+0102330$

\#

\# Abutment 4 ZeroLength Elements

\#

element zeroLength 501501400 -mat 2 -dir 3;

element zeroLength 502400502 -mat 1 -dir 1;

element zeroLength 503401503 -mat 1 -dir 1;

element zeroLength 504402504 -mat 1 -dir 1;

element zeroLength 505403505 -mat 1 -dir 1;

element zeroLength 506404506 -mat 1 -dir 1;

element zeroLength 507404507 -mat 2 -dir 3; 


\subsection{OPENSEES SCRIPT FOR 3-SPAN GRAVITY LOADS}

puts "gravity_loads_nom.tcl: Starting Gravity Load Analysis";

$\# 0=>$ no print output (default)

$\# 1=>$ print information on each step

\# 2 => print information when convergence has been achieved

$\# 4=>$ print norm, $\mathrm{dU}$ and $\mathrm{dR}$ vectors

\# 5 => at convergence failure, carry on, print error message, but do not stop analysis set test_command_flag 1;

set mult $-\$ g$;

set S1_total_weight 0.0 ;

set S2_total_weight 0.0 ;

set S3 total_weight 0.0 ;

set S4_total_weight 0.0 ; \# one last node over B4

set B1_total_weight 0.0 ;

set B2_total_weight 0.0 ;

set B3_total_weight 0.0;

set B4_total_weight 0.0;

set $\mathrm{C} 2 \overline{\mathrm{A}}$ _total_weight 0.0 ;

set $\mathrm{C} 2 \mathrm{~B}$ _total_weight 0.0 ;

set C3A_total_weight 0.0 ;

set C3B_total_weight 0.0;

set total 0.0 ;

pattern Plain 1 "Constant" \{

\# Span 1

for $\{$ set i 1000$\}\{\$ \mathrm{i}<=1009\}$ incr i $\}$

set var_name mass $\$$;

set value [expr \$ \$var_name];

puts [format "node \$i \%.6f" \$value];

set gvalue [expr \$mult*\$value];

load \$i 0.0 \$gvalue 0.0 0.0 0.0 0.0;

set S1_total_weight [expr \$S1_total_weight+\$gvalue];

\}

set total [expr \$total+\$gvalue];

\# Span 2

puts ""';

for $\{$ set i 2000$\}\{\$ i<=2009\}$ incr i $\}\{$

set var_name mass $\$$;

set value [expr \$\$var_name];

puts [format "node \$i \%.6f" \$value];

set gvalue [expr \$mult*\$value];

load \$i 0.0 \$gvalue 0.0 0.0 0.0 0.0;

set S2_total_weight [expr \$S2_total_weight+\$gvalue];

set total [expr \$total+\$gvalue];

\} 


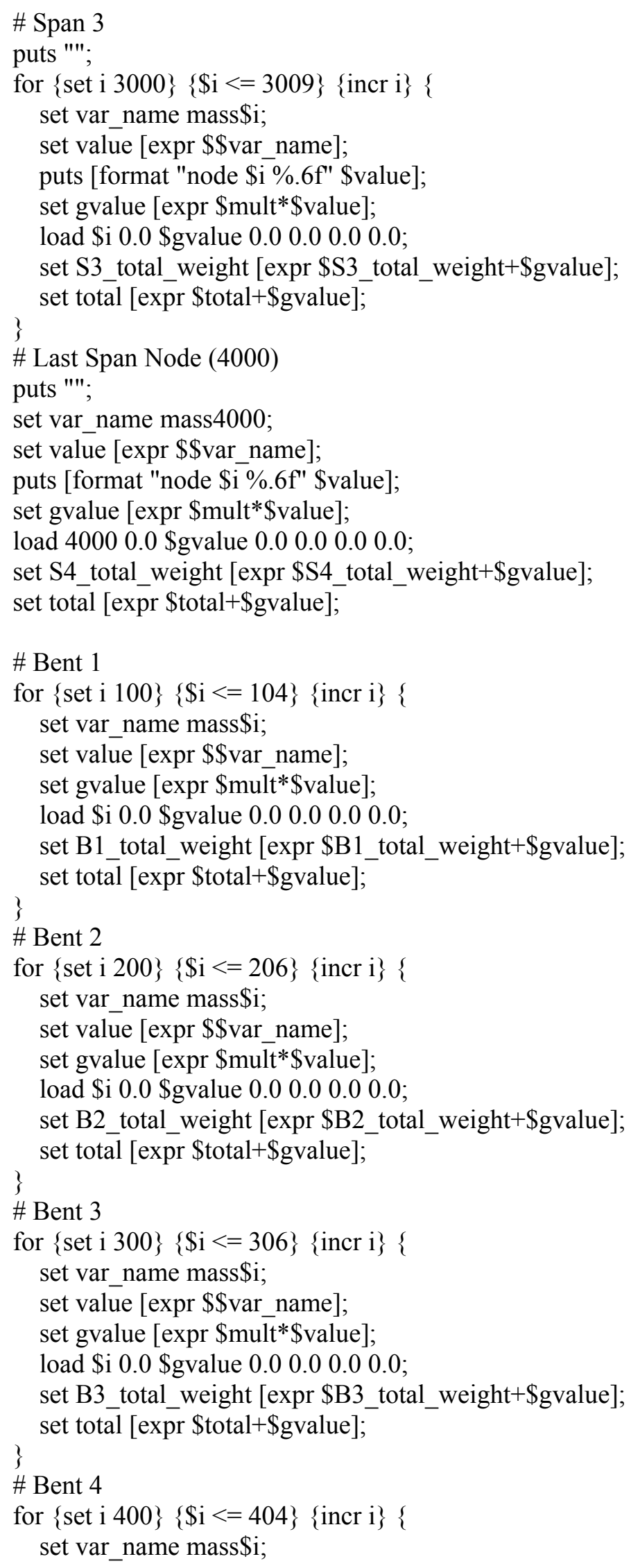




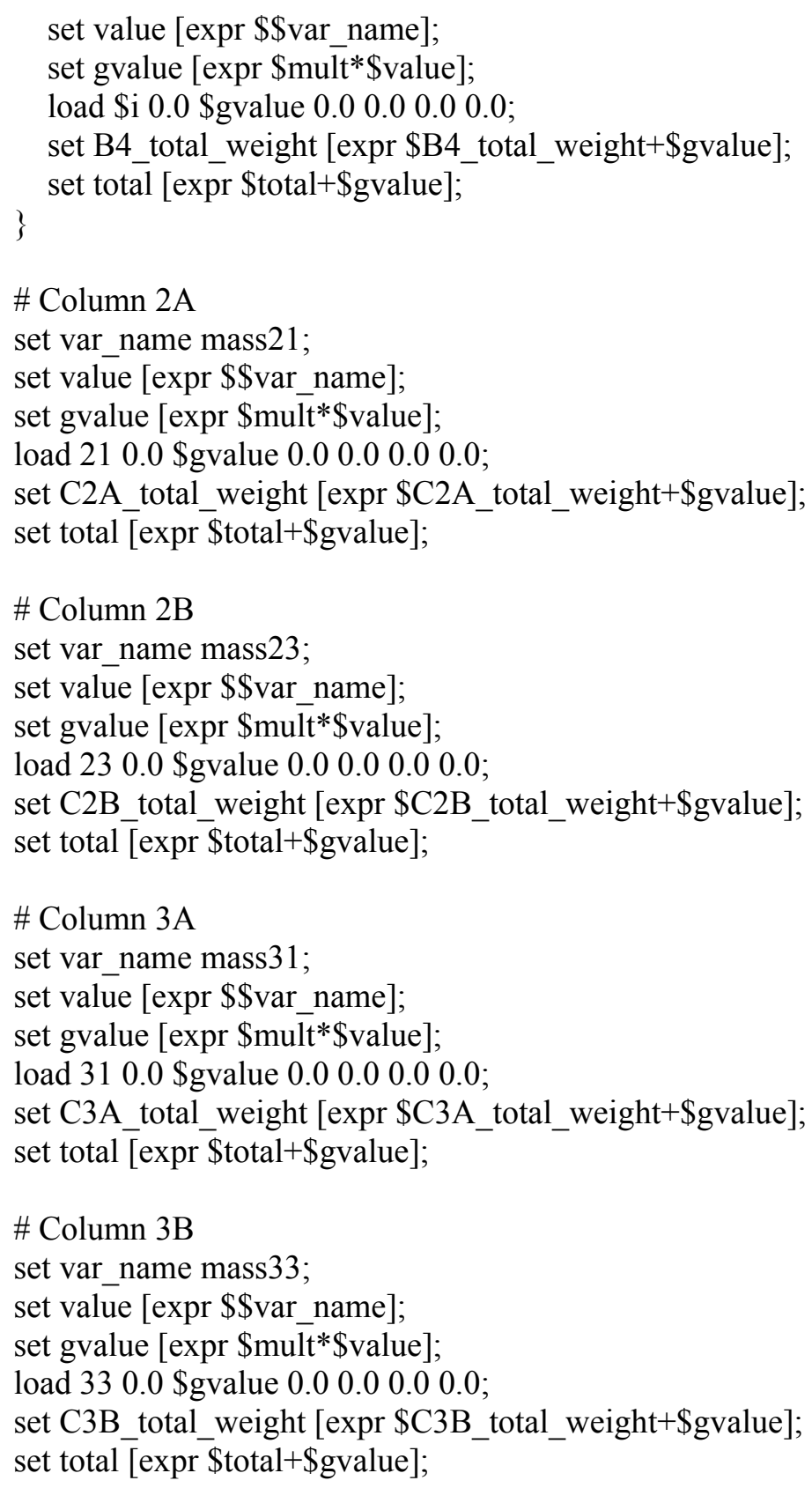

puts [format "Span 1 Weight: \%.3f kips" \$S1_total_weight]; puts [format "Span 2 Weight: \%.3f kips" \$S2_total_weight]; puts [format "Span 3 Weight: \%.3f kips" \$S3_total_weight]; puts [format "N4000 Weight: \%.3f kips" \$S4_total_weight]; puts [format " Total Span Weights: \%.3f kips"।

[expr \$S1_total_weight+\$S2_total_weight+\$S3_total_weight+\$S4_total_weight]]; puts [format "Bent 1 Weight: \%.3f kips" \$B1_total_weight]; puts [format "Bent 2 Weight: \%.3f kips" \$B2_total_weight]; puts [format "Bent 3 Weight: \%.3f kips" \$B3_total_weight]; 
puts [format "Bent 4 Weight: \%.3f kips" \$B4_total_weight];

puts [format " Total Bent Weights: \%.3f kips"।

[expr \$B1_total_weight+\$B2_total_weight+\$B3_total_weight+\$B4_total_weight]];

puts [format "Col $2 \mathrm{~A}$ Weight: \%.3f kips" \$C2A_total_weight];

puts [format "Col 2B Weight: \%.3f kips" \$C2B_total_weight];

puts [format "Col 3A Weight: \%.3f kips" \$C3A_total_weight];

puts [format "Col 3B Weight: \%.3f kips" \$C3B_total_weight];

puts [format " Total Column Weights: \%.3f kips"।

[expr \$C2A_total_weight $+\$ \mathrm{C} 2 \mathrm{~B}$ total_weight $+\$ \mathrm{C} 3 \mathrm{~A}$ total_weight $+\$ \mathrm{C} 3 \mathrm{~B}$ total_weight]];

puts [format " Total Structure Weight: $\%$.3f kips" \$total];

puts [format " Total Structure Mass : \%.6f kips-sec2/in." [expr \$total/386.4]];

puts "';

\# Gravity-analysis parameters -- load-controlled static analysis

set Tol 1.0e-8; \# convergence tolerance for test

\#set constraintsTypeGravity Plain; \# default;

set constraintsTypeGravity Transformation; \# default;

constraints \$constraintsTypeGravity ; \# how it handles boundary conditions

numberer RCM;

\# renumber dof's to minimize band-width (optimization), if you want to

system BandGeneral; $\quad$ \# how to store and solve the system of equations in the analysis (large

model: try UmfPack)

test EnergyIncr \$Tol 30 \$test_command_flag; \# determine if convergence has been achieved at the end of an iteration step

algorithm Newton; \# use Newton's solution algorithm: updates tangent stiffness at every

iteration

set NstepGravity 10; $\quad$ \# apply gravity in 10 steps

set DGravity [expr 1./\$NstepGravity]; \# first load increment;

integrator LoadControl \$DGravity; \# determine the next time step for an analysis

analysis Static; \# define type of analysis static or transient

set ok [analyze \$NstepGravity]; \# \#pply gravity

if $\{$ \$ok $!=0\}\{$

puts "PROBLEM: gravity_loads_nom.tcl";

\} else \{

puts "DONE: gravity_loads_nom.tcl: ... Done Gravity Analysis"; \} 


\subsection{OPENSEES SCRIPT FOR 3-SPAN EXTERNAL LOADS}

source units.tcl;

\# These strings are placeholders for the EQ files for the two horizontal

\# directions 1 and 3 (file names with path, time between time steps (secs), and

\# duration of records (secs)).

\# Remember that the EQ filename use different units for delta_t and duration.

\#

set_VAR_acc_filePath1 EQ1.acc;

set_VAR_acc_filePath2 EQ2.acc;

set_VAR_acc_delta_t 0.0 ;

set_VAR_acc_duration 0.0;

set_VAR_damping 1.0; \# not varied yet by batch script

\# Set by the batch script so that debug mode is always turned off when doing EQ runs. set_VAR_use_debug_mode \$true;

set use_EQ_dir_1 \$true;

set use_EQ_dir_3 \$true;

puts "external_loads_nom.tcl: Starting External Load Analysis (EQ/Pushover/Cyclic)";

$\# 0=>$ no print output (default)

$\# 1=>$ print information on each step

\# 2 => print information when convergence has been achieved

$\# 4=>$ print norm, $\mathrm{dU}$ and $\mathrm{dR}$ vectors

\# 5 => at convergence failure, carry on, print error message, but do not stop analysis

set test_command_flag 1;

\# Pick ONE of the following to be true; the others should be false.

set do_EQ \$true;

set do_pushover \$false;

set do_cyclic \$false;

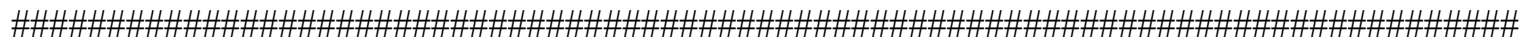

if $\{$ Sdo_EQ $\}\{$

puts "doing EQ load type"

set units_conver 2.54; \# acc files are in $\mathrm{cm} / \mathrm{sec} 2$

\# DYNAMIC ground-motion analysis -------------

if $\{$ Suse_EQ_dir_1 $\}\{$

set accelSeries 1 "Series -dt \$_VAR_acc_delta $t$-filePath $\backslash " \$$ VAR_acc_filePath $1 \backslash " \backslash$

-factor [expr \$_VAR_external_oads * \$_VAR_g_factor / \$ units_conver]";

puts "\naccelSeries 1 : \$accelSeries $1 \backslash n$ ";

pattern UniformExcitation 21 -accel \$accelSeries1; 


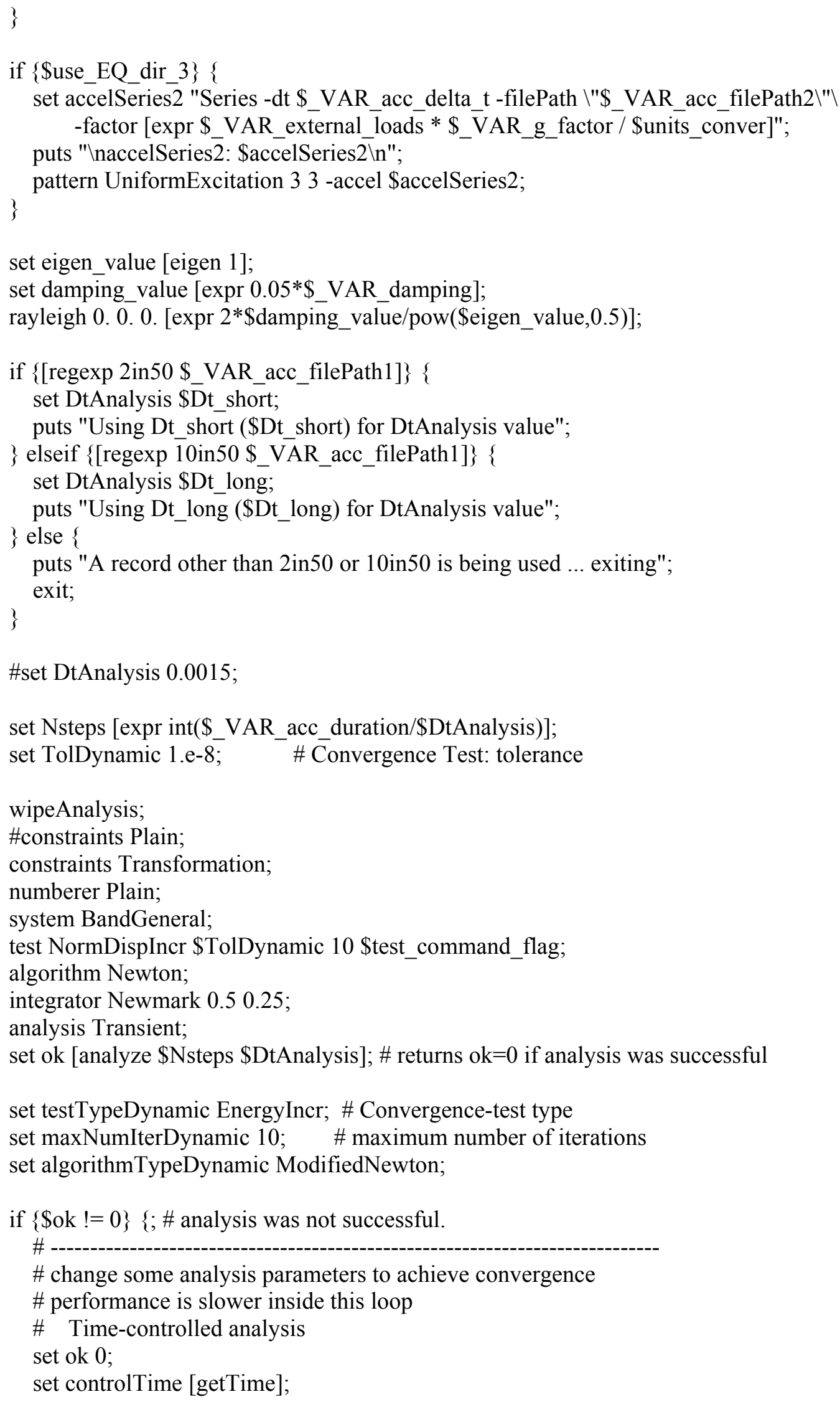


while $\{$ \$controlTime $<\$$ _VAR_acc_duration $\& \& \$$ ok $==0\}\{$

set controlTime [getTime]

set ok [analyze 1 \$DtAnalysis]

if $\{$ \$ok $!=0\}\{$

puts "Trying Newton with Initial Tangent .."

test NormDispIncr \$TolDynamic 10 \$test_command_flag;

algorithm Newton -initial

set ok [analyze 1 \$DtAnalysis]

test \$testTypeDynamic \$TolDynamic \$maxNumIterDynamic \$test_command_flag;

\}

algorithm \$algorithmTypeDynamic

if $\{\$ o k !=0\}\{$

puts "Trying Broyden .."

algorithm Broyden 8

set ok [analyze 1 \$DtAnalysis]

algorithm \$algorithmTypeDynamic

\}

if $\{$ \$ok $!=0\}\{$

puts "Trying NewtonWithLineSearch .."

algorithm NewtonLineSearch .8

set ok [analyze 1 \$DtAnalysis]

algorithm \$algorithmTypeDynamic

\}

if $\{\$$ ok $!=0\}\{$

puts "Trying reducing the time step by $2: \mathrm{dt}=[$ expr $\$ D$ tAnalysis/2]"

set ok [analyze 1 [expr \$DtAnalysis/2]]

\}

if $\{\$ o k !=0\}\{$

puts "Trying reducing the time step by $10: \mathrm{dt}=[\operatorname{expr} \$ \mathrm{DtAnalysis} / 10] "$

set ok [analyze 1 [expr \$DtAnalysis/10]]

\}

if $\{\$ o k !=0\}\{$

puts "Trying reducing the time step by 100: $\mathrm{dt}=[\operatorname{expr} \$ \mathrm{DtAnalysis} / 100] "$

set ok [analyze 1 [expr \$DtAnalysis/100]]

\}

\# Try the previous methods with the smaller timestep

set Dt_new [expr \$DtAnalysis/100];

if $\{\$ \mathrm{ok} !=0\}\{$

puts "Trying Newton with Initial Tangent .."

test NormDispIncr \$TolDynamic 10 \$test_command_flag;

algorithm Newton -initial

set ok [analyze 1 \$Dt_new]

test \$testTypeDynamic \$TolDynamic \$maxNumIterDynamic \$test_command_flag;

algorithm \$algorithmTypeDynamic

\}

if $\{$ \$ok $!=0\}\{$

puts "Trying Broyden .."

algorithm Broyden 8

set ok [analyze 1 \$Dt_new]

algorithm \$algorithmTypeDynamic

\} 


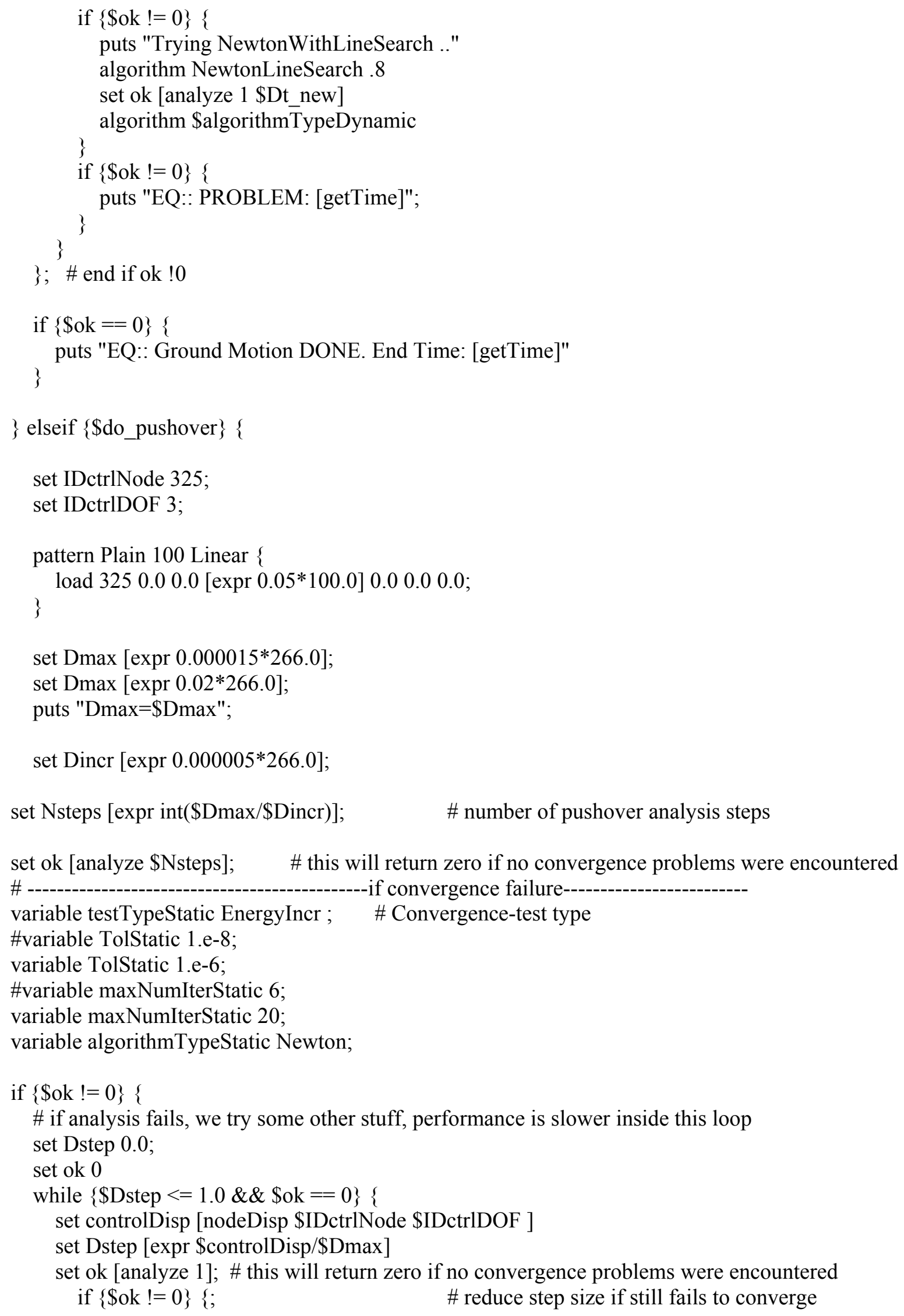


set Nk 4; $\quad$ \# reduce step size

set DincrReduced [expr \$Dincr/\$Nk];

integrator DisplacementControl \$IDctrlNode \$IDctrlDOF \$DincrReduced

for $\{$ set ik 1$\}\{\$ i k<=\$ N k\}$ incr ik 1$\}\{$

set ok [analyze 1]; \# this will return zero if no convergence problems were encountered if $\{$ \$ok $!=0\}\{$

\# if analysis fails, we try some other stuff

\# performance is slower inside this loop global maxNumIterStatic;

\# max no. of iterations performed before "failure to converge" is ret'd

puts "Trying Newton with Initial Tangent .."

\#test NormDispIncr \$Tol 2000 \$test_command_flag

\#test NormDispIncr \$Tol 100 \$test_command_flag

test NormDispIncr \$TolStatic 100 \$test_command_flag

algorithm Newton -initial

set ok [analyze 1]

test \$testTypeStatic \$TolStatic \$maxNumIterStatic \$test_command_flag

\}

algorithm \$algorithmTypeStatic

if $\{$ \$ok $!=0\}\{$

puts "Trying Broyden .."

algorithm Broyden 8

set ok [analyze 1 ]

algorithm \$algorithmTypeStatic

\}

if $\{$ \$ok $!=0\}\{$

puts "Trying NewtonWithLineSearch .."

algorithm NewtonLineSearch 0.8

set ok [analyze 1]

algorithm \$algorithmTypeStatic

\}

if $\{$ \$ok $!=0\}\{; \quad \#$ stop if still fails to converge

set fmt1 "\%s Pushover analysis: CtrlNode \%.3i, dof \%.1i, Disp=\%.4f \%s";

puts [format \$fmt1 "PROBLEM" \$IDctrlNode \$IDctrlDOF [nodeDisp \$IDctrlNode

\$IDctrlDOF] \$LunitTXT]

return -1

; ; \# end if

; ; \# end for

integrator DisplacementControl \$IDctrlNode \$IDctrlDOF \$Dincr; \# bring back to original increment

\}; \# end if

\}; \# end while loop

;; $\quad$ \# end if ok !0

\# ----------------

\} elseif $\{\$$ do_cyclic $\}\{$

\#puts "external_loads_nom.tcl: ... Done Cyclic Analysis";

\} else \{ 
puts "\nexternal_loads_nom.tcl: ERROR: invalid load type" exit; 



\section{GOTREC \\ AND EDUCATION CONSORTIUM}

P.O. Box 751

Portland, OR 97207

OTREC is dedicated to stimulating and conducting collaborative multi-disciplinary research on multi-modal surface transportation issues, educating a diverse array of current practitioners and future leaders in the transportation field, and encouraging implementation of relevant research results. 